\title{
Environment-sensitive probes for illuminating amyloid aggregation in vitro and in zebrafish
}

Francisco Fueyo-González, ${ }^{\text {a,g }}$ Juan A. González-Vera, ${ }^{* a, b}$ Ibon Alkorta, ${ }^{a}$ Lourdes Infantes, ${ }^{c}$ Maria Luisa Jimeno, ${ }^{\mathrm{d}}$ Paula Aranda, ${ }^{\mathrm{e}}$ Dario Acuña-Castroviejo, ${ }^{\mathrm{e}, \mathrm{f}}$ Alvaro Ruiz-Arias, ${ }^{\mathrm{b}}$ Angel Orte, ${ }^{\mathrm{b}}$ and Rosario Herranz ${ }^{*}$ a

${ }^{a}$ Instituto de Química Médica (CSIC). Juan de la Cierva 3, 28006 Madrid, Spain. E-mail: rosario@iqm.cisc.es.

${ }^{b}$ Departamento de Fisicoquímica, Unidad de Excelencia de Química Aplicada a Biomedicina y Medioambiente, Facultad de Farmacia, Universidad de Granada. Campus Cartuja, 18071, Granada, Spain. E-mail: gonzalezvera@ugr.es

${ }^{c}$ Instituto de Química Física Rocasolano, IQFR-CSIC. Serrano 119, 28006 Madrid, Spain.

${ }^{d}$ Centro de Química Orgánica Lora Tamayo (CSIC). Juan de la Cierva 3, 28006 Madrid, Spain.

${ }^{e}$ Departamento de Fisiología, Facultad de Medicina, Universidad de Granada, 18016 Granada, Spain.

${ }^{f}$ CIBER de Fragilidad y Envejecimiento, Ibs. Granada, Unidad de Gestión Clínica de Laboratorios Clínicos, Hospital Universitario San Cecilio, 18016 Granada, Spain

${ }^{g}$ Current address: Department of Medicine, Translational Transplant Research Center, Immunology Institute, Icahn School of Medicine at Mount Sinai, New York, USA.

\section{Supplementary Materials}

Table of Contents

$\underline{\text { PAGE }}$

I. General methods $\quad$ S2

$\begin{array}{ll}\text { II. Experimental synthetic methods } & \text { S2 }\end{array}$

III. Photophysical properties of quinolimides $\quad$ S4

IV. Dynamic NMR experiments $\quad$ S6

V.X-Ray diffraction $\quad \mathrm{S} 12$

$\begin{array}{ll}\text { VI. Computational methods } & \text { S16 }\end{array}$

VII. Fluorescence and transmission electron microscopy (TEM) experiments $\quad$ S35

a. Studies of $\beta$-amyloid peptide aggregation $\quad \mathrm{S} 35$

b. Dual-color FLIM and ratio studies $\quad \mathbf{S} 35$

$\begin{array}{ll}\text { c. TEM } & \text { S39 }\end{array}$

d. Dual-color two-photon microscopy ratio studies $\quad$ S41

e. Imaging of amyloid aggregates in zebrafish $\quad \mathrm{S} 42$

VIII. NMR spectra ( ${ }^{1}$ H-NMR and ${ }^{13}$ C-NMR) $\quad$ S44 


\section{GENERAL METHODS}

All reagents were of commercial quality. Solvents were dried and purified by standard methods. Analytical TLC was performed on aluminum sheets coated with a $0.2 \mathrm{~mm}$ layer of silica gel $60 \mathrm{~F} 254$. Silica gel 60 (230-400 mesh) was used for flash chromatography. HPLC-MS was performed on a Sunfire $\mathrm{C}_{18}(4.6 \times 50$ $\mathrm{mm}, 3.5 \mu \mathrm{m}$ ) column at $30^{\circ} \mathrm{C}$, with a flow rate of $1 \mathrm{~mL} / \mathrm{min}$ and gradient of $0.1 \%$ of formic acid in $\mathrm{CH}_{3} \mathrm{CN}$ (solvent A) in $0.1 \%$ of formic acid in $\mathrm{H}_{2} \mathrm{O}$ (solvent $\mathrm{B}$ ) was used as mobile phase. Electrospray in positive mode was used for ionization. NMR spectra were recorded using Varian Inova or Mercury 400, and Varian Unity 500 spectrometers. The NMR spectra assignments were based on COSY, HSQC, and HMBC spectra. High resolution mass spectra (HRMS) were recorded on an Agilent 6520 Q-TOF instrument with an ESI source. MW experiments were carried out in sealed vessels in a MW Emrys Synthesizer (Biotage AB), with transversal IR sensor for reaction temperature monitoring. UV-visible spectroscopy measurements were made at $25 \mathrm{C}^{\mathrm{o}}$ on a Lambda 35, Perkin Elmer, UV-vis spectrophotometer; Starna Cells (16.100-Q-10) 100 $\mu \mathrm{L}$ sub-micro cuvette, $1 \mathrm{~cm}$ path length. Steady-state fluorescence emission spectra were performed at $25 \mathrm{C}^{\circ}$ either on a PerkinElmer LS 50B luminescence spectrometer or a JASCO FP-8300 spectrofluorometer equipped with a $450 \mathrm{~W}$ xenon lamp for excitation; Starna Cells (16.100F-Q-10) $100 \mu \mathrm{L}$ sub-micro cuvette, 1 cm path length.

\section{EXPERIMENTAL SYNTHETIC METHODS}

Synthesis of 9-amino-5-butyl-4H-benzo[de][2,6]naphthyridine-4,6(5H)-dione (2). The 9-methoxyquinolimide 1 (50 mg, $0.18 \mathrm{mmol}$ ) was dissolved in saturated solution of ammonia in EtOH $(5 \mathrm{~mL})$ and the solution was heated at $150^{\circ} \mathrm{C}$ by MW irradiation for $3 \mathrm{~h}$. Afterward, the solvent was evaporated to dryness, and the residue was purified by circular chromatography (elution with $100 \% \mathrm{CH}_{2} \mathrm{Cl}_{2}$ ) to afford the desired derivative 2 ( $25 \mathrm{mg}, 50 \%$ yield) as a yellow-orange solid. M.p. $194{ }^{\circ} \mathrm{C}$. HPLC-MS (30-95\% gradient of A in B for $10 \mathrm{~min}) t_{\mathrm{R}}=5.36 \mathrm{~min} .{ }^{1} \mathrm{H} \mathrm{NMR}\left(500 \mathrm{MHz}, \mathrm{CDCl}_{3}\right) \delta 0.90\left(\mathrm{t}, 3 \mathrm{H}, J=7.5 \mathrm{~Hz}, 4^{\prime}-\mathrm{H}\right), 1.36$ (sextet, $2 \mathrm{H}, J$ $=7.5 \mathrm{~Hz}, 3^{\prime}-\mathrm{H}$ ), 1.62 (quintet, $2 \mathrm{H}, J=7.5 \mathrm{~Hz}, 2^{\prime}-\mathrm{H}$ ), 4.07 (t, 3H, $J=7.5 \mathrm{~Hz}, 1^{\prime}-\mathrm{H}$ ), 5.71 (brs, 2H, $\mathrm{NH}_{2}$ ), 6.91 $(\mathrm{d}, 1 \mathrm{H}, J=8 \mathrm{~Hz}, 8-\mathrm{H}), 8.22(\mathrm{~d}, 1 \mathrm{H}, J=4.5 \mathrm{~Hz}, 3-\mathrm{H}), 8.30(\mathrm{~d}, 1 \mathrm{H}, J=8 \mathrm{~Hz}, 7-\mathrm{H}), 8.90(\mathrm{~d}, 1 \mathrm{H}, J=4.5 \mathrm{~Hz}$, 1H). ${ }^{13} \mathrm{C}$ NMR (126 MHz, $\left.\mathrm{CDCl}_{3}\right) \delta 14.2\left(\mathrm{C}_{4}\right), 20.7\left(\mathrm{C}_{3}\right), 30.5\left(\mathrm{C}_{2}\right), 40.4\left(\mathrm{C}_{1}\right), 109.9\left(\mathrm{C}_{8}\right), 110.1\left(\mathrm{C}_{6 \mathrm{a}}\right)$, $123.4\left(\mathrm{C}_{3}\right), 124.3\left(\mathrm{C}_{9 \mathrm{~b}}\right), 129.9\left(\mathrm{C}_{3 \mathrm{a}}\right), 134.4\left(\mathrm{C}_{7}\right), 136.5\left(\mathrm{C}_{9 \mathrm{a}}\right), 148.1\left(\mathrm{C}_{2}\right), 150.3\left(\mathrm{C}_{9}\right), 163.4\left(\mathrm{C}_{6}\right), 163.9$ $\left(\mathrm{C}_{4}\right) \cdot \mathrm{HRMS}(\mathrm{ESI}) \mathrm{m} / \mathrm{z}$ : Calcd. for $\mathrm{C}_{15} \mathrm{H}_{16} \mathrm{~N}_{3} \mathrm{O}_{2}\left([\mathrm{M}+\mathrm{H}]^{+}\right)$: 270.1237, found: 270.1230 .

Synthesis of 5-butyl-9-(butylamino)-4H-benzo[de][2,6]naphthyridine-4,6(5H)-dione (3). n-Butylamine (161 mg, $2.2 \mathrm{mmol})$ was added to a solution of $1(58 \mathrm{mg}, 0.22 \mathrm{mmol})$ in dry EtOH (3 mL) and the solution was heated at $120^{\circ} \mathrm{C}$ under MW irradiation for $1.5 \mathrm{~h}$. Afterward, the solvent was evaporated to dryness, and the residue was purified by flash chromatography using 1-15\% gradient of $\mathrm{MeOH}$ in $\mathrm{CH}_{2} \mathrm{Cl}_{2}$ as eluent, to give the desired imide 3 as an orange solid (44.2 mg, $62 \%$ ). M.p. $95{ }^{\circ} \mathrm{C}$. HPLC-MS (30-95\% gradient of A in B for $10 \mathrm{~min}) t_{\mathrm{R}}=9.38 \mathrm{~min} .{ }^{1} \mathrm{H}$ NMR $\left(400 \mathrm{MHz}, \mathrm{CDCl}_{3}\right) \delta=0.90\left(\mathrm{t}, 3 \mathrm{H}, J=7.5 \mathrm{~Hz}, 4^{\prime}-\mathrm{H}\right), 0.95(\mathrm{t}, 3 \mathrm{H}, J$ $=7.5 \mathrm{~Hz}, 4^{\prime \prime}-\mathrm{H}$ ), 1.35 (sextet, $2 \mathrm{H}, J=7.5,3^{\prime}-\mathrm{H}$ ), 1.47 (sextet, $2 \mathrm{H}, J=7.5 \mathrm{~Hz}, 3^{\prime \prime}-\mathrm{H}$ ), 1.62 (quintet, $2 \mathrm{H}, J=$ $7.5 \mathrm{~Hz}, 2^{\prime}-\mathrm{H}$ ), 1.75 (quintet, $\left.2 \mathrm{H}, J=7.5 \mathrm{~Hz}, 2^{\prime \prime}-\mathrm{H}\right), 3.36\left(\mathrm{dt}, 2 \mathrm{H}, J=7\right.$ and $\left.5.5 \mathrm{~Hz}, 1^{\prime \prime}-\mathrm{H}\right), 4.14(\mathrm{t}, 2 \mathrm{H}, J=$ $\left.7.5 \mathrm{~Hz}, 1^{\prime}-\mathrm{H}\right), 6.68(\mathrm{~d}, 1 \mathrm{H}, J=8.5 \mathrm{~Hz}, 8-\mathrm{H}), 6.89(\mathrm{t}, 1 \mathrm{H}, J=5.5 \mathrm{~Hz}, \mathrm{NH}), 8.20(\mathrm{~d}, 1 \mathrm{H}, J=4.5 \mathrm{~Hz}, 3-\mathrm{H}), 8.34$ $(\mathrm{d}, 1 \mathrm{H}, J=8.5 \mathrm{~Hz}, 7-\mathrm{H}), 8.83(\mathrm{~d}, 1 \mathrm{H}, J=4.5 \mathrm{~Hz}, 2-\mathrm{H}) \mathrm{ppm} .{ }^{13} \mathrm{C} \mathrm{NMR}\left(100 \mathrm{MHz}, \mathrm{CDCl}_{3}\right) \delta=14.0\left(2 \mathrm{xCH}_{3}\right)$, $20.5\left(\mathrm{C}_{3},+\mathrm{C}_{3^{\prime}}\right), 30.4\left(\mathrm{C}_{2}{ }^{\prime}\right), 31.1\left(\mathrm{C}_{2^{\prime \prime}}\right), 40.2\left(\mathrm{C}_{1^{\prime}}\right), 42.8\left(\mathrm{C}_{1^{\prime}}\right), 104.7\left(\mathrm{C}_{8}\right), 107.5\left(\mathrm{C}_{6 \mathrm{a}}\right), 123.0\left(\mathrm{C}_{3}\right), 124.1\left(\mathrm{C}_{9 \mathrm{~b}}\right)$, $129.7\left(\mathrm{C}_{3 \mathrm{a}}\right), 135.1\left(\mathrm{C}_{7}\right), 136.6\left(\mathrm{C}_{9 \mathrm{a}}\right), 147.1\left(\mathrm{C}_{2}\right), 150.2\left(\mathrm{C}_{9}\right), 163.4\left(\mathrm{C}_{6}\right), 163.8\left(\mathrm{C}_{4}\right) \mathrm{ppm}$. HRMS (ESI) m/z: Calcd. for $\mathrm{C}_{19} \mathrm{H}_{24} \mathrm{~N}_{3} \mathrm{O}_{2}\left([\mathrm{M}+\mathrm{H}]^{+}\right)$: 326.1863 , found: 326.1866 . 
Synthesis of 5-butyl-9-(methylamino)- $4 H$-benzo[de][2,6]naphthyridine-4,6(5H)-dione (4). The 9methoxy-quinolimide 1 (15 mg, $0.05 \mathrm{mmol})$ was dissolved in saturated solution of methylamine in $\mathrm{EtOH}(2$ $\mathrm{mL}$ ) and the mixture was stirred at $120^{\circ} \mathrm{C}$ by MW irradiation for $2 \mathrm{~h}$. Afterward, the solvent was evaporated to dryness and the residue was purified by flash chromatography on silica gel (elution with $100 \% \mathrm{CH}_{2} \mathrm{Cl}_{2}$ ) to afford the desired methylamino derivative 4 (12 mg, $81.5 \%$ yield) as an orange solid. M.p. $89.5^{\circ} \mathrm{C}$. HPLCMS (30-95\% gradient of A in B for $10 \mathrm{~min}) t_{\mathrm{R}}=6.94 \mathrm{~min} .{ }^{1} \mathrm{H}$ NMR ${ }^{1} \mathrm{H}$ NMR $\left(500 \mathrm{MHz}, \mathrm{CDCl}_{3}\right) \delta 0.90(\mathrm{t}$, $\left.3 \mathrm{H}, J=7.5 \mathrm{~Hz}, 4^{\prime}-\mathrm{H}\right), 1.37$ (sextet, 2H, J=7.5 Hz, 3'-H), $1.62\left(\mathrm{~m}, 2 \mathrm{H}, 2^{\prime}-\mathrm{H}\right), 3.09$ (d, 3H, $J=5.5 \mathrm{~Hz}$, NHMe $), 4.08$ (t, 2H, J= 7.5 Hz, 1'-H), $6.68(\mathrm{~d}, 1 \mathrm{H}, \mathrm{J}=8 \mathrm{~Hz}, 8-\mathrm{H}), 6.93(\mathrm{~m}, 1 \mathrm{H}, \mathrm{NH}), 8.22(\mathrm{~d}, 1 \mathrm{H}, J=4.5 \mathrm{~Hz}$, 3-H), $8.37(\mathrm{~d}, 1 \mathrm{H}, \mathrm{J}=8 \mathrm{~Hz}, 7-\mathrm{H}), 8.85(\mathrm{~d}, 1 \mathrm{H}, J=4.5 \mathrm{~Hz}, 2-\mathrm{H}) .{ }^{13} \mathrm{C}$ NMR $\left(125 \mathrm{MHz}, \mathrm{CDCl}_{3}\right) \delta 12.9\left(\mathrm{C}_{4}\right)$, $19.4\left(\mathrm{C}_{3^{\prime}}\right), 28.7\left(\mathrm{C}_{1}\right), 29.2\left(\mathrm{C}_{2}\right), 39.1\left(\mathrm{C}_{1}\right), 102,3\left(\mathrm{C}_{8}\right), 105.7\left(\mathrm{C}_{6 \mathrm{a}}\right) 120.9\left(\mathrm{C}_{3}\right), 121.8\left(\mathrm{C}_{9 \mathrm{~b}}\right), 127.51\left(\mathrm{C}_{3 \mathrm{a}}\right)$, $132.9\left(\mathrm{C}_{7}\right), 134.5\left(\mathrm{C}_{9 \mathrm{a}}\right), 145.1\left(\mathrm{C}_{2}\right), 148.8\left(\mathrm{C}_{9}\right), 161.2\left(\mathrm{C}_{6}\right), 161.6\left(\mathrm{C}_{4}\right)$. HRMS (ESI) m/z: Calcd. for $\mathrm{C}_{16} \mathrm{H}_{18} \mathrm{~N}_{3} \mathrm{O}_{2}\left([\mathrm{M}+\mathrm{H}]^{+}\right): 284.1394$, found: 284.1398 .

Synthesis of 5-butyl-9-(dimethylamino)-4H-benzo[de $][2,6]$ naphthyridine-4,6(5H)-dione (5). A solution of the 9-methoxy-quinolimide $\mathbf{1}(25 \mathrm{mg}, 0.09 \mathrm{mmol})$ in dimethylamine $(2 \mathrm{~mL})$ was stirred at $160^{\circ} \mathrm{C}$ by $\mathrm{MW}$ irradiation for $3 \mathrm{~h}$. Afterward, the solvent was evaporated to dryness and the residue was purified by flash chromatography on silica gel (elution with 150:1 to 20:1 $\mathrm{CH}_{2} \mathrm{Cl}_{2}$ /acetone gradient) to afford the 9dimethylamino derivative 5 (13 mg, $49 \%$ yield) as an orange solid. M.p. $128{ }^{\circ} \mathrm{C}$. HPLC-MS (30-95\% gradient of A in B for $10 \mathrm{~min}) t_{\mathrm{R}}=7.47 \mathrm{~min}$. ${ }^{1} \mathrm{H} \mathrm{NMR}\left(500 \mathrm{MHz}, \mathrm{CDCl}_{3}\right) \delta=0.90\left(\mathrm{t}, 3 \mathrm{H}, J=7.5 \mathrm{~Hz}, 4^{\prime}-\mathrm{H}\right)$, 1.37 (sextet, $\left.2 \mathrm{H}, \mathrm{J}=7.5 \mathrm{~Hz}, 3^{\prime}-\mathrm{H}\right), 1.63\left(\mathrm{~m}, 2 \mathrm{H}, 2^{\prime}-\mathrm{H}\right), 3.58$ [s, 6H, N( $\left.\left(\mathrm{CH}_{3}\right)_{2}\right], 4.08\left(\mathrm{t}, 2 \mathrm{H}, \mathrm{J}=7.5 \mathrm{~Hz}, 1^{\prime}-\mathrm{H}\right)$, $6.93(\mathrm{~d}, 1 \mathrm{H}, J=8.5 \mathrm{~Hz}, 8-\mathrm{H}), 8.20(\mathrm{~d}, 1 \mathrm{H}, J=4.5 \mathrm{~Hz}, 3-\mathrm{H}), 8.34(\mathrm{~d}, 1 \mathrm{H}, J=8.5 \mathrm{~Hz}, 7-\mathrm{H}), 8.95(\mathrm{~d}, 1 \mathrm{H}, J=$ $4.5 \mathrm{~Hz}, 2-\mathrm{H})$ ppm. ${ }^{13} \mathrm{C}$ NMR $\left(125 \mathrm{MHz}, \mathrm{CDCl}_{3}\right) \delta=14.0\left(\mathrm{C}_{4}\right), 20.6\left(\mathrm{C}_{3}\right), 30.4\left(\mathrm{C}_{2}\right), 40.3\left(\mathrm{C}_{1}\right), 44.5$ $\left[\mathrm{N}\left(\mathrm{CH}_{3}\right)_{2}\right], 110.6\left(\mathrm{C}_{6 \mathrm{a}}\right), 112.4\left(\mathrm{C}_{8}\right), 122.3\left(\mathrm{C}_{3}\right), 125.4\left(\mathrm{C}_{9 \mathrm{~b}}\right), 129.7\left(\mathrm{C}_{3 \mathrm{a}}\right), 133.3\left(\mathrm{C}_{7}\right), 140.0\left(\mathrm{C}_{9 \mathrm{a}}\right), 146.3\left(\mathrm{C}_{2}\right)$, $154.2\left(\mathrm{C}_{9}\right), 163.2\left(\mathrm{C}_{6}\right), 164.0\left(\mathrm{C}_{4}\right)$ ppm. HRMS (ESI) m/z: Calcd. for $\mathrm{C}_{17} \mathrm{H}_{20} \mathrm{~N}_{3} \mathrm{O}_{2}\left([\mathrm{M}+\mathrm{H}]^{+}\right): 298.1550$, found: 298.1545 .

Synthesis of 9-(azetidin-1-yl)-5-butyl-4H-benzo[de][2,6]naphthyridine-4,6(5H)-dione (6). Azetidine $(42.6 \mu \mathrm{L}, 0.63 \mathrm{mmol})$ was added to a solution of $1(29 \mathrm{mg}, 0.10 \mathrm{mmol})$ in dry EtOH $(2.5 \mathrm{~mL})$. The solution was heated at $120^{\circ} \mathrm{C}$ by MW irradiation for $1.5 \mathrm{~h}$. Afterward, the solvent was evaporated to dryness, and the residue was purified by circular chromatography (elution with $100 \% \mathrm{CH}_{2} \mathrm{Cl}_{2}$ ) to afford the desired derivative $6(10 \mathrm{mg}, 33 \%$ yield $)$ as a red solid. M.p. $109^{\circ} \mathrm{C}$. HPLC-MS (30-95\% gradient of A in B for $\left.10 \mathrm{~min}\right) t_{\mathrm{R}}=$ 8.18 min. ${ }^{1} \mathrm{H}$ NMR $\left(400 \mathrm{MHz}, \mathrm{CDCl}_{3}\right) \delta 0.89\left(\mathrm{t}, J=7.5 \mathrm{~Hz}, 3 \mathrm{H}, 4^{\prime}-\mathrm{H}\right), 1.37$ (sextet, $2 \mathrm{H}, J=7.5 \mathrm{~Hz}, 3^{\prime}-\mathrm{H}$ ), 1.61 (quintet, 2H, $J=7.5 \mathrm{~Hz}, 2$ '-H), 2.49 (m, 2H, 2"'-H), 4.07 (t, 2H, 1'-H), 4.54 (m, 4H, 2"'- and 4"'-H), 6.36 $(\mathrm{d}, J=8.5 \mathrm{~Hz}, 1 \mathrm{H}, 2-\mathrm{H}), 8.13(\mathrm{~d}, J=4.5 \mathrm{~Hz}, 1 \mathrm{H}, 3-\mathrm{H}), 8.25(\mathrm{~d}, J=8.5 \mathrm{~Hz}, 1 \mathrm{H}, 7-\mathrm{H}), 8.81(\mathrm{~d}, J=4.5 \mathrm{~Hz}$, 1H, 2-H). ${ }^{13} \mathrm{C}$ NMR (100 MHz, $\left.\mathrm{CDCl}_{3}\right) \delta 14.0\left(\mathrm{C}_{4^{\prime}}\right), 17.7\left(\mathrm{C}_{3^{\prime}}\right), 20.5\left(\mathrm{C}_{3^{\prime}}\right), 29.8\left(\mathrm{C}_{1^{\prime}}\right), 30.3\left(\mathrm{C}_{2^{\prime}}\right), 40.2\left(\mathrm{C}_{1^{\prime}}\right)$, $106.6\left(\mathrm{C}_{8}\right), 107.4\left(\mathrm{C}_{6 \mathrm{a}}\right), 122.4\left(\mathrm{C}_{3}\right), 125.2\left(\mathrm{C}_{9 \mathrm{~b}}\right), 128.8\left(\mathrm{C}_{3 \mathrm{a}}\right), 133.6\left(\mathrm{C}_{7}\right), 138.6\left(\mathrm{C}_{9 \mathrm{a}}\right), 146.4\left(\mathrm{C}_{2}\right), 150.9\left(\mathrm{C}_{9}\right)$, $163.2\left(\mathrm{C}_{6}\right), 164.0\left(\mathrm{C}_{4}\right)$. HRMS (ESI) $m / z$ : Calcd. for $\mathrm{C}_{18} \mathrm{H}_{20} \mathrm{~N}_{3} \mathrm{O}_{2}\left([\mathrm{M}+\mathrm{H}]^{+}\right)$: 310.1550 , found: 310.1547 . 


\section{PHOTOPHYSICAL PROPERTIES OF QUINOLIMIDES}

Excitation and emission spectra of compounds were determined for $12 \mu \mathrm{M}$ solutions in solvents of diverse polarity. The spectra were recorded between 300 and $690 \mathrm{~nm}(0.5 \mathrm{~nm}$ increments and $0.1 \mathrm{~s}$ integration time) with excitation set at the appropriate excitation wavelength. Slit widths were set to $15 \mathrm{~nm}$ for excitation and to 6 or $20 \mathrm{~nm}$ for emission, depending on the observed emission intensity. All the spectra were corrected for background fluorescence by subtracting a blank scan of the solvent solution.

Fluorescence quantum yield determination. Fluorescence quantum yields $(\Phi)$ were determined in solvents of different polarity, and calculated with reference to a standard, which was selected depending on the photophysical properties of the corresponding fluorophore. ${ }^{1}$ Coumarine $153 \mathrm{in} \mathrm{EtOH}(\Phi=0.53)$ was used as reference, except for 1 that was calculated with reference to Quinine sulphate dihydrate in $0.1 \mathrm{M} \mathrm{H}_{2} \mathrm{SO}_{4}(\Phi=$ 0.55). A $12 \mu \mathrm{M}$ solution of the corresponding fluorophore was compared to a $12 \mu \mathrm{M}$ solution of the standard to assure that the absorbance is less than 0.1 at identical excitation wavelengths. The following equation was used to calculate the quantum yield:

$$
\Phi=\frac{I_{x} A_{r} n^{2}{ }_{x} \Phi_{r}}{A_{x} I_{r} n_{r}^{2}}
$$

where $\mathrm{x}$ and $\mathrm{r}$ denote the sample and standard, respectively, $\mathrm{A}$ is the absorption at the excitation wavelength, $\mathrm{I}$ is the integrated fluorescence intensity, and $\mathrm{n}$ is the refractive index of the solvent. Cross-calibration between standards yielded less than $10 \%$ error for this method and instrumentation.

Fluorescence lifetimes determination. Fluorescence lifetimes were obtained with $\lambda_{\mathrm{ex}}=375 \mathrm{~nm}$ for $\mathbf{1}, \lambda_{\mathrm{ex}}=$ $440 \mathrm{~nm}$ for $\mathbf{2}$ and $\lambda_{\mathrm{ex}}=470 \mathrm{~nm}$ for 3-6, as global fits sum of exponentials for fluorescence decay traces collected at $\lambda_{\max , \mathrm{em}}-10 \mathrm{~nm}, \lambda_{\max , \mathrm{em}}$, and $\lambda_{\max , \mathrm{em}}+10 \mathrm{~nm}$. The standard errors were obtained from the diagonal elements of the covariance matrix available from the global analysis fit of decay traces recorded at three emission wavelengths and were between 5 and 30 ps.

Fluorescence-decay traces of solutions were recorded by the single-photon timing method on a FluoTime 200 fluorometer (PicoQuant $\mathrm{GmbH}){ }^{2}$ Depending on the quinolimide derivative, the pulsed excitation source was a $375 \mathrm{~nm}, 440 \mathrm{~nm}, 470 \mathrm{~nm}$ or $485 \mathrm{~nm}$ diode laser (LDH series from PicoQuant $\mathrm{GmbH}$ ), operated with a PDL-800 driver (PicoQuant) at a pulse repetition rate of $20 \mathrm{MHz}$. Fluorescence-decay histograms were collected in 1320 channels, with a time increment of $36 \mathrm{ps}$. Histograms of the instrument-response functions (using a LUDOX scatterer) and sample decays were recorded until they typically reached $2 \times 10^{4}$ counts in the peak channel. Three fluorescence decays were recorded for all of the samples and were collected at $\lambda_{\max ,}{ }^{\mathrm{em}}-10 \mathrm{~nm}, \lambda_{\max }{ }^{\text {em }}$, and $\lambda_{\max }{ }^{\mathrm{em}}+10 \mathrm{~nm}$. The fluorescence-decay traces were individually analyzed by using an iterative deconvolution method with exponential models that employed FluoFit software (PicoQuant). 
Table S1. Photophysical properties of quinolimides 1 and 2-6.

\begin{tabular}{|c|c|c|c|c|c|c|c|}
\hline Compd $^{a}$ & Solvent & $\lambda_{\max }^{\text {abs }}(\mathrm{nm})$ & $\varepsilon\left(\mathrm{M}^{-1} \mathrm{~cm}^{-1}\right)$ & $\lambda_{\max }^{\mathrm{em}}(\mathrm{nm})$ & $\Phi_{\mathrm{F}}^{b}$ & Brightness & $\tau(\mathrm{ns})^{c}$ \\
\hline \multirow{5}{*}{$\mathbf{1}^{3}$} & Toluene & 373 & 10166 & 454 & 0.99 & 10064 & 10.17 \\
\hline & Dioxane & 370 & 10640 & 461 & 0.79 & 8405 & 11.89 \\
\hline & $\mathrm{MeOH}$ & 373 & 6961 & 495 & 0.38 & 2654 & 1.25 \\
\hline & DMSO & 378 & 9898 & 492 & 0.05 & 495 & 12.11 \\
\hline & $\mathrm{H}_{2} \mathrm{O}$ & 379 & 2889 & 510 & 0.10 & 289 & 6.39 \\
\hline \multirow{6}{*}{2} & Cyclohexane & 431 & 11485 & 502 & 0.56 & 6374 & 8.60 \\
\hline & Toluene & 437 & 10068 & 524 & 0.45 & 4500 & 6.57 \\
\hline & Dioxane & 444 & 10569 & 530 & 0.13 & 1321 & 4.51 \\
\hline & $\mathrm{MeOH}$ & 457 & 11908 & 570 & 0.004 & 48 & $0.87^{d}$ \\
\hline & DMSO & 465 & 11577 & 580 & 0.02 & 185 & $0.40^{d}$ \\
\hline & $\mathrm{H}_{2} \mathrm{O}$ & 457 & 14880 & 596 & $<0.001$ & 0.28 & $0.13^{e}$ \\
\hline \multirow{6}{*}{3} & Cyclohexane & 460 & 6950 & 516 & 0.32 & 2196 & 6.93 \\
\hline & Toluene & 478 & 8170 & 539 & 0.20 & 1117 & 6.68 \\
\hline & Dioxane & 474 & 8550 & 552 & 0.08 & 641 & 4.59 \\
\hline & $\mathrm{MeOH}$ & 486 & 7910 & 590 & 0.003 & 18 & $1.31^{d}$ \\
\hline & DMSO & 493 & 8260 & 592 & 0.01 & 104 & $0.58^{d}$ \\
\hline & $\mathrm{H}_{2} \mathrm{O}$ & 472 & 7180 & 585 & $<0.001$ & 5.6 & $0.18^{e}$ \\
\hline \multirow{6}{*}{4} & Cyclohexane & 449 & 9155 & 510 & 0.27 & 2472 & 6.09 \\
\hline & Toluene & 457 & 9120 & 535 & 0.18 & 1642 & 6.54 \\
\hline & Dioxane & 458 & 9200 & 555 & 0.05 & 460 & $2.45^{d}$ \\
\hline & $\mathrm{MeOH}$ & 470 & 11110 & 586 & 0.002 & 22 & $1.25^{d}$ \\
\hline & DMSO & 475 & 8345 & 585 & 0.01 & 100 & $0.52^{d}$ \\
\hline & $\mathrm{H}_{2} \mathrm{O}$ & 483 & 10949 & 610 & $<0.001$ & 0.14 & $0.04^{e}$ \\
\hline \multirow{6}{*}{5} & Cyclohexane & 452 & 2241 & 511 & 0.18 & 403 & $2.00^{d}$ \\
\hline & Toluene & 466 & 1832 & 539 & 0.20 & 366 & $4.17^{d}$ \\
\hline & Dioxane & 460 & 2440 & 540 & 0.06 & 149 & $2.46^{d}$ \\
\hline & $\mathrm{MeOH}$ & 471 & 2473 & 567 & 0.003 & 6 & $1.28^{d}$ \\
\hline & DMSO & 478 & 2702 & 560 & 0.04 & 119 & $0.61^{d}$ \\
\hline & $\mathrm{H}_{2} \mathrm{O}$ & 485 & 5910 & 597 & $<0.001$ & 0.76 & $0.09^{d}$ \\
\hline \multirow{6}{*}{6} & Cyclohexane & 466 & 15005 & 562 & 0.99 & 14840 & 12.58 \\
\hline & Toluene & 478 & 13894 & 547 & 0.46 & 6322 & 10.88 \\
\hline & Dioxane & 472 & 15547 & 561 & 0.20 & 3032 & 8.88 \\
\hline & $\mathrm{MeOH}$ & 488 & 14271 & 597 & 0.02 & 328 & 2.35 \\
\hline & DMSO & 489 & 14390 & 580 & 0.02 & 230 & 0.92 \\
\hline & $\mathrm{H}_{2} \mathrm{O}$ & 495 & 9108 & 625 & $<0.001$ & 1.63 & $0.14^{e}$ \\
\hline
\end{tabular}

${ }^{a}$ Measured in duplicate at a $12 \mu \mathrm{M}$ concentration. ${ }^{b}$ Quantum yields calculated with reference to coumarin 153 (in $\mathrm{EtOH}$ ), except for 1 that was calculated with reference to quinine sulfate (in $0.1 \mathrm{M} \mathrm{H}_{2} \mathrm{SO}_{4}$ ). ${ }^{c}$ Fluorescence lifetimes obtained with $\lambda_{\mathrm{ex}}=375 \mathrm{~nm}$ for $\mathbf{1}, \lambda_{\mathrm{ex}}=440 \mathrm{~nm}$ for $\mathbf{2}$ and $\lambda_{\mathrm{ex}}=470 \mathrm{~nm}$ for 3-6, as global fits of three fluorescence decay traces collected at $\lambda_{\max }{ }_{\mathrm{em}}-10 \mathrm{~nm}, \lambda_{\max }$, and $\lambda_{\max }{ }_{\mathrm{em}}+10 \mathrm{~nm}$. The standard errors were obtained from the diagonal elements of the covariance matrix available from the global analysis fit of decay traces recorded at three emission wavelengths and were between 5 and 30 ps. ${ }^{d}$ Average fluorescence lifetime of biexponential decay. ${ }^{e}$ Average fluorescence lifetime of triexponencial decay.

\section{DYNAMIC NMR EXPERIMENTS}


As the 9-azetidinyl-quinolimide derivative 6 exhibited the best photophysical properties, a full NMR study was performed by the combined use of $1 \mathrm{D}$ and $2 \mathrm{D}\left[{ }^{1} \mathrm{H},{ }^{1} \mathrm{H}\right]$ and $\left[{ }^{1} \mathrm{H}-{ }^{13} \mathrm{C}\right]$ NMR experiments. In the ${ }^{1} \mathrm{H}$ NMR spectrum of 6 in $\mathrm{CDCl}_{3}$ at room temperature, the 2- and 4- $\mathrm{H}$ protons of the azetidine ring appeared as a broad single signal at $4.55 \mathrm{ppm}$, while its $3-\mathrm{H}$ protons appeared as a resolved quintuplet at $2.49 \mathrm{ppm}$ (Figures $\mathrm{S} 1-\mathrm{S} 2$ ). In the corresponding ${ }^{13} \mathrm{C}$ NMR spectrum, the azetidine $\mathrm{C}_{2}$ and $\mathrm{C}_{4}$ did not appeared (Figures S3-S5). These data suggested an exchange of proton and carbon sites, due to inversion of the azetidine nitrogen or to twisting around the $\mathrm{C}_{9}-\mathrm{N}$ bond (dynamic equilibrium), ${ }^{4}$ which could be influencing the photophysical behavior of quinolimide $\mathbf{6}$.

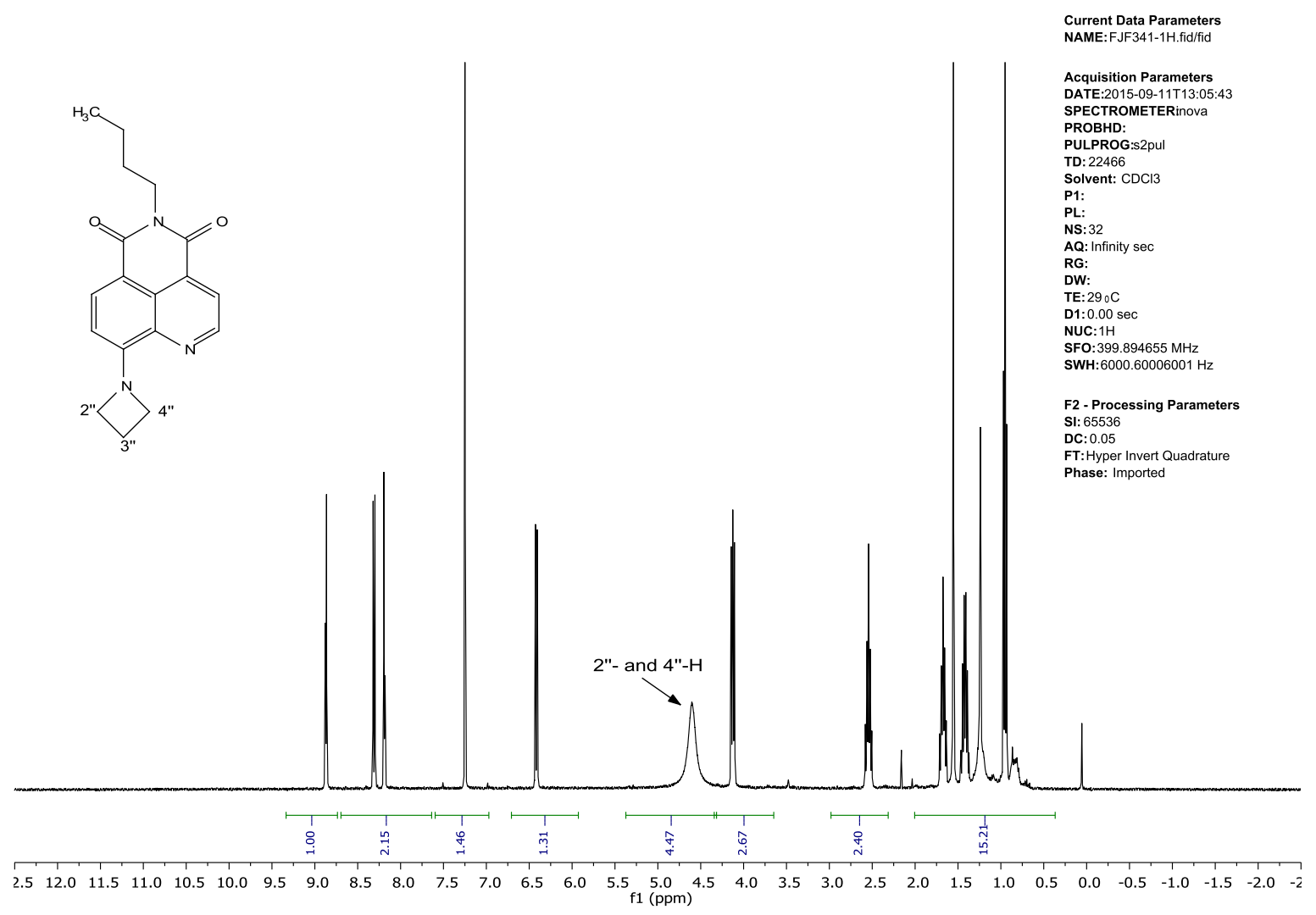

Figure S1. ${ }^{1} \mathrm{H} \mathrm{NMR}\left(400 \mathrm{MHz}, \mathrm{CDCl}_{3}\right)$ of compound 6 . 


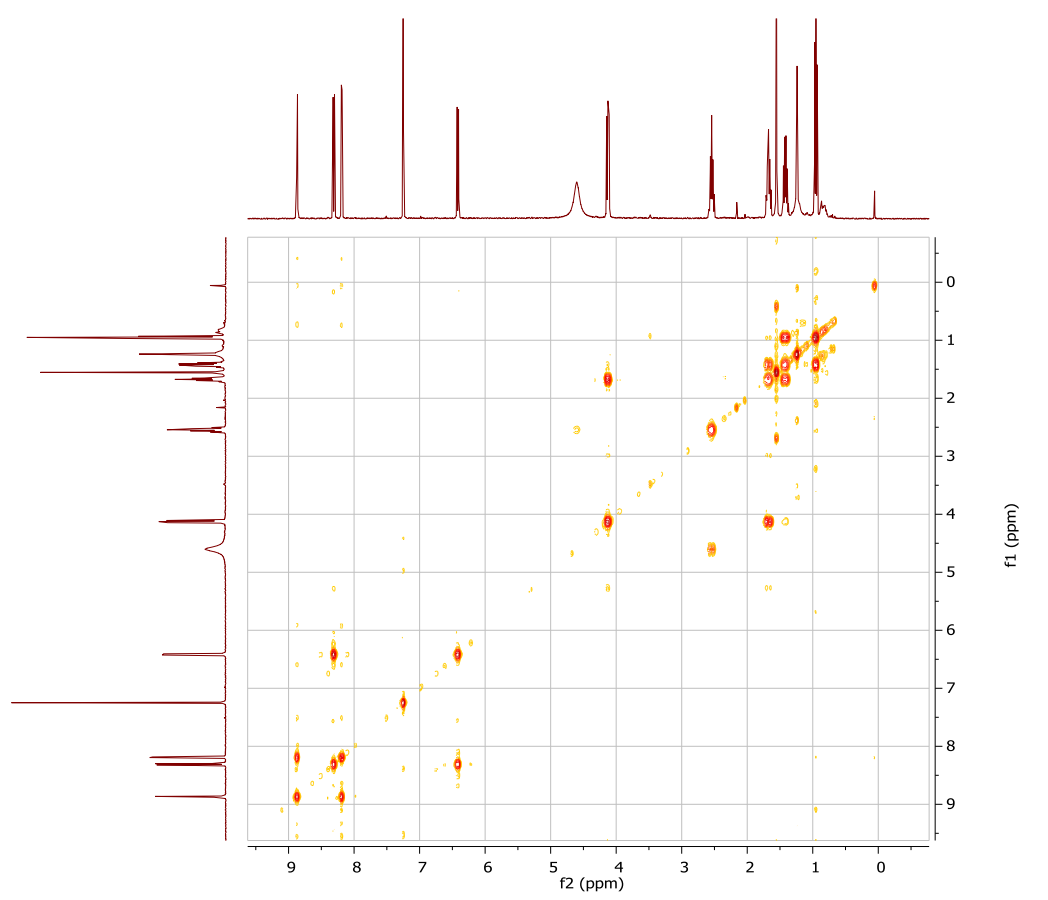

Current Data Parameters
NAME: FJF341-gCOSY.fid/fid

Acquisition Parameters [F1,
F2]

DATE:2015-09-11T16:00:59

PROBHD:

PULPROG:gCOSY

TD:[256, 1024]

P1:

PL:

AQ: $\mathrm{NaN}$ sec

RG:

TE: $290 \mathrm{C}$

D1:1:00 sec

SFO:[399.8944223, 399.8944223]

SWH:[4163.19733555

S1: 1024

DC: 0.05

FT:Hyper Invert Quadrature

PT:Hyper Invert Quadrature
Phagnitude

F1 - Processing Parameters
SI: 1024

SI: 1024

FT:Hyper Invert Quadrature

Phase: NoPC

Figure S2. gCOSY (400 MHz, $\left.\mathrm{CDCl}_{3}\right)$ of compound 6.

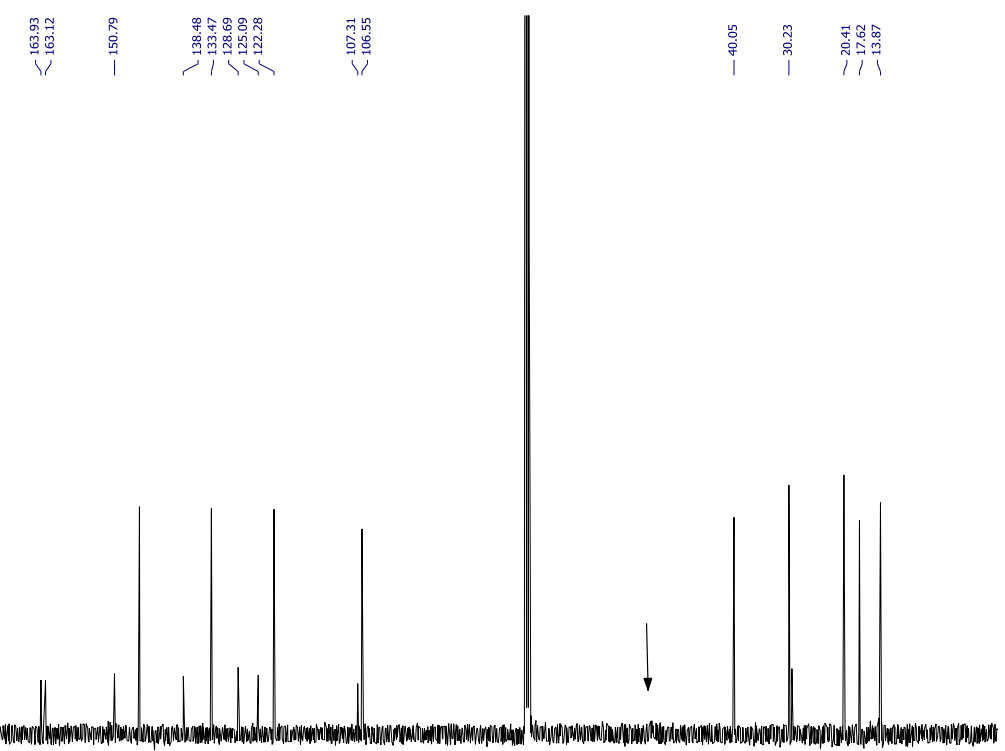

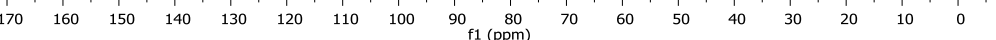

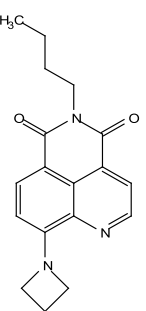

Current Data Parameters
NAME: FJF341-13C.fidffid

Acquisition Parameters

SPECTROMETERinova

PROBHD:

Solvent: CDC13

P1:

PL:

NS: 91088 :

DW:

DW:
TE: $290 \mathrm{C}$
D1:100 seC

DU: 1.00 sec

NU: $13 \mathrm{C}$

WH: $25000 \mathrm{~Hz}$

F2 - Processing Parameters

DC:0.05

FT:Hyper Invert Quadrature

Figure S3. ${ }^{13} \mathrm{C}$ NMR $\left(100 \mathrm{MHz}, \mathrm{CDCl}_{3}\right)$ of compound 6 . 


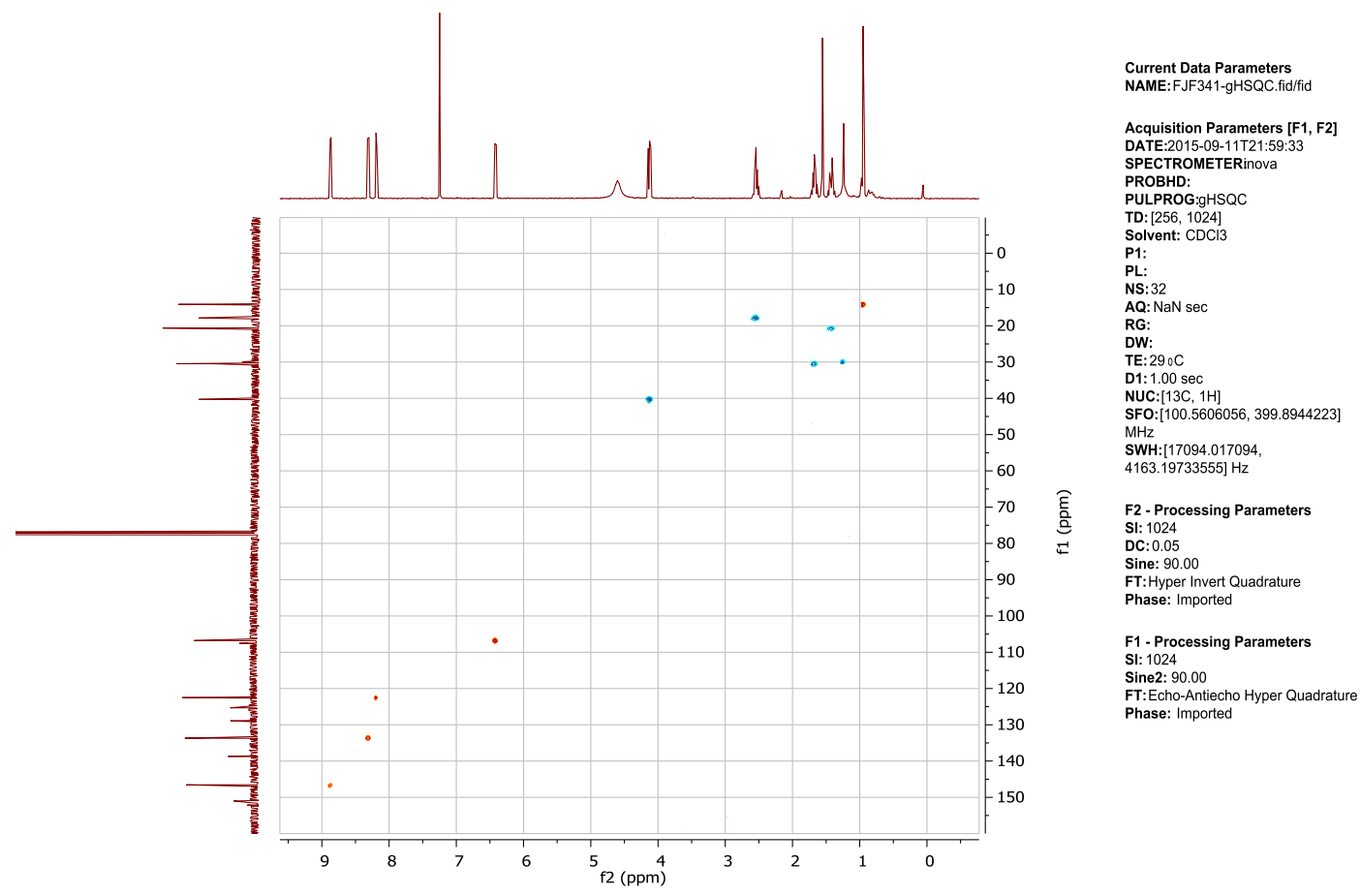

Figure S4. Multiplicity-edited gHSQC (400 $\mathrm{MHz}, \mathrm{CDCl}_{3}$ ) of compound 6 (methylene: blue cross peaks; methyl and methine: red cross peaks)

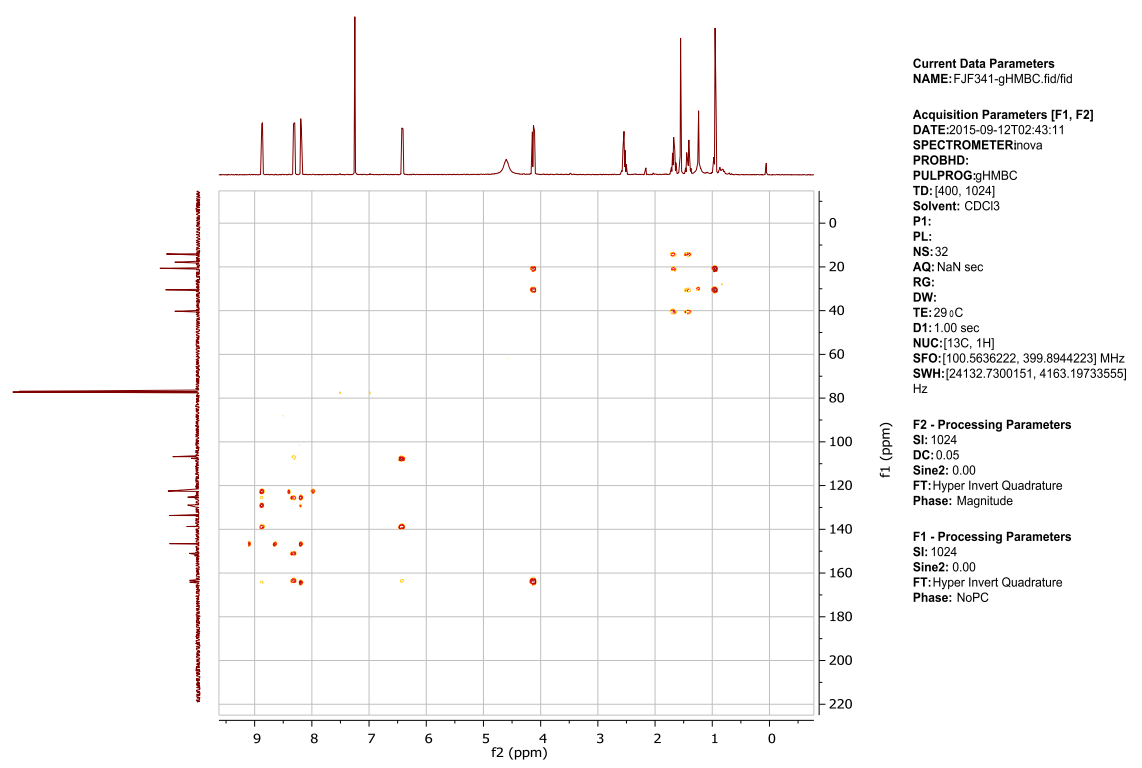

Figure S5. gHMBC (400 MHz, $\left.\mathrm{CDCl}_{3}\right)$ of compound 6. 
Table S2. ${ }^{13} \mathrm{C}$ and ${ }^{1} \mathrm{H}$ NMR chemical shift, in $\mathrm{CDCl}_{3}$, at room temperature, for compound $\mathbf{6}$.

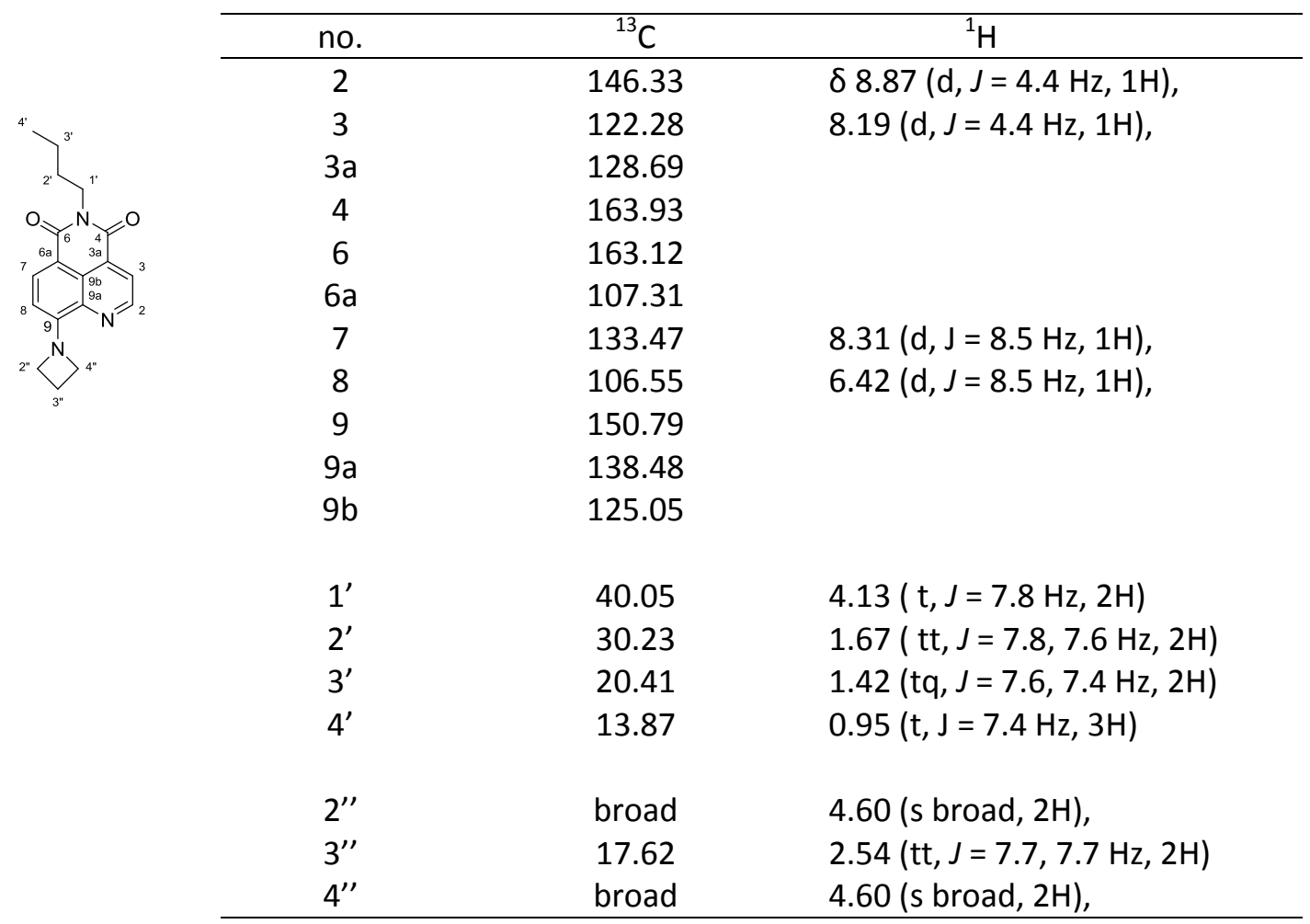

The dynamic study of compound $\mathbf{6}$ was performed by lineshape analysis of a series of variable temperature ${ }^{1} \mathrm{H}$ NMR experiments in $\mathrm{CDCl}_{3}$, in the temperature range 217 to $329{ }^{\circ} \mathrm{C}$ (Figure S6), using the gNMR program. ${ }^{5}$ The temperature was raised in steps of $14{ }^{\circ} \mathrm{C}$, and 20 minutes were allowed for temperature equilibration before shimming at each temperature. If the exchange were due to nitrogen inversion, the two 2- or 4-H protons should be different (one axial and the other equatorial), with geminal coupling constant and low chemical shift difference. However, in the case of twisting around the $\mathrm{C}_{9}-\mathrm{N}$ bond, the $2-\mathrm{H}$ protons would be different from the $4-\mathrm{H}$, due to the asymmetry of the quinolimide ring. At $217 \mathrm{~K}$ the 2- and 4-H protons appeared as two triplets at 4.32 and $4.97 \mathrm{ppm}(J=7.5 \mathrm{~Hz})$, respectively, which coalesce at $273 \mathrm{~K}\left(\mathrm{~T}_{\mathrm{c}}\right)$. Irradiation of the doublet at $6.46 \mathrm{ppm}$, corresponding to the quinolimide $8-\mathrm{H}$ proton, produced a small NOE effect upon the triplet at $4.32 \mathrm{ppm}$, allowing the assignment of the orientation of the 2- and 4-H protons in the two exchanging rotamers (Figure S8). The enthalpy and free energy of exchange at $273 \mathrm{~K}$ were calculated with the gnmr software as 46.56 and $52.28 \mathrm{~kJ} \cdot \mathrm{mol}^{-1}$, respectively (Figure S9). All these results indicated that the slow nuclear exchange is due to the internal rotation around the quinolimideazetidine bond and not to nitrogen inversion that is too rapid to be observed in the NMR time scale. No similar nuclear exchange was observed in the NMR spectra of the 8-dimethylamino-quinolimide analogue 5 in the 217-329 K interval (Figure S7). 


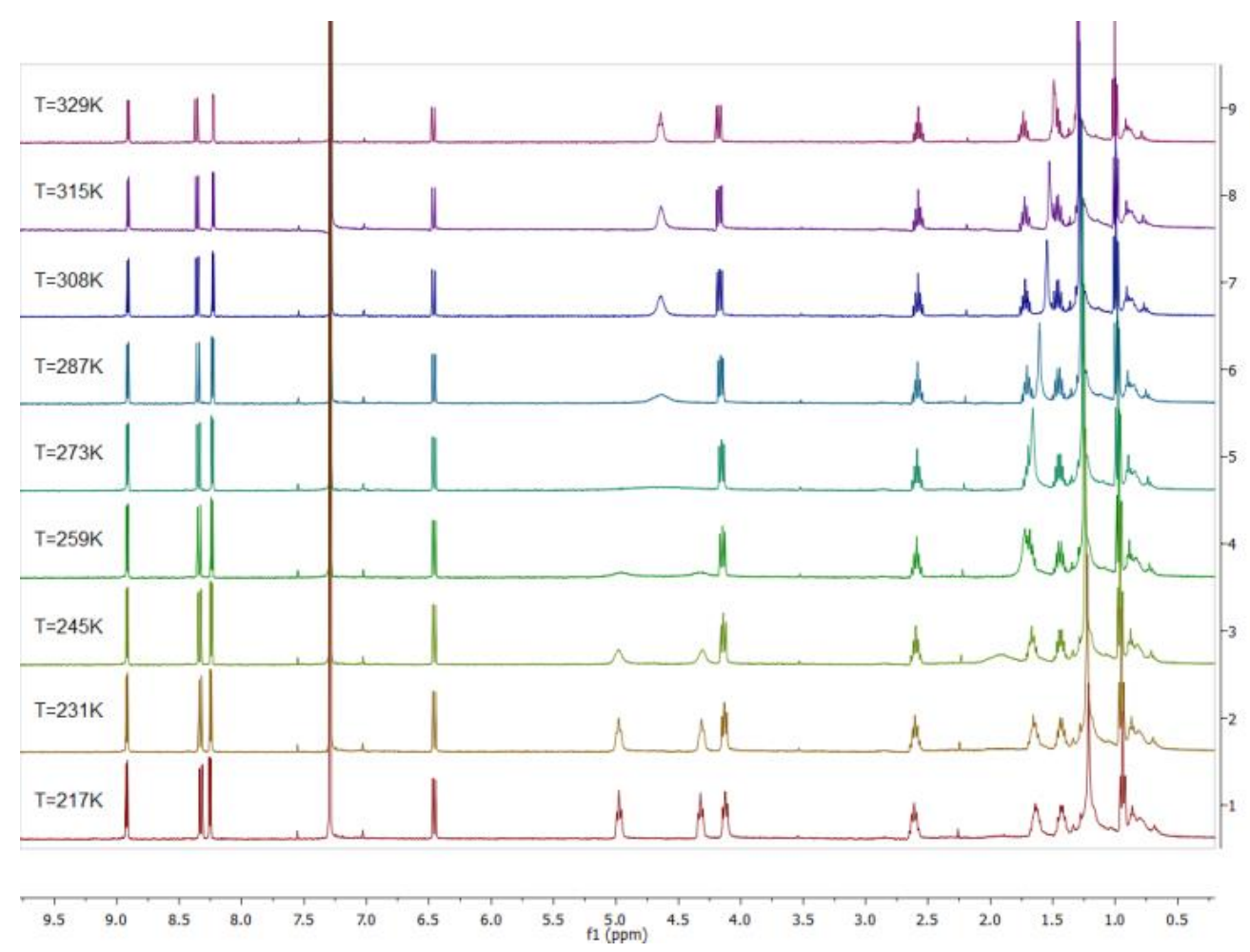

Figure S6. ${ }^{1} \mathrm{H}$ NMR spectra of the azetidine derivative $\mathbf{6}$ as a function of temperature.

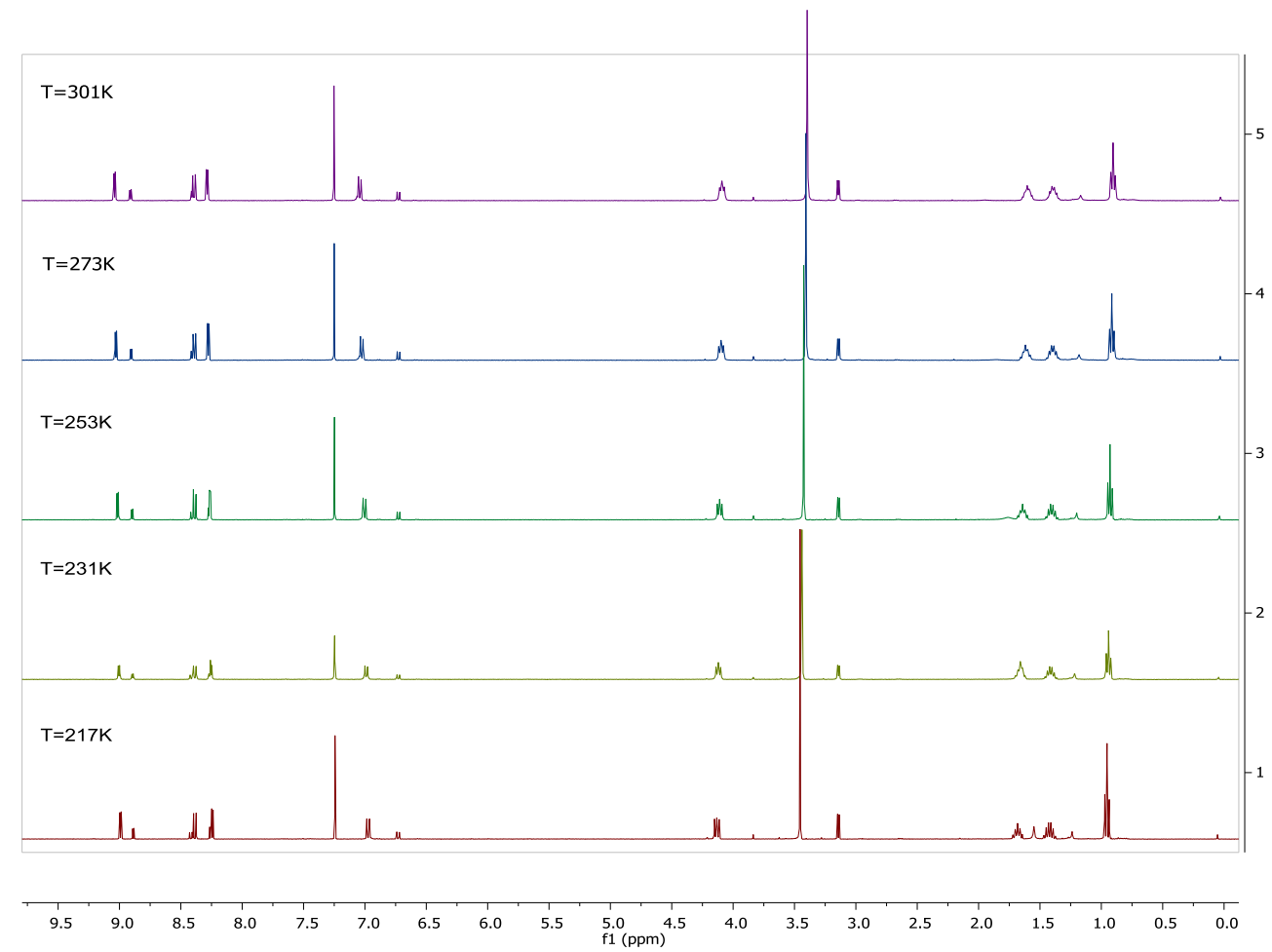

Figure S7. Variable temperature ${ }^{1} \mathrm{H}$ NMR spectra for compound 5. 


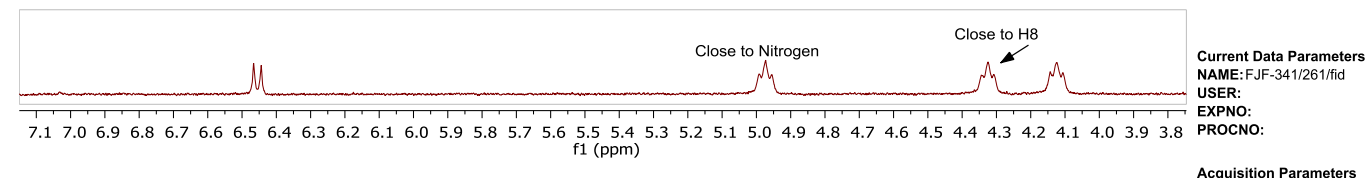

Acquisition Parameters

Date-

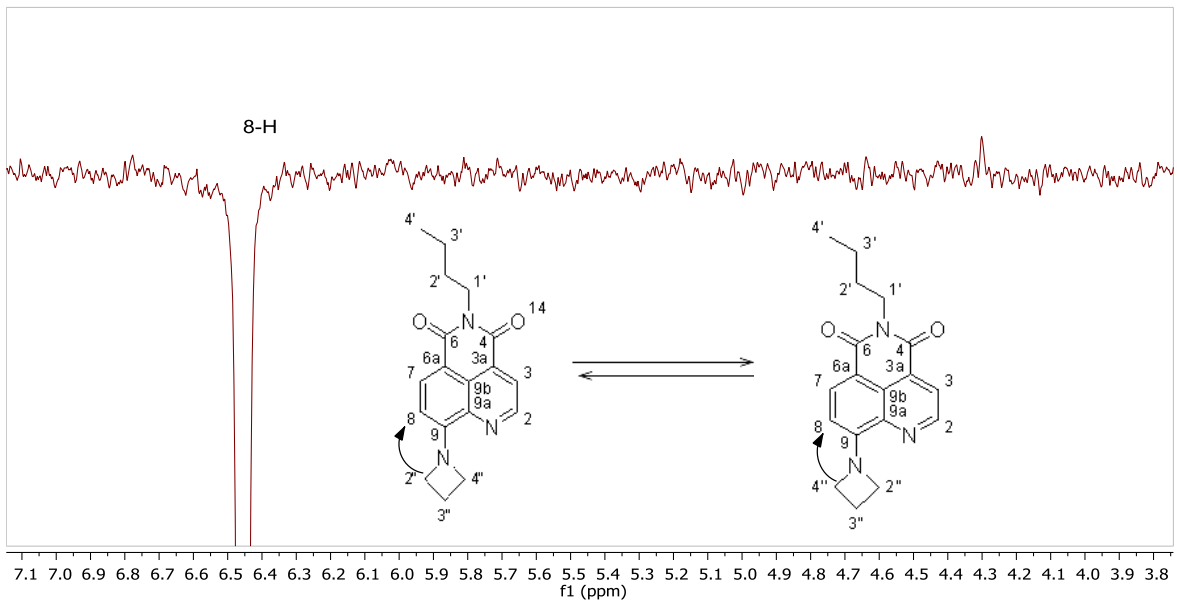

INTSE:

Figure S8. Rotamer assignment of H2" and H4" based on NOESY-1D ${ }^{1} \mathrm{H}$ NMR spectrum for compound 6.

Thermodynamic parameters were calculated from Eyring plot using the following equation.

$$
R \ln \frac{h k_{r}}{\kappa k T}=-\frac{\Delta H^{*}}{T}+\Delta S^{*}
$$

where $k_{r}$ represents the reaction rate constant obtained from chemical exchange simulation, $\kappa$ the transmission coefficient, $\mathrm{k}$ the Boltzmann constant and $\Delta H^{*}$ and $\Delta S^{*}$ the enthalpy and entropy of activation.

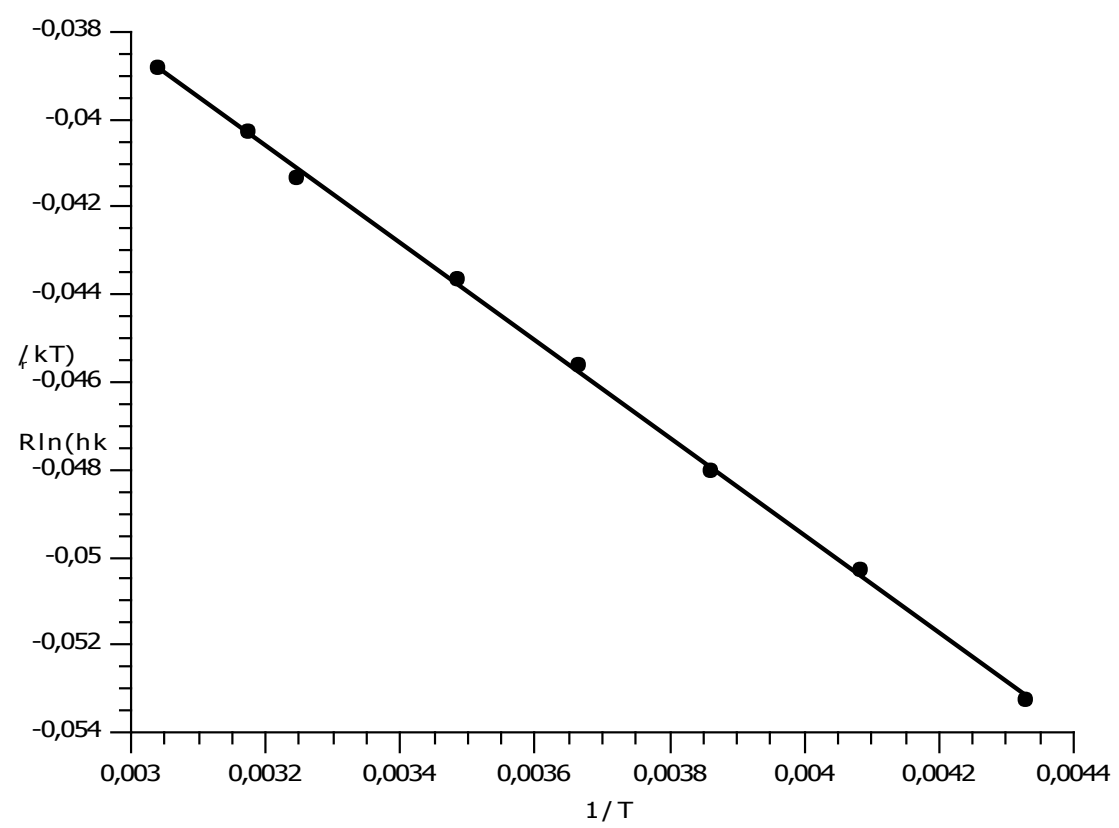

Figure S9. Eyring plot for compound 6. $\mathrm{R}^{\wedge} 2=0,999 . \Delta \mathrm{H}^{*}=-\mathrm{A}$ (slope) $=11,12+/-0.12 \mathrm{kcal} \mathrm{mol}^{-1}(46.56$ $\left.\mathrm{kJ} \cdot \mathrm{mol}^{-1}\right) \cdot \Delta \mathrm{S}^{*}=(\mathrm{y}$-intercept $)=-0.0050+/-4.2 \mathrm{e}-04 \mathrm{Kcal} \mathrm{K}^{-1} \mathrm{~mol}^{-1}$. 


\section{X-RAY DIFFRACTION}

To explain the significant influence of the amino group substitution upon the fluorescence emission properties of quinolimides, we tried to crystalize them to determine their structural coordinates. Unfortunately, it was not possible to obtain good crystals of the azetidinyl derivative $\mathbf{6}$ for its X-ray analysis. The relevant molecular parameters of quinolimides 2-5, obtained from X-ray crystallography are summarized in Table S3. Views of the four molecule structures are depicted in Figures S10 and S11, and a summary of the crystal data and structure refinement is included in Table S4.

While the crystal structure of the 9-amino-quinolimide 2 showed a unique molecule in its asymmetric unit, in the structure of the $\mathrm{nBuHN}$ and MeHN substituted derivatives $\mathbf{3}$ and $\mathbf{4}$, two independent molecules could be identified, $\mathrm{A}$ and $\mathrm{B}$, which differ in their molecular conformation and in their intermolecular hydrogen bond network. The dihedral angle $\left(\mathrm{C}_{9 \mathrm{a}}-\mathrm{C}_{9}-\mathrm{N}-\mathrm{R}^{2}\right)$ observed in molecules $\mathrm{A}$ and $\mathrm{B}$ are $1^{\circ}$ and $8^{\circ}$, and $2^{\circ}$ and $13^{\circ}$ for compounds 3 and $\mathbf{4}$ respectively. Both compounds present asymmetric dimers through $\mathrm{NH} . . \mathrm{O}=\mathrm{C} 6$ strong and $\mathrm{C}_{7} \mathrm{H} \ldots \mathrm{N}_{1}$ weak hydrogen bonds (Figures $\mathrm{S} 10$ and $\mathrm{S} 11$ ). Two independent molecules (A and $\mathrm{B}$ ) were also observed in compound $\mathbf{5}$. Both molecules form centrosymmetric dimers that differs in the twist angles between the plane of the $(\mathrm{Me})_{2} \mathrm{~N}$ group and the plane of the quinolimide ring. In all compounds, both the C9-N bond lengths (1.339-1.369 $\AA$ ) and the sum of angles around the $\mathrm{N}\left(\approx 360^{\circ}\right)$ were indicative of planar trigonal nitrogen and partial double bond character, with restricted rotation around that bond. The dihedral angle between the plane of the amino group and the plane of the quinolimide ring $\left(\mathrm{C}_{9 \mathrm{a}^{-}}\right.$ $\mathrm{C}_{9}-\mathrm{N}-\mathrm{R}^{2} \approx 0^{\circ}$ ) indicated their coplanarity, except for the dimethylamino derivative $\mathbf{5}$, where this group was twisted ( $7^{\circ}$ in structure A and $30^{\circ}$ in structure B). This compound also showed the largest C-N bond length, thus indicating a lower double bond character.

Table S3. Selected X-ray crystallography geometrical parameters for compounds $\mathbf{2}$ to $\mathbf{5}$ for the independent molecules A and B. Sum is the bond angle sum around the $\mathrm{N}$ atom $(\mathrm{a}+\mathrm{b}+\mathrm{c})$.

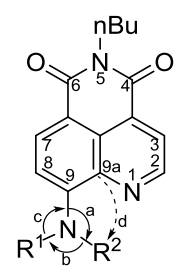

\begin{tabular}{|c|c|c|c|c|c|c|c|}
\hline & 2 & \multicolumn{2}{|c|}{3} & \multicolumn{2}{|c|}{4} & \multicolumn{2}{|c|}{5} \\
\hline $\mathrm{R}^{1}$ & $\mathrm{H}$ & \multicolumn{2}{|c|}{$n \mathrm{Bu}$} & \multicolumn{2}{|c|}{$\mathrm{Me}$} & \multicolumn{2}{|c|}{$\mathrm{Me}$} \\
\hline $\mathrm{R}^{2}$ & $\mathrm{H}$ & \multicolumn{2}{|c|}{$\mathrm{H}$} & \multicolumn{2}{|c|}{$\mathrm{H}$} & \multicolumn{2}{|c|}{$\mathrm{Me}$} \\
\hline Mol. & A & A & B & A & B & A & B \\
\hline $\mathrm{C}_{9}-\mathrm{N}(\AA)^{a}$ & $1.348(2)$ & $1.346(5)$ & $1.339(5)$ & $1.350(8)$ & $1.347(7)$ & $1.362(3)$ & $1.369(3)$ \\
\hline$a\left(\left(^{\circ}\right)^{a}\right.$ & $114(1)$ & $112(3)$ & $107(4)$ & $114(4)$ & 119(3) & $128.7(2)$ & $124.8(2)$ \\
\hline $\mathrm{b}\left({ }^{\circ}\right)^{a}$ & $126(2)$ & $123(3)$ & $128(4)$ & $122(4)$ & $116(3)$ & $111.0(2)$ & $113.5(2)$ \\
\hline $\mathrm{c}\left({ }^{\circ}\right)^{a}$ & $120(2)$ & $125.1(4)$ & $124.4(4)$ & $124.3(5)$ & $124.1(5)$ & $120.1(2)$ & $119.2(2)$ \\
\hline $\operatorname{Sum}\left({ }^{\circ}\right)^{a}$ & $360(3)$ & $360(4)$ & $359(6)$ & $360(6)$ & $359(4)$ & $359.8(3)$ & $357.5(3)$ \\
\hline $\mathrm{d}\left({ }^{\circ}\right)^{a}$ & $1(2)$ & $-1(3)$ & $8(3)$ & $2(5)$ & $13(4)$ & $-7.1(4)$ & $30.4(4)$ \\
\hline
\end{tabular}

${ }^{a}$ Standard deviation within parentheses. 
CCDC 1877593-1877596 contain the supplementary crystallographic data for compounds 2-5, respectively. These data can be obtained free of charge from The Cambridge Crystallographic Data Centre via www.ccdc.cam.ac.uk/getstructures.

Table S4. Crystal data, data collection and structure refinement for compounds 2-5.

\begin{tabular}{|c|c|c|c|c|}
\hline & 2 & 3 & 4 & 5 \\
\hline \multicolumn{5}{|l|}{ Crystal data } \\
\hline Chemical formula & $\mathrm{C}_{15} \mathrm{H}_{15} \mathrm{~N}_{3} \mathrm{O}_{2}$ & $\mathrm{C}_{19} \mathrm{H}_{23} \mathrm{~N}_{3} \mathrm{O}_{2}$ & $\mathrm{C}_{16} \mathrm{H}_{17} \mathrm{~N}_{3} \mathrm{O}_{2}$ & $\mathrm{C}_{17} \mathrm{H}_{19} \mathrm{~N}_{3} \mathrm{O}_{2}$ \\
\hline$M_{\mathrm{r}}$ & 269.30 & 325.40 & 283.32 & 297.35 \\
\hline $\begin{array}{l}\text { Crystal system, space } \\
\text { group }\end{array}$ & Monoclinic, $P 2_{1} / c$ & Triclinic, $P-1$ & Triclinic, $P-1$ & Triclinic, $P-1$ \\
\hline Temperature (K) & 296 & 296 & 296 & 120 \\
\hline$a, b, c(\AA)$ & $\begin{array}{l}4.7871(2), \\
12.3386(4), \\
22.9641(7)\end{array}$ & $\begin{array}{l}\text { 4.7687(2), } \\
13.2756(5), \\
28.070(1)\end{array}$ & $\begin{array}{l}7.5856(4), \\
12.9466(6), \\
14.9833(7)\end{array}$ & $\begin{array}{l}4.6367(2), \\
16.1389(8), \\
19.5100(9)\end{array}$ \\
\hline$\alpha, \beta, \gamma\left({ }^{\circ}\right)$ & $90,92.314(2), 90$ & $\begin{array}{l}96.174(2), \\
90.099(2), \\
95.527(2)\end{array}$ & $\begin{array}{l}92.936(2), \\
98.654(2), \\
91.993(2)\end{array}$ & $\begin{array}{l}85.012(3), \\
85.595(2), \\
88.662(2)\end{array}$ \\
\hline$V\left(\AA^{3}\right)$ & $1355.29(8)$ & $1758.4(1)$ & $1451.5(1)$ & $1449.9(1)$ \\
\hline$Z$ & 4 & 4 & 4 & 4 \\
\hline Radiation type & \multicolumn{4}{|c|}{$\mathrm{Cu} K \alpha$} \\
\hline$\mu\left(\mathrm{mm}^{-1}\right)$ & 0.734 & 0.648 & 0.710 & 0.736 \\
\hline Crystal size (mm) & $0.57 \times 0.09 \times 0.02$ & $0.3 \times 0.08 \times 0.02$ & $0.47 \times 0.15 \times 0.05$ & $0.68 \times 0.07 \times 0.03$ \\
\hline \multicolumn{5}{|l|}{ Data collection } \\
\hline Diffractometer & \multicolumn{4}{|c|}{ Bruker APEX-II CCD } \\
\hline Absorption correction & \multicolumn{4}{|c|}{ Multi-scan (SADABS; Bruker, 2013) } \\
\hline$T_{\min }, T_{\max }$ & $0.6026,0.7538$ & $0.6299,0.7516$ & $0.5958,0.7522$ & $0.2621,0.7531$ \\
\hline $\begin{array}{l}\text { No. of measured, } \\
\text { independent and } \\
\text { observed }[I>2 \sigma(I)] \\
\text { reflections }\end{array}$ & $17540,2649,2084$ & $47386,5003,2978$ & $37098,4502,2993$ & $53567,5258,4178$ \\
\hline$R_{\text {int }}$ & 0.0419 & 0.0777 & 0.0669 & 0.0789 \\
\hline $\begin{array}{l}2 \Theta \text { range for data } \\
\text { collection }\left({ }^{\circ}\right)\end{array}$ & 7.706 to 148.786 & 3.166 to 118.182 & 6.842 to 124.87 & 6.838 to 136.586 \\
\hline \multicolumn{5}{|l|}{ Refinement } \\
\hline$R\left[F^{2}>2 \sigma\left(F^{2}\right)\right], w R\left(F^{2}\right), S$ & $\begin{array}{l}0.0459,0.1315 \\
1.032\end{array}$ & $\begin{array}{l}0.0794,0.2418, \\
1.044\end{array}$ & $\begin{array}{l}0.0941,0.3101, \\
1.061\end{array}$ & $\begin{array}{l}0.0639,0.1925, \\
1.028\end{array}$ \\
\hline Data/restraints/param. & 2649/0/190 & $5003 / 9 / 453$ & $4502 / 7 / 401$ & $5258 / 0 / 403$ \\
\hline $\mathrm{H}$-atom treatment & $\begin{array}{l}\text { H-atom parameters } \\
\text { mixed }\end{array}$ & $\begin{array}{l}\mathrm{H} \text {-atom parameters } \\
\text { mixed }\end{array}$ & $\begin{array}{l}\text { H-atom parameters } \\
\text { mixed }\end{array}$ & $\begin{array}{l}\text { H-atom parameters } \\
\text { constrained }\end{array}$ \\
\hline$\Delta \rho_{\max }, \Delta \rho_{\min }\left(\mathrm{e} \AA^{-3}\right)$ & $0.20 /-0.19$ & $0.39 /-0.26$ & $0.33 /-0.25$ & $0.30 /-0.52$ \\
\hline
\end{tabular}

Computer programs: APEX2 (Bruker, 2013), SAINT (Bruker, 2013), SHELXL-2014/7 (Sheldrick, 2015), Mercury (Macrae et al., 2008) and OLEX2 (Dolomanov et al., 2009). 


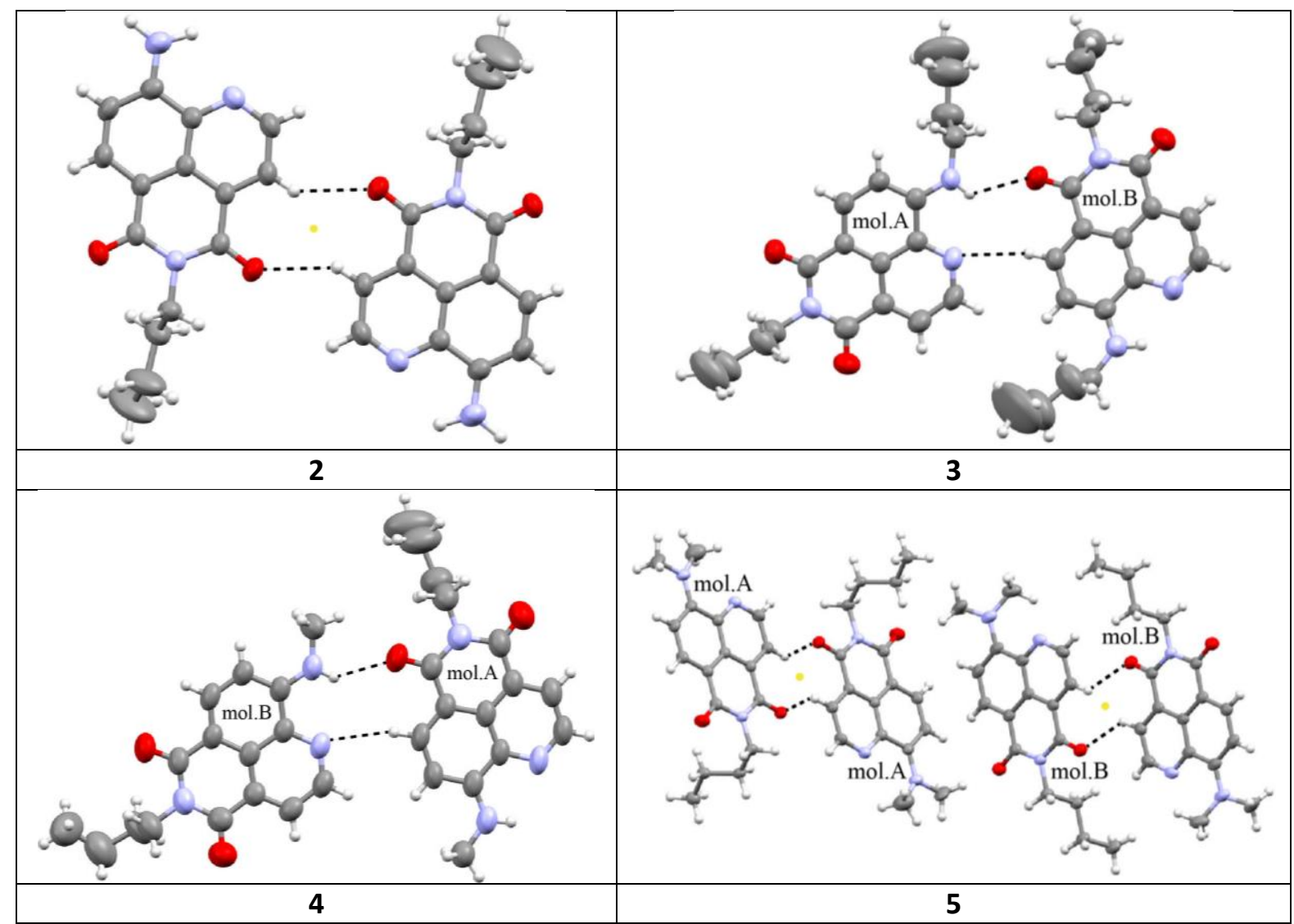

Figure S10. View of the X-ray dimer structures for compounds 2-5. Displacement ellipsoids are drawn at $50 \%$ probability level and hydrogen atoms are denoted as spheres of $0.2 \AA$ radii. Disorder model in the butyl substituent of compounds $\mathbf{3}$ and $\mathbf{4}$ has been omitted for clarity purpose. 


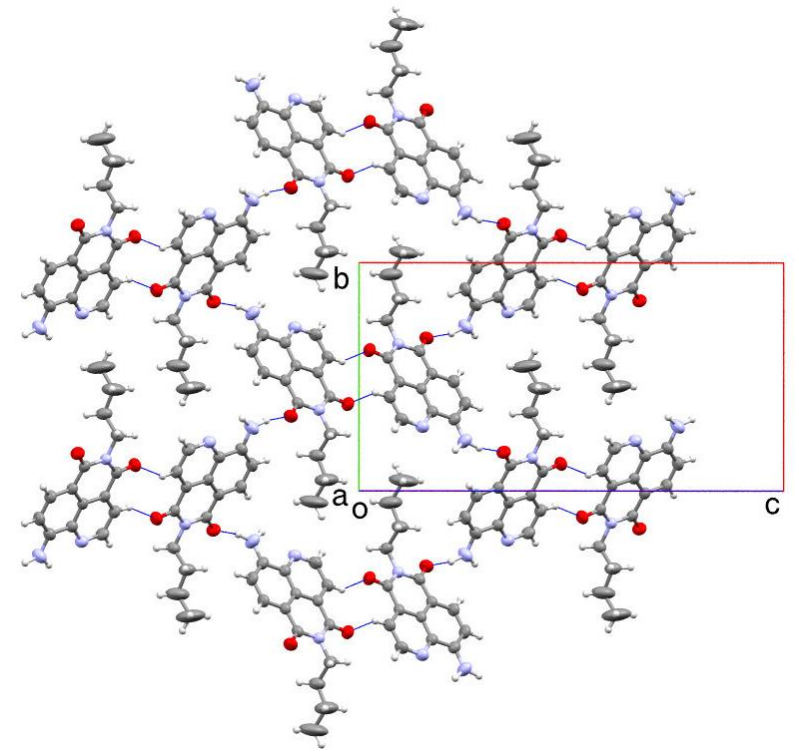

2

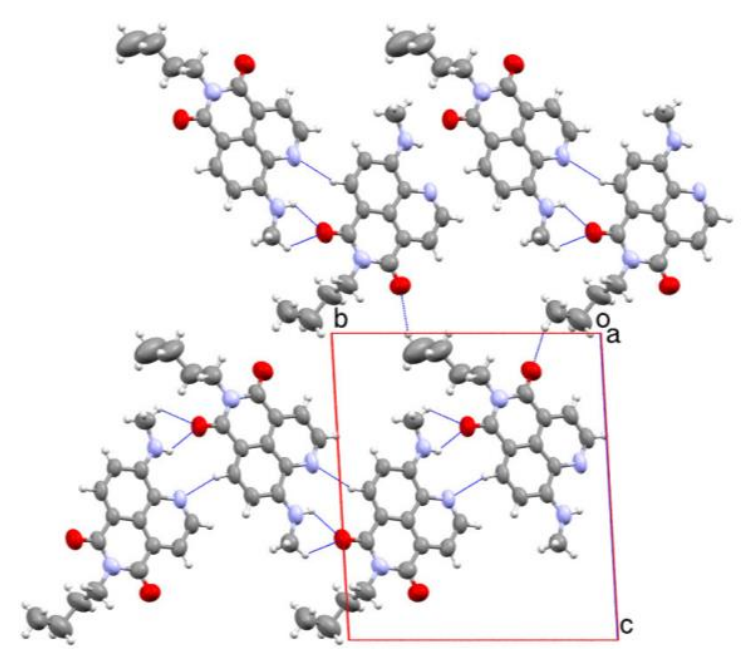

4

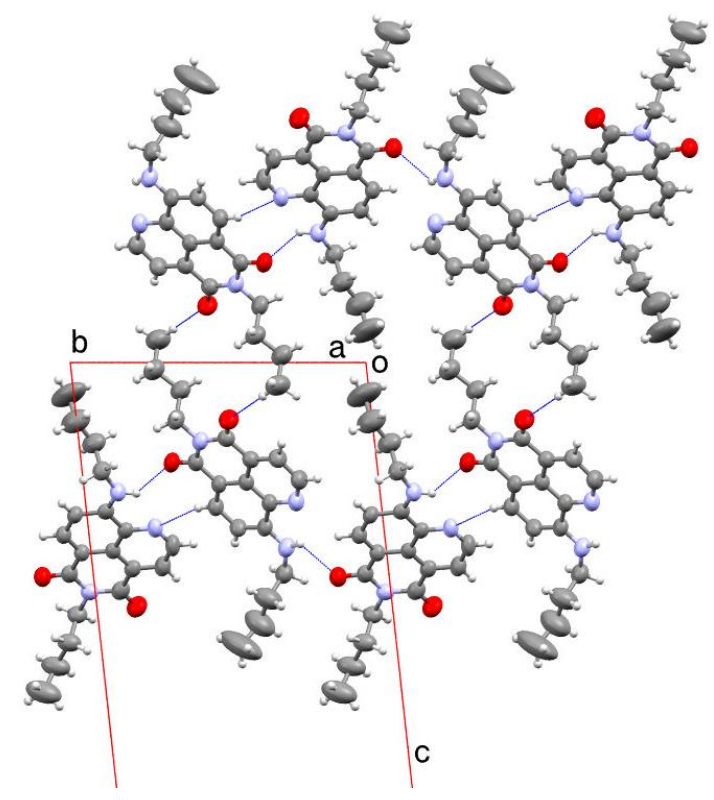

3

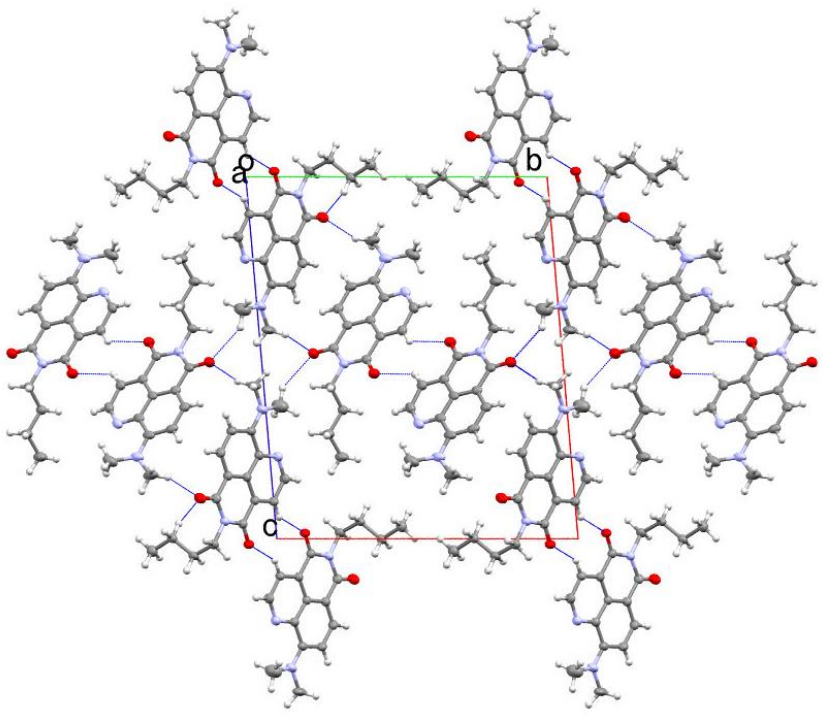

5

Figure S11. A view of the X-ray crystal structures for compounds 2-5. 


\section{COMPUTATIONAL METHODS}

TD-DTF calculations have been carried out at the PBE0/6-31+G(d,p) computational level ${ }^{6}$ within the Gaussian-09 package. $^{7}$ The calculations in vacuo have been confirmed to correspond to energetic minima or transition state structures by frequency calculations (no imaginary and only one imaginary frequencies, respectively). The effect of the solvent has been incorporated by means of the PCM continuum model for a variety of parametrized solvents. The excited states have been done with the TD-DFT methodology. The geometry of the ground (GS) and first singlet excited electronic (ES) states of all systems was optimized and most significant structural parameters of 2-6 are summarized in Table S5.

The geometry calculations identified two minimum energy structures in the ground state for compounds $\mathbf{3}, \mathbf{4}$ and 5, very similar to the structures A and B identified in the X-ray analysis, denoted in Table S5 also as A and B. However, a unique minimum was identified for the 9-amino- and the 9-azetidinyl-quinolimides 2 and 6, respectively. In general, there is a good correlation between the calculated ground state and the X-ray data. It is interesting to note that the azetidinyl derivative $\mathbf{6}$ gave the shortest $\mathrm{C}_{9}-\mathrm{N}$ bond length, and, therefore, it should have a higher $\pi$ character and a better charge transfer, which could explain its higher fluorescence quantum yield and red-shifted $\lambda_{\max }{ }^{\text {abs }}$ and $\lambda_{\max }{ }^{\mathrm{em}}$. On the contrary, in both the X-ray analysis and the TD-DFT calculations the 9-dimethylamino derivative 5 showed the longest $\mathrm{C}_{9}-\mathrm{N}$ bond length and a lower coplanarity respect to the quinolimide ring, which could be the cause of its poorer fluorescence behavior.

Table S5. Calculated molecular parameters of quinolimides 2-6.

\begin{tabular}{|c|c|c|c|c|c|c|c|c|}
\hline \multirow{2}{*}{ Compd } & \multirow{2}{*}{\multicolumn{2}{|c|}{ Energy state $\Delta \mathrm{H}^{a}\left(\mathrm{kJmol}^{-1}\right)$}} & \multirow{2}{*}{$\begin{array}{l}\mathrm{C}_{9}-\mathrm{N} \text { bond } \\
\text { length }(\AA)\end{array}$} & \multicolumn{4}{|c|}{ 9-N bond angles (degrees) } & \multirow{2}{*}{$\begin{array}{c}\text { Twist angle } \\
\text { (d) }\end{array}$} \\
\hline & & & & $\mathrm{a}$ & $\mathrm{b}$ & $\mathrm{c}$ & $a+b+c$ & \\
\hline \multirow{2}{*}{2} & GS & 48.3 & 1.349 & 118.0 & 120.2 & 121.7 & 359.9 & -1.5 \\
\hline & ES & & 1.333 & 115.3 & 121.6 & 123.1 & 360.0 & -0.1 \\
\hline \multirow{2}{*}{$3(A)$} & GS & 63.3 & 1.346 & 115.1 & 120.0 & 124.9 & 360.0 & 0.2 \\
\hline & ES & & 1.336 & 111.7 & 120.9 & 127.4 & 360.0 & 0.2 \\
\hline \multirow{2}{*}{$3(\mathrm{~B})$} & GS & 74.7 & 1.355 & 130.7 & 114.9 & 114.4 & 360.0 & -1.1 \\
\hline & ES & & 1.347 & 131.2 & 114.3 & 114.5 & 360.0 & -0.3 \\
\hline \multirow{2}{*}{$4(A)$} & GS & 62.7 & 1.347 & 115.0 & 120.7 & 124.4 & 360.0 & 0.0 \\
\hline & ES & & 1.337 & 111.7 & 121.6 & 126.8 & 360.0 & -0.1 \\
\hline \multirow{2}{*}{$4(B)$} & GS & 75.4 & 1.356 & 130.0 & 115.7 & 114.2 & 360.0 & -0.2 \\
\hline & ES & & 1.347 & 130.6 & 115.1 & 114.3 & 360.0 & -0.1 \\
\hline \multirow{2}{*}{$5(A)$} & GS & 22.5 & 1.372 & 123.0 & 112.6 & 118.6 & 354.2 & 42.1 \\
\hline & ES & & 1.376 & 122.1 & 115.3 & 120.8 & 358.2 & 38.0 \\
\hline \multirow{2}{*}{$5(B)$} & GS & 32.7 & 1.364 & 124.3 & 114.7 & 119.6 & 358.5 & -31.0 \\
\hline & ES & & 1.376 & 122.3 & 115.2 & 120.7 & 358.2 & -38.0 \\
\hline \multirow{2}{*}{6} & GS & 48.5 & 1.343 & 135.8 & 94.2 & 129.3 & 359.3 & 0.4 \\
\hline & ES & & 1.340 & 135.4 & 94.3 & 130.4 & 360.0 & -0.3 \\
\hline
\end{tabular}

${ }^{a}$ Amino group rotation enthalpy.

Geometry and energy of 2-6 minima in gas phase in the electronic ground state (GS) and excited state (ES) calculated at PBE0/6-31+G(d,p) computational level.

2 (GS), Total Energy= -894.442866224 Hartree, $\mathrm{NIMAG}=0$

$\mathrm{C},-0.4021444092,2.8987157357,5.5023968058$

$\mathrm{C}, 0.3282082511,2.1823533953,4.5515034161$

C, $0.7023214428,2.7513490496,3.3424507173$

$\mathrm{C}, 0.3323800853,4.0867798471,3.0822413916$

C, $-0.4053446528,4.840466466,4.0262784803$

C,-0.7835703646,4.222522197,5.271417291

C,1.4668621802,1.9934023259,2.3505333252

C, $0.6865627675,4.7203741845,1.8741085095$

C, $1.4608658232,3.9760207258,0.8488832484$ 
C, $0.3075376356,6.0285594427,1.6650653374$ C, $-0.4258721866,6.6872905405,2.671638957$ $\mathrm{H},-0.7366214945,7.7201163981,2.5300951601$ $\mathrm{H},-0.6800966878,2.4199869628,6.4372637903$ H,0.6173621951,1.1537122301,4.7465260993 $\mathrm{H}, 0.5755147182,6.5281764858,0.7397463919$ $\mathrm{O}, 1.8297256848,0.8385048008,2.5195482339$ O,1.7963306856,4.4940671937,-0.2058078395 N,-0.7735468046,6.1207588226,3.8132738143 C, $2.5402090128,1.9100527084,0.1442912724$ $\mathrm{H}, 2.2558844266,0.8613808642,0.2506847175$ H,2.2235970057,2.2784937399,-0.8341146873 C,4.0466365084,2.0724684904,0.3119807825 H,4.3011565591,3.1378057194,0.2453363258 $\mathrm{H}, 4.3325737359,1.7278750764,1.3138670017$ $\mathrm{N}, 1.7813570789,2.659169206,1.1480767841$ C,4.8251778835,1.2919196332,-0.7422252876 H,4.5549298486,0.2290550194,-0.6800495829 $\mathrm{H}, 4.5199845639,1.6292058164,-1.7421622995$ C,6.3342954779,1.4437398407,-0.5924557387 H,6.6722738482, 1.0830747547,0.3856396995 H,6.8720040152,0.8775532139,-1.3597645656 H,6.635672751,2.4936364589,-0.6805617746 $\mathrm{N},-1.4934160032,4.9611714817,6.1497247204$ H,-1.7059605163,5.9159931062,5.9031450924 $\mathrm{H},-1.7628123247,4.5996268265,7.0469727501$

2(ES), Total Energy= -894.431543709 Hartree C, $-0.373751326,2.856545054,5.4951752769$ C, $0.3497894651,2.1477294608,4.5516360418$ C,0.7002999045,2.7676423442,3.3478724479 C,0.325985057,4.1235896259,3.0736995365 C,-0.3955973732,4.8542581065,4.0071927654 C,-0.7502152169,4.2056498515,5.2368325091 C, $1.4825840376,2.0037962998,2.3385936418$ C, $0.6897375204,4.7304061999,1.8475985036$ C, $1.4305092525,4.0036608243,0.8538689919$ C, $0.2780505199,6.0769590964,1.6742595791$ C,-0.4402812677,6.7090450969,2.6794945911 $\mathrm{H},-0.753634687,7.7417696315,2.5406103524$ $\mathrm{H},-0.6597967244,2.3966072927,6.4371260137$ $\mathrm{H}, 0.657044131,1.1203351393,4.7139780356$ $\mathrm{H}, 0.528078961,6.5980961053,0.7569999684$ $\mathrm{O}, 1.8321531808,0.8500085894,2.5760459181$ O,1.7792911593,4.4679673834,-0.2298173909 $\mathrm{N},-0.8008123028,6.1500643595,3.8511918261$ C, $2.5325946853,1.9041987603,0.1586725239$ $\mathrm{H}, 2.2448431342,0.8537104513,0.247299062$ H,2.2218962109, 2.2889874466,-0.8147270943 
C,4.039456606,2.0598692866, 0.3310085452

$\mathrm{H}, 4.2917707822,3.1261076639,0.2746554633$

$\mathrm{H}, 4.32599167,1.7057130376,1.3297146965$

$\mathrm{N}, 1.7738368392,2.6457497012,1.1648939848$

C,4.8184048945,1.2894762108,-0.7301635233

$\mathrm{H}, 4.5474864884,0.2259735322,-0.6800511054$

$\mathrm{H}, 4.5141064535,1.6380400942,-1.7263950056$

C,6.3276158056,1.4384047639,-0.5780420005

H,6.6648835669, 1.0673552165,0.3965310786

H,6.8657216336,0.8801219318,-1.3510169978

H,6.6293033495,2.4890708343,-0.6547010519

$\mathrm{N},-1.4452818543,4.9389836833,6.1071131181$

$\mathrm{H},-1.652784006,5.8901788805,5.8069583028$

H,-1.7492418102,4.5893068037,7.0014397353

3-min1 (GS), Total Energy= -1051.51096680 Hartree, NIMAG= 0

C, $-0.388075723,2.8767323469,5.502562749$

C, $0.3417885981,2.1704571242,4.5426393892$

C, $0.7085140991,2.7437161805,3.333811015$

C, $0.3293550872,4.0788270928,3.0778354015$

C,-0.4092493122,4.824906749,4.0261988686

C,-0.7785282564,4.2025063117,5.27777702109

C, $1.4715869675,1.9930429559,2.3378756443$

C, $0.6747507629,4.717156856,1.8704880745$

C, $1.4541165751,3.9818584593,0.8430993657$

C, $0.2837411037,6.0231678222,1.6632649832$

C, $-0.4512856734,6.6730612401,2.6717067477$

$\mathrm{H},-0.7735424023,7.7027827919,2.5334091458$

$\mathrm{H},-0.6535568407,2.3867720678,6.4328646738$

$\mathrm{H}, 0.6376464511,1.1426498109,4.7324910275$

$\mathrm{H}, 0.5448886056,6.5255296758,0.7374977428$

$\mathrm{O}, 1.8388014083,0.8378174747,2.4985095495$

$\mathrm{O}, 1.787902953,4.5063501391,-0.2093697185$

$\mathrm{N},-0.7884900034,6.1003731037,3.8150548643$

C, $2.5450581841,1.9238177641,0.1319890192$

$\mathrm{H}, 2.2556383535,0.8751957331,0.2258024741$

H, 2.2381569003,2.3035466573,-0.8450953357

C,4.0508819795,2.0771586025,0.31313305

H,4.3116027194,3.1416231594,0.254760977

H,4.3262467972,1.7251125595,1.3152564783

$\mathrm{N}, 1.7817239755,2.6658144249,1.1372443558$

C, $4.832822945,1.2973656482,-0.7388594284$

$\mathrm{H}, 4.5506076962,0.236948725,-0.6876781379$

$\mathrm{H}, 4.5422400941,1.645400131,-1.7394301326$

C,6.3418143421,1.4306089316,-0.5712431862

H,6.6637819932, 1.0602240891,0.4085841961

H,6.8815911958,0.8623686079,-1.3356457279

H,6.6573111414,2.4772034517,-0.6495617787

$\mathrm{N},-1.4800944244,4.9421021329,6.1564637381$ 
$\mathrm{H},-1.6913901684,5.8842763403,5.8520527363$

C, $-1.9326814937,4.4831562478,7.4471440675$

$\mathrm{H},-2.5846583903,3.6046588496,7.3243454893$

H,-1.0712969618,4.1589045959,8.0509166969

C,-2.6861954221,5.583700679,8.1786987875

H,-3.5374187005,5.9079339871,7.5639922436

H,-2.0279012612,6.4560688458,8.2926881836

C, $-3.1880173637,5.1420311405,9.5495432534$

$\mathrm{H},-3.8399927095,4.2660926573,9.4325624196$

H,-2.3362919077,4.8108312383,10.1586255115

C,-3.9421181914,6.2441629687,10.2836021792

H,-4.8189538646,6.5714009136,9.7137942119

$\mathrm{H},-4.2910018814,5.9034492197,11.2632111056$

H,-3.3051056166,7.1211145153,10.444170238

3-min2 (GS), Total Energy $=-1051.50015673$ Hartree, NIMAG= 0

$\mathrm{C},-1.1324867346,3.4900111271,4.4950579363$

C, $-0.4296434915,2.7178217967,3.5802954243$

C, $0.9594592568,2.7101424052,3.5632086464$

C, $1.6456854128,3.5056554771,4.5001753297$

C, $0.9563107061,4.3092720078,5.4545008441$

C, $-0.4890209215,4.2995830657,5.4483704159$

C, $1.6914950832,1.895772765,2.5946960726$

C,3.0576077484,3.5264725583,4.5199917135

C,3.830949345,2.709844488,3.5515614993

C,3.7107566492,4.309292706,5.444546873

C, $2.937373043,5.0674970365,6.3423875137$

H,3.4260375371,5.6966923548,7.0837707899

H,-2.2197260069,3.472298315,4.4789344955

H,-0.9589723297,2.1034851979, 2.8579259862

H,4.7956082696,4.3293918956,5.4663004242

O,1.1441623052,1.1805261867,1.7666702751

O,5.0536953224,2.6970637316,3.5519933295

$\mathrm{N}, 1.6176866945,5.0714733604,6.3521654492$

C,3.8437483451,1.1618687725,1.6710781411

$\mathrm{H}, 3.2281532172,1.10155174,0.7712599554$

H,4.765120086, 1.7056561645,1.4503725013

C,4.1626448311,-0.2351761616,2.1912273227

H,4.7450402589,-0.1480124541,3.1172729073

H,3.2234577507,-0.7454610113,2.4397220084

N,3.0974302486,1.9647360307,2.6408747676

C,4.9413748702,-1.0574639037,1.1697570494

H,4.357984758,-1.1298982212,0.2418221181

H,5.8687016746,-0.5288761186,0.9098667081

C,5.2771483869,-2.457122048,1.670813681

H,4.3675933206,-3.0204465954,1.9084311444

H,5.8355427799,-3.027632781,0.9216191776

H,5.8873779439,-2.4149405361,2.580153559

$\mathrm{N},-1.2517618589,5.0228298676,6.3027730487$ 
H,-2.2458544795,4.9063403355,6.174254967

C,-0.8741461542,5.9161962715,7.385724132

$\mathrm{H},-0.2607978949,5.3808614591,8.11877233$

H, $-0.2525752942,6.7317381873,7.0011867766$

C,-2.1286931463,6.4698633125,8.045959627

$\mathrm{H},-2.7475074144,5.6379396597,8.4133477882$

$\mathrm{H},-2.7302778116,7.0075020327,7.2985478484$

C,-1.8090865578,7.4088458837,9.2047854746

H,-1.2049597991,6.8723093409,9.948166136

H,-1.1827588917,8.2334402626,8.8395562401

C,-3.058108714,7.9725764903,9.8712360545

$\mathrm{H},-3.6862463705,7.1723194442,10.2785406742$

$\mathrm{H},-2.8006060749,8.6441206144,10.6960564225$

$\mathrm{H},-3.666106719,8.5406405157,9.1581043303$

3-min1 (ES), Total Energy= -1051.50005457 Hartree

C, $-0.3750787907,2.762632768,5.4971119625$

C, $0.3539588933,2.0771458842,4.5339115718$

C, $0.694884223,2.717510868,3.3429289766$

C, $0.3055208797,4.0740228361,3.0943882849$

C,-0.4204370393,4.7779100884,4.0426178774

C,-0.7669427674,4.1092311072,5.2671749532

C, $1.481588552,1.9800409668,2.3177660728$

C, $0.6613498605,4.7071882153,1.8780179849$

C, $1.412730073,4.0080369073,0.8720220903$

C, $0.2331868143,6.0496305486,1.7277556785$

C,- $-0.4908773011,6.6560232784,2.7452072631$

H,-0.8178519967,7.6869232054,2.6238134988

H, $-0.6470959983,2.2738567934,6.4270306619$

$\mathrm{H}, 0.6707362646,1.0501077727,4.6798925291$

$\mathrm{H}, 0.4745492528,6.5896705929,0.8191103648$

$\mathrm{O}, 1.8401508709,0.8238807847,2.5283664496$

O, $1.7598648179,4.497373926,-0.2016481126$

$\mathrm{N},-0.8405856538,6.0731009842,3.9077019713$

C,2.5400913022,1.9340055936,0.1403838449

$\mathrm{H}, 2.2526158828,0.8811476325,0.1980085638$

H, 2.2401807158,2.343931677,-0.8260622225

C,4.044930873,2.0852952905,0.333655164

H,4.2982184483,3.152541102,0.3043091482

$\mathrm{H}, 4.3191612344,1.7087514369,1.3275200506$

$\mathrm{N}, 1.7698203203,2.6482419323,1.1570985278$

C,4.8356734646,1.3375528348,-0.7346768521

$\mathrm{H}, 4.5576728578,0.2747990787,-0.7148036224$

H,4.5485310727, 1.7122726338,-1.7264756526

C,6.3433970895,1.4720566643,-0.5560649121

H,6.6622007302,1.0764981637,0.4150619237

H,6.8898946741,0.9274339974,-1.3329709069

$\mathrm{H}, 6.6543299921,2.521835241,-0.6038552255$

$\mathrm{N},-1.4663630959,4.8409056776,6.1396258198$ 
H,-1.6487086201,5.7838422896,5.7829751258

C,-1.9507101468,4.4337103847,7.4379819743

$\mathrm{H},-2.6400725319,3.5844651491,7.3215527474$

$\mathrm{H},-1.1064242172,4.0802821099,8.0471815282$

C,-2.6546203601,5.5851916696,8.1399090912

$\mathrm{H},-3.4866857114,5.9346937636,7.5139965364$

H,-1.9564141368,6.4269427286,8.2391690324

C,-3.1807583654,5.1909324107,9.5163784943

H,-3.8713234686,4.3432508157,9.4130293599

$\mathrm{H},-2.3469823063,4.8344117831,10.1359563978$

C,-3.8873763408,6.3406300413,10.2240990043

H,-4.7464264138,6.6948273906,9.6438602728

$\mathrm{H},-4.2545423547,6.0344238749,11.2081079558$

H,-3.2122371826,7.1908201246,10.3706561718

3-min2 (ES), Total Energy= -1051.49031590 Hartree

C,-1.0963553695,3.4712594066,4.532096023

C, $-0.4148151867,2.6994633859,3.6119996758$

C, $0.9773956113,2.7237260319,3.6138517745$

C, $1.6961280279,3.5328786258,4.5541958447$

C,1.0264493679,4.3206574359,5.5002672259

C, $-0.4080730496,4.2875633482,5.4842108616$

C, $1.7085314388,1.8909892645,2.6226198483$

C,3.1098765203,3.5300054861,4.5221067851

C,3.8391635035,2.7422820412,3.5639455467

C,3.7706360665,4.342847118,5.4791396447

C,3.0086506949,5.0820707394,6.37006049

H,3.5115289476,5.7081445766,7.1057908663

H,-2.1840950139,3.4678608685,4.5455688021

$\mathrm{H},-0.9276388721,2.07561344,2.8880556673$

H,4.8538950524,4.3749487842,5.4984637512

O,1.087702954,1.1821240395,1.8333605909

O,5.0672279483,2.7040862029,3.49663163

$\mathrm{N}, 1.6673949677,5.1082269071,6.422072954$

C,3.8123463655,1.1650954679,1.6632851216

H,3.1984951926,1.1118865809,0.7606105823

$\mathrm{H}, 4.7361239204,1.7061686884,1.4484278362$

C,4.1289757988,-0.2361773345,2.1742028247

H,4.7146870206,-0.1502941853,3.0979962402

H,3.1907991721,-0.7478344708,2.4249619489

$\mathrm{N}, 3.074744679,1.9653890779,2.6384659251$

C,4.903160375,-1.0553244313,1.1469119716

H,4.31682672,-1.1243735127,0.2204003243

H,5.8294828337,-0.5256184883,0.8860634466

C,5.2411015743,-2.4569569408,1.6412981959

H,4.3325446224,-3.0214685651,1.8804251786

H,5.7971443081,-3.0249833138,0.8882883809

H,5.8543057372,-2.417331385,2.5486843046

N,-1.1910821125,4.990407947,6.3247155796 
$\mathrm{H},-2.1843880083,4.8556905265,6.1838351392$

C,-0.8573329209,5.9062222949,7.4079888419

$\mathrm{H},-0.2484378615,5.3796189798,8.1492770979$

$\mathrm{H},-0.2244618141,6.7083431384,7.0181001629$

C,-2.1355955015,6.4523670719,8.0253580398

$\mathrm{H},-2.7547144048,5.6203927158,8.3924007468$

$\mathrm{H},-2.7239568318,6.9748199594,7.2569233632$

C,-1.8502809314,7.411197443,9.1776034006

$\mathrm{H},-1.2576331452,6.8910006127,9.9411956802$

$\mathrm{H},-1.2240560678,8.2360102237,8.8136263173$

C,-3.1201770777,7.9706389815,9.8067744641

$\mathrm{H},-3.7489930811,7.1700016714,10.2120596625$

$\mathrm{H},-2.8871655877,8.6561009019,10.6270861942$

H,-3.717257403,8.5228656721,9.0724309559

4-min1 (GS), Total Energy= -933.703525148 Hartree, NIMAG= 0

C, $-0.3789245519,2.8727679287,5.5104354891$

C,0.3473311075,2.1658955619,4.5474961101

C, $0.7126091478,2.7408755425,3.3394088831$

C,0.3367614187,4.0774872042,3.0866453572

C, $-0.3974172107,4.823589201,4.0380460439$

C,-0.7660807793,4.1989825053,5.2878290938

C,1.4715516555,1.989819995,2.3398783717

C,0.6808544732,4.7170008959,1.8796916548

C, $1.454408988,3.9809279662,0.8483342953$

C, $0.2935691901,6.0246075022,1.6763562336$

C,-0.436975156,6.6749133237,2.688099033

$\mathrm{H},-0.7560206284,7.7060123806,2.552906825$

H,-0.6440005368,2.3820009608,6.4405827519

$\mathrm{H}, 0.6408274172,1.1369088974,4.7344916285$

$\mathrm{H}, 0.5538835355,6.5282294832,0.7510530645$

$\mathrm{O}, 1.8364012407,0.8337725195,2.498651137$

O,1.78547436,4.5060843273,-0.2044744936

$\mathrm{N},-0.7734615805,6.1008121678,3.8309207136$

C, $2.5395129627,1.9215792972,0.1312132078$

$\mathrm{H}, 2.2505101465,0.8729340031,0.2256042359$

H,2.2291254916,2.301462236,-0.8447172601

C,4.045720515,2.0757098474,0.3082232621

$\mathrm{H}, 4.3056870208,3.1401955194,0.2487475189$

H,4.3234593971, 1.724303824,1.309916575

$\mathrm{N}, 1.7796086058,2.6634643024,1.1393657831$

C,4.8258167946,1.296161644,-0.7454004939

$\mathrm{H}, 4.5489214535,0.2346317594,-0.6896503452$

H,4.528191386, 1.6398750524,-1.7454285061

C,6.3349526162,1.4380794265,-0.5865864857

H,6.6651865007, 1.0721132287,0.3921919036

H,6.873465085,0.8709584957,-1.3527061693

H,6.6438481382,2.4862606566,-0.6694638862

N,-1.4660644237,4.9390131576,6.1689065543 
$\mathrm{H},-1.6720933904,5.8812896046,5.8662742045$

C,-1.9099870514,4.467710478,7.4523896664

$\mathrm{H},-2.4535719786,5.2695901858,7.9539007967$

$\mathrm{H},-2.5831723321,3.6058781626,7.3556012995$

$\mathrm{H},-1.065355368,4.175441895,8.0899462461$

4-min2 (GS), Total Energy= -933.692552793 Hartree, NIMAG= 0

C,-0.3816600509,2.9596586519,5.4517259724

C, $0.3449530955,2.2304123369,4.519838134$

C, $0.7198586044,2.7889833016,3.3047287808$

C,0.3472173972,4.1193701444,3.0349651961

C,-0.3969023372,4.8971786515,3.9691854629

C,-0.7743594521,4.290350296,5.2248601851

C, $1.4842479175,2.0135830948,2.3284608609$

C, $0.708802805,4.7277016428,1.8129047532$

C, $1.4844547188,3.9682158066,0.8006703772$

C, $0.3375832358,6.030206279,1.5686199401$

C, $-0.3977938944,6.7111363018,2.5561166418$

$\mathrm{H},-0.7062755803,7.7415172632,2.3905250166$

$\mathrm{H},-0.6590781938,2.4894659353,6.3922916196$

$\mathrm{H}, 0.6326426957,1.2041247301,4.7280728988$

$\mathrm{H}, 0.6132132136,6.5047690888,0.6323691015$

$\mathrm{O}, 1.8422565732,0.8594209752,2.5183477783$

$\mathrm{O}, 1.8221101446,4.4709708185,-0.2614798727$

$\mathrm{N},-0.752589748,6.1738164133,3.7079520852$

C, $2.5621104765,1.8908335591,0.1264311369$

$\mathrm{H}, 2.2753215493,0.8445513068,0.249234691$

H, 2.2472704519,2.2452600819,-0.8577534698

C, $4.0687817849,2.0524175323,0.2928950933$

$\mathrm{H}, 4.3257123617,3.1160001587,0.2097092924$

H,4.353025395,1.7227861892,1.3002685923

$\mathrm{N}, 1.8041296106,2.6566398009,1.1172839396$

C,4.8457601191,1.2536347225,-0.7485668699

H,4.5737070442,0.1923907466,-0.6691341293

H,4.5409434334,1.5753331831,-1.7537417439

C,6.3552415398,1.4051310891,-0.6018709985

H,6.6929947015,1.0599301121,0.3818866533

H,6.8916046904,0.8254917128,-1.3600668234

H,6.6584601791,2.4529287116,-0.7072160884

N,-1.4812924227,4.9289025287,6.1892609489

$\mathrm{H},-1.6650943089,4.3694154168,7.006116715$

C,-2.0038243672,6.2796934657,6.2236262056

$\mathrm{H},-2.5114170239,6.4042650295,7.1830734634$

H,-1.2095842286,7.0254308102,6.1401348307

H,-2.7170312303,6.4609952706,5.4159298493

4-min1 (ES), Total Energy= -933.692548568 Hartree

C, $-0.3536369548,2.8151125172,5.5055202614$

C, $0.3700325074,2.1161879934,4.5478595683$ 
C, $0.7112320484,2.7434086048,3.3496660481$ C,0.3293275412,4.0994467452,3.0884440787 C,- $-0.3898617743,4.8166643645,4.0314993851$ C, $-0.7381402658,4.1608354824,5.2618078928$ C, $1.4896002887,1.9906617325,2.3285102742$ C,0.6848521907,4.718685116,1.8649376129 C, $1.4262728902,4.004258712,0.8622799353$ C, $0.2652865868,6.0626679075,1.7042302518$ C,-0.4520453624,6.6833304942,2.7179990373 H, $-0.7721610995,7.7152857375,2.588330722$ H,-0.626684094,2.3373722768,6.4409987967 $\mathrm{H}, 0.6816093137,1.0888564064,4.7026556409$ $\mathrm{H}, 0.5075150332,6.5929817748,0.7901223465$ $\mathrm{O}, 1.8422967283,0.8350138072,2.550816895$ $\mathrm{O}, 1.770917087,4.4802504084,-0.2179137898$ $\mathrm{N},-0.8026722492,6.1129001181,3.886599975$ C, $2.5345341464,1.9148769326,0.145154402$ $\mathrm{H}, 2.2432654483,0.8640281171,0.2176775313$ H,2.2280902589,2.3142755983,-0.8236589547 C,4.0413667331,2.0628623839,0.324303914 $\mathrm{H}, 4.2978999313,3.1287982322,0.2814522622$ H,4.322421227,1.6960271028,1.3199079046 $\mathrm{N}, 1.7754334556,2.644655214,1.1594240838$ C,4.8207339998,1.3014214524,-0.7428218248 $\mathrm{H}, 4.5440495672,0.2387994352,-0.706123505$ $\mathrm{H}, 4.521772542,1.6629551107,-1.736077786$ C,6.3301360959,1.4404173472,-0.5837741766 H,6.6620846322, 1.0571265861,0.3879222344 H,6.8680998523,0.8875190371,-1.3607747895 H,6.6382917492,2.4901067181,-0.6479649055 $\mathrm{N},-1.4334726402,4.9057157352,6.1272724928$ H,-1.6065574959,5.8455060497,5.7611411672 C,-1.9092686397,4.5014204293,7.4229155104 H,-2.4461201202,5.3351627538,7.8752929092 $\mathrm{H},-2.5935138839,3.647899371,7.3462806761$

4-min2 (ES), Total Energy= -933.682656890 Hartree C,-0.3589522521,2.9511013479,5.434584548 C, $0.3660396172,2.2201456952,4.5144771563$ C, $0.7178251023,2.8190103924,3.3073467732$ C,0.3380307856,4.1712347491,3.0202895009 C, $-0.3934382957,4.9341064346,3.9404821376$ C, $-0.7502827603,4.3028189364,5.1783770743$ C, $1.5010156802,2.0301823643,2.3191871151$ C, $0.7130668423,4.7413670553,1.7816251662$ C, $1.4574652776,3.9929965542,0.8037889092$ C, $0.3170267914,6.0846177955,1.5529635753$ C, $-0.4039631181,6.7467914771,2.5341852115$ $\mathrm{H},-0.7102967088,7.77767861,2.3627106997$ 
H,-0.6455180146,2.5005724455,6.3824022533

$\mathrm{H}, 0.6700849488,1.1957954672,4.7001643122$

$\mathrm{H}, 0.5810017914,6.569749607,0.620335275$

$\mathrm{O}, 1.8439833289,0.8793583385,2.5810246777$

$\mathrm{O}, 1.8075011684,4.4428450827,-0.2865835935$

$\mathrm{N},-0.7778798043,6.2310965215,3.716025208$

C,2.556265902,1.88217162,0.1424073015

$\mathrm{H}, 2.2658145964,0.83431462,0.2516106091$

H,2.2463833391,2.2491821816,-0.8382119337

C,4.0636196456,2.0371696403,0.3114220676

H,4.3189411965,3.1013927377,0.2341419028

H,4.3491628318,1.7018653441,1.3169134135

$\mathrm{N}, 1.7994568735,2.644109403,1.1336714458$

C,4.8397473443,1.2438044084,-0.7346334487

$\mathrm{H}, 4.5663636342,0.1821586473,-0.6628007328$

$\mathrm{H}, 4.5350840514,1.57286185,-1.7374045532$

C,6.349532713,1.3920625959,-0.5875649656

H,6.6873466449, 1.0401924696,0.3939529638

H,6.8853177306,0.8168399038,-1.3497000889

H,6.6536998618,2.4402353496,-0.6859682607

$\mathrm{N},-1.4533038735,4.9025323913,6.1590256118$

$\mathrm{H},-1.6220836722,4.3190116157,6.9660436613$

C,-2.0035998509,6.2431884784,6.2414403918

H,-2.505682328,6.3269955692,7.2073903895

$\mathrm{H},-1.2170502046,6.995154747,6.1603567643$

H,-2.7122259162,6.4262007126,5.4321776812

5-min1 (GS), Total Energy= -972.947617589 Hartree, NIMAG= 0

C, $-0.371884224,2.9540658913,5.497080328$

C, $0.369094113,2.2379470926,4.5556880064$

C, $0.7101056807,2.7941028305,3.3369481046$

C, $0.3106766582,4.1202896627,3.0701587138$

C,-0.4359560622,4.8845151688,4.0125077217

C,-0.8174533236,4.2649148923,5.2708591145

C, $1.4763258868,2.0256200307,2.3522546808$

C, $0.6804163506,4.7367959584,1.855811299$

C, $1.4494176632,3.9821793005,0.8331087974$

C, $0.3381650293,6.0506677234,1.6292596659$

C,-0.3690110924,6.7310756133,2.6351985495

$\mathrm{H},-0.6365433224,7.7773609416,2.4999671481$

$\mathrm{H},-0.6374659042,2.4522699362,6.4190923459$

$\mathrm{H}, 0.673532922,1.2162456136,4.7630719166$

H,0.6231610092,6.5340839366,0.7005670426

C,-1.603985995,4.3611534205,7.562418197

$\mathrm{H},-1.9610744001,5.132114903,8.249870968$

$\mathrm{H},-2.3042465303,3.5114472704,7.6132979577$

H,-0.620420382,4.0301942753,7.9055483903

$\mathrm{O}, 1.8486403564,0.8768216554,2.5425643638$

O, $1.7780892963,4.4917168118,-0.2278786608$ 
$\mathrm{N},-0.7421779358,6.1778940234,3.7737413357$

C,2.533087919,1.9108796008,0.1412218801

$\mathrm{H}, 2.2449644912,0.8637877205,0.2546094539$

H,2.2186128763,2.2738489779,-0.8397948925

C,4.0397047333,2.0692395786,0.3103817148

H,4.2981512635,3.1329406623,0.2333442882

H,4.3215165836,1.7336405034,1.3163034903

$\mathrm{N}, 1.7758089533,2.6692827184,1.1388289734$

C,4.8166426444,1.2743156215,-0.7340850509

H,4.5401847904,0.2136474317,-0.6619309829

$\mathrm{H}, 4.5159074826,1.6033083391,-1.7381094865$

C,6.3262123013,1.4187117613,-0.5819403132

H,6.6595563288, 1.0667987826,0.4009126494

H,6.862349318,0.8407361856,-1.3415629548

H,6.634731193,2.4656054362,-0.6807945013

$\mathrm{N},-1.5166621848,4.9400561496,6.2396945224$

C,-2.6361715842,5.8210738508,5.9397640223

H,-3.5857310875,5.2729191731,6.0399406942

$\mathrm{H},-2.6420833706,6.6552427927,6.64881251$

H,-2.5451471355,6.2282683221,4.9380990968

5-min2 (GS), Total Energy= -972.947621928 Hartree, NIMAG= 0

C, $-0.2325327075,2.9673743966,5.585202729$

C, $0.4384533171,2.234967006,4.6077478535$

C, $0.7940261466,2.8035053628,3.3961348065$

C, $0.4388535177,4.1463986646,3.1567067346$

C, $-0.2568561885,4.9228886669,4.1270556761$

C, $-0.5758840157,4.3187859738,5.4083051743$

C, $1.5107450464,2.025152574,2.3849567304$

C, $0.7417254165,4.7502364707,1.9177254967$

C, $1.4834778949,3.9940423285,0.8775671323$

C, $0.3324834496,6.0422914967,1.675024187$

C,-0.3899823702,6.7082189051,2.6800439544

$\mathrm{H},-0.7549223264,7.7191739049,2.5089195086$

$\mathrm{H},-0.4517132386,2.4796314975,6.5271289857$

$\mathrm{H}, 0.7113657658,1.2001785525,4.7931535836$

$\mathrm{H}, 0.5582118573,6.5130498225,0.7237088784$

C, $-1.8241953885,4.2785491709,7.4910643669$

H,-2.5660913536,4.9223570434,7.9693755125

$\mathrm{H},-2.340009524,3.3849908246,7.1293072077$

H,-1.0884628845,3.9784641799, 8.2534656559

$\mathrm{O}, 1.851514277,0.8622902612,2.5503847939$

$\mathrm{O}, 1.7910157145,4.5026847842,-0.1906323399$

$\mathrm{N},-0.6721656079,6.1785832935,3.856125462$

C,2.5317403233,1.9156619943,0.1562484354

$\mathrm{H}, 2.2370442534,0.8709775317,0.2739829665$

H,2.1980612836,2.2844437765,-0.8162831284

C,4.0435540719,2.0600139244,0.2897413524

$\mathrm{H}, 4.310076044,3.1212192496,0.2065950332$ 
$\mathrm{H}, 4.3463198461,1.7219493763,1.2888598411$ $\mathrm{N}, 1.8059497138,2.677834826,1.1736913048$ C,4.7879852455,1.258145663,-0.7727789893 $\mathrm{H}, 4.5088227345,0.1990921894,-0.6894956121$ H,4.4612062544,1.5852965624,-1.7692539938 C,6.3019249385,1.3967315702,-0.6630398094 $\mathrm{H}, 6.6608921109,1.0477646732,0.31183571$ H,6.8147346953,0.8134065104,-1.4346084798 H,6.6113431886,2.4420302277,-0.7749405935 $\mathrm{N},-1.226069803,5.0041046179,6.3918542496$ C,-1.1144550334,6.4402397852,6.6008880771 $\mathrm{H},-1.998777907,6.9766985693,6.2406701193$ $\mathrm{H},-0.9988707885,6.6203316244,7.6757527569$ H,-0.2462969499,6.8438150478,6.0848804295

5-min1 (ES), Total Energy= -972.936878127 Hartree C, $-0.360881409,2.9153911701,5.473041598$ C, $0.3647715499,2.1998549004,4.5288713921$ C, $0.6723381978,2.8052449759,3.3203311082$ C, $0.2739985478,4.148434646,3.0532899854$ C,- $-0.4589607953,4.8926153865,3.9923375749$ C,-0.800537513,4.2402771387,5.231482229 C, $1.4501594651,2.0312108311,2.3114536057$ C, $0.6692342439,4.7521019187,1.8298105884$ C, $1.4250920113,4.0275990625,0.8419233911$ C,0.2914942311,6.0977127209,1.6309736809 C, $-0.4118502288,6.7497547803,2.6319324642$ H, $-0.6884325217,7.794036305,2.4953741918$ H,-0.6460306726,2.4230846955,6.3959660852 $\mathrm{H}, 0.6857268198,1.1789202334,4.7045575345$ $\mathrm{H}, 0.568144826,6.6034265691,0.7129062419$ C,-1.4799521782,4.418406172,7.5825244842 $\mathrm{H},-1.7160360286,5.2669294925,8.2299481533$ $\mathrm{H},-2.2154472924,3.6261007559,7.7905572409$ $\mathrm{H},-0.48062256,4.060221569,7.8315102908$ O,1.7881203794,0.8741012343,2.5468372946 O, 1.7852952272,4.5027249082,-0.2346340845 $\mathrm{N},-0.7927333582,6.208955183,3.799453195$ C,2.5213603894,1.928674212,0.140719755 H,2.2141381409,0.8822385094,0.2117014087 H,2.235733307,2.3309920995,-0.8332179219 C,4.026998387,2.0557455589, 0.3441745608 $\mathrm{H}, 4.2991186807,3.1180586293,0.3065607756$ H,4.2858356478, 1.6840545406, 1.3438410782 $\mathrm{N}, 1.7574675666,2.6708559371,1.1418929132$ C, $4.8131164828,1.2842119512,-0.7106745421$ H,4.5153916067,0.22693665,-0.6846685487 H,4.5418324928, 1.6558800402,-1.7080629855 C,6.3213806372,1.392641147,-0.5194515502 
H,6.6245396501,0.9981382027,0.4570794893

H,6.8646858128,0.8329353027,-1.2878352186

H,6.6515397588,2.436319735,-0.571553492

$\mathrm{N},-1.5419286768,4.8647394834,6.2081938802$

C,-2.6489096387,5.7439580598,5.8912792133

H,-3.5620123439,5.1462950071,5.7417614377

$\mathrm{H},-2.8119392681,6.4312353669,6.7243465365$

H,-2.4121982649,6.2967654788,4.9782960651

5-min2 (ES), Total Energy= -972.936984020 Hartree

C,-0.2262957418,2.9773998661,5.5773450187

C, $0.4698106695,2.2402579791,4.6277621391$

C, $0.8094389454,2.8443196973,3.427104462$

C, $0.4373535029,4.1946323261,3.1574277795$

C,-0.2599231167,4.9626483824,4.1041302015

C,-0.584589136,4.3308749478,5.3586156602

C, $1.5598648739,2.0484778804,2.4143975502$

C,0.7455919345,4.7513598765,1.8876483374

C, $1.4465651078,3.9950369667,0.8834752152$

C, $0.3260629715,6.0790840265,1.6543220939$

C,-0.3746999641,6.7432877227,2.6489558765

$\mathrm{H},-0.7200687327,7.7602181057,2.4693051746$

H,-0.4480379199, 2.5191491224,6.5345390822

$\mathrm{H}, 0.7655260137,1.2117191259,4.8033941529$

$\mathrm{H}, 0.5407132541,6.5509465645,0.7022684053$

C,-1.9716444008,4.2653652741,7.3809061812

$\mathrm{H},-2.7721125108,4.9065308194,7.759123973$

$\mathrm{H},-2.418677819,3.3609220784,6.9673305933$

$\mathrm{H},-1.3278024801,3.9990447058,8.2332260075$

$\mathrm{O}, 1.9153511158,0.9011435889,2.6706774505$

$\mathrm{O}, 1.7500655586,4.4363273322,-0.2245449571$

$\mathrm{N},-0.6916093913,6.2398332486,3.8518726744$

C, $2.5324570605,1.8853233575,0.2006727861$

$\mathrm{H}, 2.2548308627,0.8367953833,0.3333344053$

H,2.1817378584,2.2388225986,-0.7710890543

C,4.0440118899,2.0535340215,0.3091227783

H,4.2882679509,3.1180164386,0.205142675

$\mathrm{H}, 4.3697830915,1.7365315007,1.3082777316$

$\mathrm{N}, 1.8099112982,2.6531142184,1.2130028644$

C, $4.7851650471,1.2482531381,-0.7529772674$

H,4.5257895144,0.1856740469,-0.6503639319

H,4.43651192,1.5554285122,-1.7483409396

C,6.2981589319,1.4139498816,-0.6708323816

$\mathrm{H}, 6.6794491224,1.0854273033,0.3028212696$

H,6.8085789296,0.8286527699,-1.4426812568

H,6.5869331813,2.4628330676,-0.8023921615

$\mathrm{N},-1.2469723331,4.9957136497,6.3643278075$

C, $-0.9957419907,6.3902804569,6.667239058$

H,-1.884496351,6.8234679234,7.1321337817 
$\mathrm{H},-0.1553187628,6.4653635474,7.3752975028$

H,-0.7556989357,6.9178114475,5.7410930204

6 (GS), Total Energy= -1011.00002559 Hartree, NIMAG= 0

C, $-0.2304722177,3.0574928721,5.5205143546$

C, $0.5738800903,2.3409533428,4.6396489454$

C, $0.8227088313,2.7945891668,3.3505730105$

C, $0.2412673323,4.0116031635,2.9402035505$

C, $-0.5851766701,4.7736133419,3.8101451578$

C,- $0.8269097584,4.2745862479,5.1455570126$

C, $1.66894944,2.0314819501,2.4361509201$

C, $0.4662359836,4.5157105783,1.642235121$

C, $1.3240461758,3.7663894465,0.6915124959$

C, $-0.1144778036,5.7086369718,1.2704459208$

C,-0.9171323987,6.3829549657,2.2072951382

$\mathrm{H},-1.3888261983,7.3264697745,1.9401499074$

$\mathrm{H},-0.4025420862,2.6699022525,6.5193621331$

$\mathrm{H}, 1.0250129306,1.4030304617,4.9503432689$

$\mathrm{H}, 0.0544232856,6.1044708157,0.2741731006$

C,-1.9565615675,4.5996015687,7.3839148788

$\mathrm{H},-2.5261211041,3.6639848158,7.4656582278$

H,-1.0962560011,4.5495536283,8.0648895489

$\mathrm{O}, 2.2077183377,0.975212739,2.7380145436$

O,1.5526365776,4.1820992253,-0.4356350132

N,-1.1477731076,5.9395725034,3.4311560994

C,2.6990003211,1.8123804324,0.2192117393

$\mathrm{H}, 2.5782938712,0.756341923,0.4688866283$

$\mathrm{H}, 2.3162447259,1.9986178373,-0.786760598$

C,4.1662104075,2.2159167466,0.3129177576

$\mathrm{H}, 4.2562178642,3.2882862225,0.0982806022$

$\mathrm{H}, 4.5135239672,2.0554801465,1.3413253231$

$\mathrm{N}, 1.852139197,2.5665197288,1.1447119435$

C,5.0381148785,1.4228487808,-0.6549826828

H,4.9323480315,0.3503309762,-0.4426588921

H,4.6707709583,1.5716160868,-1.6795383945

C,6.5092164263,1.8146801458,-0.5799474241

H,6.9116079476,1.6467839705,0.4254817786

H,7.1153409677,1.2333473681,-1.2823108464

H,6.6476564978,2.8751952068,-0.8189654958

$\mathrm{N},-1.5981409559,4.9440820542,6.0173327433$

C, $-2.3650463811,6.1888174702,5.9964040106$

H,-3.1673601796,6.1949890831,5.252689691

H,-1.748288092,7.0792918352,5.8433065916

C,-2.791068569,5.8982504513,7.454294472

H,-3.8617415556,5.7407421604,7.5939050632

$\mathrm{H},-2.4350583801,6.624855131,8.1863861867$

6 (ES) Total Energy= -1010.99081040 Hartree C,-0.2133238078,3.0511183508,5.5029139091 
C, $0.5905352818,2.3325694018,4.6324079463$

C, $0.8086389565,2.8223128093,3.348787394$

C, $0.2142760235,4.0551326808,2.9222031334$

C,- $-0.5976696871,4.7997362117,3.7816232526$

C, $-0.8140146609,4.2808275387,5.1029487929$

C,1.6759140614,2.0486172621,2.4207248429

C, $0.4571665493,4.5233909671,1.6092459763$

C, $1.2856490588,3.7873229176,0.6917768333$

C, $-0.1567991481,5.7500751572,1.2514209947$

C,-0.9448397457,6.4061154923,2.1858120095

H,-1.4174614276,7.3482162518,1.9113945219

H,-0.3921963989,2.6790773369,6.5067828465

H,1.0571207461,1.3970794666,4.9215932072

H,-0.0041289707,6.1564796265,0.2581720875

C, $-1.9251196832,4.5789132914,7.3690600678$

H,-2.4883853045,3.6405281762,7.4475856589

H, $-1.0534721426,4.5272747083,8.0336299191$

O,2.2017255122,1.00203407,2.7933825459

$\mathrm{O}, 1.5338801811,4.1505897719,-0.4575847984$

N,-1.1940401602,5.9854473049,3.4366298934

C,2.6924882027,1.8088412424,0.234213298

$\mathrm{H}, 2.565329378,0.7479131436,0.463860325$

H, 2.3174228094,2.0147692976,-0.7702872272

C,4.1615517788,2.2034350522,0.3402045893

$\mathrm{H}, 4.2524902975,3.2785792047,0.1409141856$

$\mathrm{H}, 4.5065092828,2.0284517176,1.3673887834$

$\mathrm{N}, 1.8446502183,2.5560570725,1.1604687456$

C, $5.0348342293,1.4221247699,-0.6357031737$

H,4.9216141956,0.3462857629,-0.4436822312

$\mathrm{H}, 4.6743285796,1.5913976958,-1.6594385336$

C,6.5078429155,1.8032441422,-0.5451086868

H,6.9031967863,1.6148879594,0.459631829

H,7.1150678974,1.2312464536,-1.2543425144

H,6.6538955718,2.8671486324,-0.763758727

N,-1.5782578508,4.9259607204,5.9940452058

C,-2.349768519,6.1740235057,5.998604385

$\mathrm{H},-3.1472688161,6.1807338071,5.2523311713$

H,-1.7266376593,7.0560302739,5.834438627

C,-2.760543848,5.8730329249,7.4564606363

$\mathrm{H},-3.8288482053,5.7101240754,7.6049300849$

H,-2.3987404577,6.5941373417,8.1905967128

\section{Rotational barriers (Ground State, vacuo)}

In all compounds, two transition states (TS) structures were identified for the rotation of the amino group around the $\mathrm{C}_{9}-\mathrm{N}$ bond (Tables S6-S8). In each case, the energy of the lower transition state was considered as its rotational barrier. The enthalpy of this barrier calculated for the azetidinyl derivative 6 was $48.5 \mathrm{~kJ}^{\mathrm{mol}}{ }^{-1}$, which is in good agreement with that obtained by dynamic NMR $\left(46.56 \mathrm{~kJ} \cdot \mathrm{mol}^{-1}\right)$. 
The difference between the TS geometries is the orientation of the substituents at the amino nitrogen atom. In TS1, those substituents are pointing towards the nitrogen of the quinolimide ring, while in TS2 they are pointing in the opposite direction. In all cases the barrier of TS1 is smaller to that of TS2. In the case of the methylamino derivative 4, two minima have been found, one with the methyl group pointing towards the nitrogen of the quinolimide, and the other with the methyl group pointing in the opposite direction. The latter structure was the most stable one, by $29 \mathrm{~kJ} / \mathrm{mol}$.

Table S6. Erel $(\mathrm{kJ} / \mathrm{mol})$ of the different stationary points in the conformational study

\begin{tabular}{|lccccc|}
\hline & $\mathbf{2}$ & $\mathbf{3}$ & $\mathbf{4}$ & $\mathbf{5}$ & $\mathbf{6}$ \\
\hline Min-1 & 0.0 & 0.0 & 0.0 & 0.0 & 0.0 \\
Min-2 & - & 28.4 & 28.8 & 0.0 & - \\
TS-1 & 48.3 & 67.8 & 66.6 & 26.4 & 51.7 \\
TS-2 & 70.5 & 79.4 & 79.7 & 37.3 & 63.4 \\
\hline
\end{tabular}

Table S7. $\Delta \mathrm{H}(\mathrm{kJ} / \mathrm{mol})$ at room temperature

\begin{tabular}{|lccccc|}
\hline & $\mathbf{2}$ & $\mathbf{3}$ & $\mathbf{4}$ & $\mathbf{5}$ & $\mathbf{6}$ \\
\hline Min-1 & 0.0 & 0.0 & 0.0 & 0.0 & 0.0 \\
Min-2 & - & 27.9 & 29.0 & 0.2 & - \\
TS-1 & 48.3 & 63.3 & 62.7 & 22.5 & 48.5 \\
TS-2 & 70.5 & 74.7 & 75.4 & 32.7 & 59.4 \\
\hline
\end{tabular}

Table S8. $\Delta \mathrm{G}(\mathrm{kJ} / \mathrm{mol})$ at room temperature

\begin{tabular}{|lccccc|}
\hline & $\mathbf{2}$ & $\mathbf{3}$ & $\mathbf{4}$ & $\mathbf{5}$ & $\mathbf{3}$ \\
\hline Min-1 & 0.0 & 0.0 & 0.0 & 0.3 & 0.0 \\
Min-2 & - & 26.7 & 30.0 & 0.0 & 26.7 \\
TS-1 & 50.0 & 67.1 & 68.1 & 30.1 & 67.1 \\
TS-2 & 70.8 & 79.7 & 80.4 & 39.4 & 79.7 \\
\hline
\end{tabular}

A small shortening of the $\mathrm{C}_{9}-\mathrm{N}$ bond length, was observed in the excited state of quinolimides $\mathbf{2 - 4}$ and $\mathbf{6}$, while in the dimethylamino derivative $\mathbf{5}$ the excitation produces a small elongation. No other significant changes in the geometry of the excited states with respect to that of the ground states were found in the calculations.

\section{Dipole Moments}

Dipole moments of the ground and excited states of quinolimides 2-6 were calculated (Table S9). The excitation of these systems produces a significant increment of the dipolar moment magnitude and a change of its direction as illustrated for the parent compound $\mathbf{2}$ (Figure S12). The calculations showed that the dipole 
moments both of the ground and excited states of the 9-azetidinyl-quinolimide 6 were the highest of the series. The increase in the dipole moment upon excitation is in agreement with a further stabilization of the excited sate in polar solvents, and hence, of the red-shifts exhibited in $\lambda_{\max }{ }^{\text {abs }}$ and $\lambda_{\max }{ }^{\mathrm{em}}$ with increasing solvent polarity.

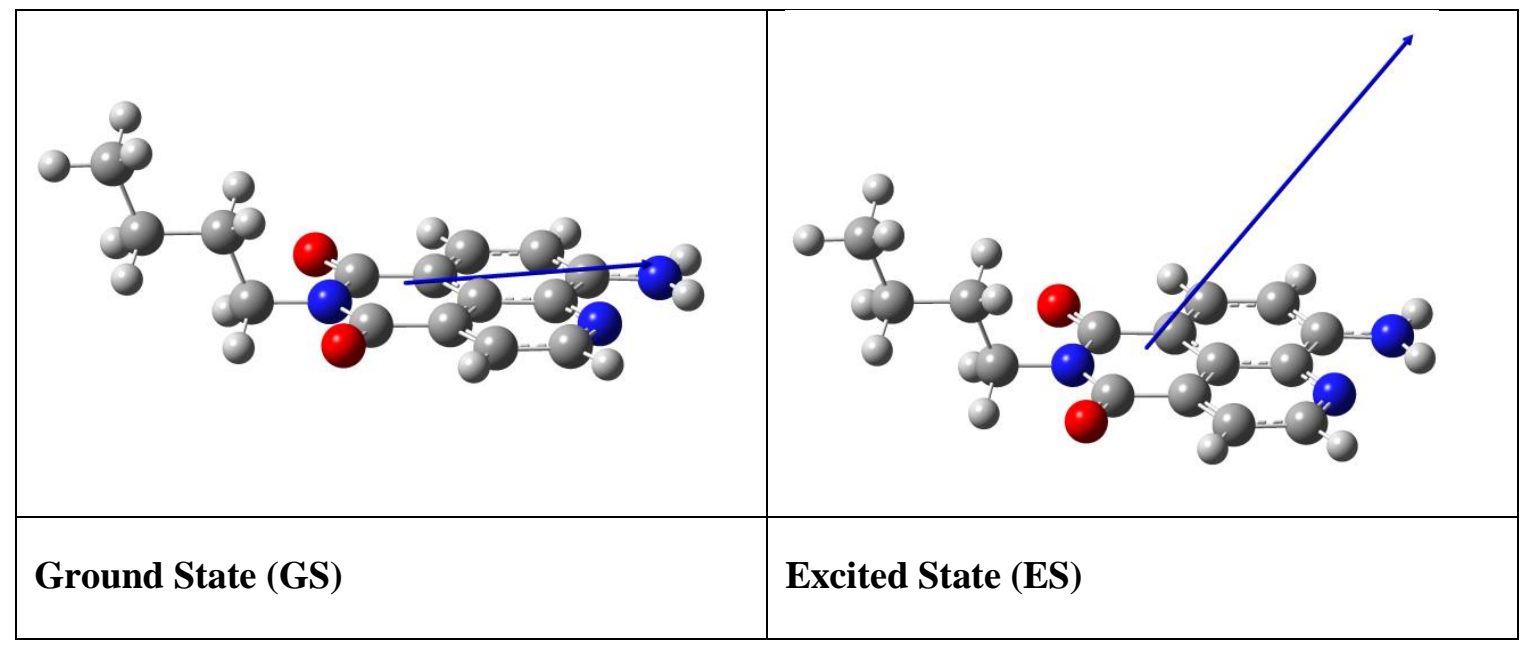

Figure S12. Dipole moment (indicated with an arrow) of the 9-amino-quinolimide $\mathbf{2}$ in the ground and excited states. The length of the arrow is proportional to the total magnitude of the dipole moment.

Table S9. Calculated dipole moments (debye) of quinolimides 2-6 in the ground and excited states

\begin{tabular}{|lcccccc|}
\hline & $\mathbf{2}$ & $\mathbf{3}$ & $\mathbf{4}(\min 1)$ & $\mathbf{4}(\min 2)$ & $\mathbf{5}$ & $\mathbf{6}$ \\
\hline GS & 4.7 & 5.9 & 5.3 & 5.6 & 4.8 & 6.5 \\
ES & 8.2 & 10.2 & 9.3 & 9.2 & 9.6 & 10.5 \\
\hline
\end{tabular}

The UV absorption and fluorescence emission spectra of quinolimides 2 and 4-6 were calculated in vacuum and with explicit solvent in equilibrium and in non-equilibrium models (Tables S10-S13). A better approximation to the experimental values of $\lambda_{\max }{ }^{\text {abs }}$ in non-polar solvents (cyclohexane and toluene) was obtained in the calculations with the model of explicit solvent in non-equilibrium, while in polar solvents ( $\mathrm{MeOH}$ and DMSO) a better approximation was obtained with explicit solvents in equilibrium. Respect the emission spectra, in general, a better approximation to the experimental values of $\lambda_{\max }{ }^{\mathrm{em}}$ was obtained in the calculations in vacuum or with non-equilibrium explicit solvent.

Table S10. Calculated absorption and emission maxima (nm) for the quinolimide 2

\begin{tabular}{|l|c|c|c|c|}
\hline Solvent & $\begin{array}{c}\text { Absorption non- } \\
\text { equilibrium }\end{array}$ & $\begin{array}{c}\text { Absorption } \\
\text { st_spec_solv. }\end{array}$ & $\begin{array}{c}\text { Emisión non- } \\
\text { equilibrium }\end{array}$ & $\begin{array}{c}\text { Emission } \\
\text { st_spec_solv }\end{array}$ \\
\hline Gas & 418 & & 522 & 560 \\
\hline n-Hexane & 429 & 448 & 529 & 564 \\
\hline Cyclohexane & 430 & 452 & 530 & 574 \\
\hline Toluene & 432 & 457 & 543 & 646 \\
\hline Dichloromethane & 437 & 465 & 546 & 669 \\
\hline Acetone & 438 & 465 & 531 & 571 \\
\hline 1,4-Dioxane & 431 & 453 & 547 & 677 \\
\hline Methanol & 438 & 465 & &
\end{tabular}




\begin{tabular}{|l|l|l|l|l|}
\hline DMSO & 440 & 469 & 548 & 677 \\
\hline $\mathrm{H}_{2} \mathrm{O}$ & 439 & 466 & 548 & 683 \\
\hline
\end{tabular}

Table S11. Calculated absorption and emission maxima (nm) for the quinolimide 4

\begin{tabular}{|l|c|c|c|c|}
\hline \multicolumn{1}{|c|}{ Solvent } & $\begin{array}{c}\text { Absorption non- } \\
\text { equilibrium }\end{array}$ & $\begin{array}{c}\text { Absorption } \\
\text { st_spec_solv. }\end{array}$ & $\begin{array}{c}\text { Emisión non- } \\
\text { equilibrium }\end{array}$ & $\begin{array}{c}\text { Emission } \\
\text { st_spec_solv }\end{array}$ \\
\hline Gas & 431 & & 537 & 579 \\
\hline n-Hexane & 443 & 464 & 545 & 583 \\
\hline Cyclohexane & 444 & 468 & 545 & 593 \\
\hline Toluene & 446 & 474 & 547 & 664 \\
\hline Dichloromethane & 452 & 482 & 557 & 685 \\
\hline Acetone & 452 & 482 & 560 & 590 \\
\hline $1,4-D i o x a n e$ & 445 & 469 & 546 & 692 \\
\hline Methanol & 452 & 481 & 561 & 692 \\
\hline DMSO & 454 & 486 & 562 & 698 \\
\hline $\mathrm{H}_{2} \mathrm{O}$ & 453 & 482 & 562 & \\
\hline
\end{tabular}

Table S12. Calculated absorption and emission maxima $(\mathrm{nm})$ for the quinolimide 5

\begin{tabular}{|l|c|c|c|c|}
\hline Solvent & $\begin{array}{c}\text { Absorption non- } \\
\text { equilibrium }\end{array}$ & $\begin{array}{c}\text { Absorption } \\
\text { st_spec_solv. }\end{array}$ & $\begin{array}{c}\text { Emisión non- } \\
\text { equilibrium }\end{array}$ & $\begin{array}{c}\text { Emission } \\
\text { st_spec_solv }\end{array}$ \\
\hline Gas & 434 & & 537 & \\
\hline n-Hexane & 449 & 469 & 545 & 580 \\
\hline Cyclohexane & 450 & 472 & 545 & 584 \\
\hline Toluene & 453 & 478 & 547 & 594 \\
\hline Dichloromethane & 459 & 489 & 558 & 660 \\
\hline Acetone & 460 & 490 & 563 & 682 \\
\hline Methanol & 460 & 489 & 564 & 690 \\
\hline DMSO & 462 & 494 & 565 & 690 \\
\hline $\mathrm{H}_{2} \mathrm{O}$ & 461 & 490 & 565 & 696 \\
\hline
\end{tabular}

Table S13. Calculated absorption and emission maxima $(\mathrm{nm})$ for the quinolimide 6

\begin{tabular}{|l|c|c|c|c|}
\hline Solvent & $\begin{array}{c}\text { Absorption non- } \\
\text { equilibrium }\end{array}$ & $\begin{array}{c}\text { Absorption } \\
\text { st_spec_solv. }\end{array}$ & $\begin{array}{c}\text { Emisión non- } \\
\text { equilibrium }\end{array}$ & $\begin{array}{c}\text { Emission } \\
\text { st_spec_solv }\end{array}$ \\
\hline Gas & 441 & & 532 & \\
\hline n-Hexane & 455 & 473 & 543 & 573 \\
\hline Cyclohexane & 456 & 477 & 544 & 577 \\
\hline Toluene & 459 & 483 & 547 & 587 \\
\hline Dichloromethane & 465 & 493 & 561 & 654 \\
\hline Acetone & 465 & 493 & 565 & 674 \\
\hline 1,4-Dioxane & 457 & 478 & 546 & 583 \\
\hline Methanol & 465 & 493 & 567 & 681 \\
\hline
\end{tabular}




\begin{tabular}{|l|l|l|l|l|}
\hline DMSO & 467 & 497 & 567 & 682 \\
\hline $\mathrm{H}_{2} \mathrm{O}$ & 466 & 494 & 568 & 687 \\
\hline
\end{tabular}

The calculated absorption bands correlated linearly with the experimental data, especially for the less polar solvents. The comparison of the calculated and experimental absorption data of $\mathbf{2}$ and 4-6 in toluene is shown below (Figure S13).
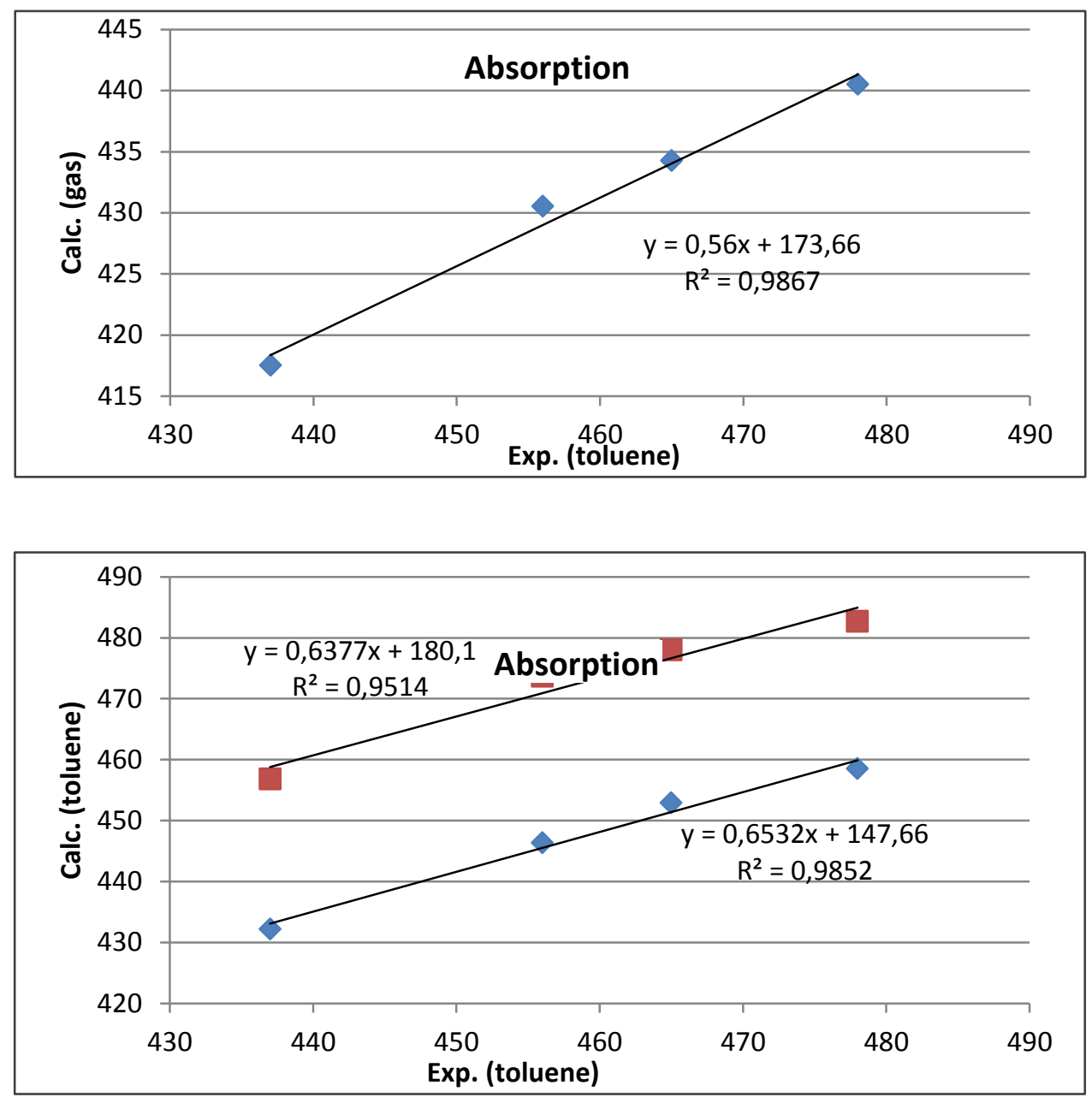

Figure S13. Squares and rhombus indicate the solvent equilibrium and non-equilibrium results, respectively.

\section{FLUORESCENCE AND TEM EXPERIMENTS}

\section{a. Studies of $\beta$-amyloid peptide aggregation}

The A $\beta$ peptide (Amyloid $\beta$ protein fragment 1-42, Sigma-Aldrich) was incubated at a total concentration of $100 \mu \mathrm{M}$, in SSPE buffer $\left(150 \mathrm{mM} \mathrm{NaCl}, 10 \mathrm{mM} \mathrm{Na}_{2} \mathrm{H}_{2} \mathrm{PO}_{4} \times \mathrm{H}_{2} \mathrm{O}, 10 \mathrm{mM} \mathrm{Na} 2\right.$ EDTA, pH 7.4; SigmaAldrich) at $37{ }^{\circ} \mathrm{C}$, with continuous shaking. The lyophilized peptide was dissolved at $\mathrm{pH} 12$ before use, and filtered to remove pre-formed aggregates. Under these conditions, long, straight amyloid fibrils were detected after $20 \mathrm{~h}$ of incubation (Figure S18). The quinolimide 6 was added at a total concentration of 2 $\mu$ M. Steady-state emission spectra $\left(\lambda_{\mathrm{ex}}=490 \mathrm{~nm}\right)$ were collected on a Jasco FP8300 spectrofluorometer. Time-resolved fluorescence decays were obtained on a PicoQuant FT200 fluorescence lifetime spectrometer based on single photon timing (SPT) using a 485-nm pulsed diode laser as excitation source (PicoQuant 
LDH-485) working at $20 \mathrm{MHz}$. Therefore, the corresponding fluorescence lifetimes at different incubation times upon interaction of the probe with $\beta$-amyloid peptide were obtained.

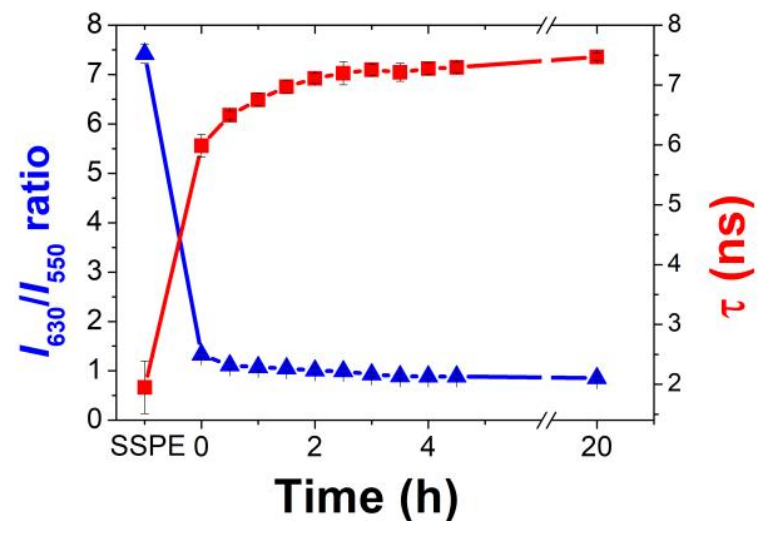

Figure S14. $I_{630} / I_{550}$ ratio (in blue) and the corresponding fluorescence lifetime (in red) of $6(2 \mu \mathrm{M})$ added to incubating $\mathrm{A} \beta(100 \mu \mathrm{M})$ at different incubation times. The graphics include the data of the dye in the SSPE aggregation buffer $(\mathrm{pH}$ 7.4) before the addition to $A \beta$.

\section{b. Dual-color FLIM and ratio studies}

Dual-color FLIM was performed on a MicroTime 200 system (Fig. S15, PicoQuant GmbH, Berlin, Germany) based on an inverted microscope (Olympus IX-71, Japan). The excitation source consisted of a laser diode head $(\mathrm{LDH})$ pulsed laser at $\lambda_{\mathrm{ex}}=470 \mathrm{~nm}$ (PicoQuant), operated at a repetition rate of $20 \mathrm{MHz}$. The light beam was focused on the specimen through a x100, 1.4NA oil immersion objective. The fluorescence was collected back through the same objective and focused on a $75-\mu \mathrm{m}$ pinhole after passing a 500 DCXR dichoric mirror and a 500LP long-pass filter (Chroma). The fluorescence light was then separated into two detection channels by a 600DCXR dichroic mirror, and focused on two avalanche single photon detectors (Perkin Elmer). A 550/40 bandpass filter (Thorlabs) was employed in the green channel, to define $I_{550}$; whereas a 630/60 bandpass filter (Chroma) was used in the red channel to collect $I_{630}$. Imaging reconstruction, photon counting, and data acquisition were realized with a TimeHarp 200 TCSPC module (PicoQuant, Berlin, Germany). Raw images were obtained at a $512 \times 512$-pixel resolution over an area of 10 $\times 10 \mu \mathrm{m}^{2}$. Image analysis was carried out in SymPhoTime 32 (PicoQuant) by fitting the fluorescence decay traces obtained in the individual pixels to a single exponential decay function after a $5 \times 5$ spatial binning, using the maximum likelihood estimator (MLE) for parameter optimization, which yields the correct parameter sets for low count rates. A previous prehistogramming of 8 temporal channels (for a final resolution of $232 \mathrm{ps} / \mathrm{channel}$ ) was also used to achieve a larger number of counts in each pixel. Selection of pixels corresponding to aggregates was performed using home-coded scripts in FiJi (distribution of ImageJ. Schindelin, J.; Arganda-Carreras, I.; Frise, E.; Kaynig, V.; Longair, M.; Pietzsch, T.; Preibisch, S.; Rueden, C.; Saalfeld, S.; Schmid, B.; Tinevez, J.-Y.; White, D. J.; Hartenstein, V.; Eliceiri, K.; Tomancak, P.; Cardona, A. Fiji: an open-source platform for biological-image analysis. Nat. Methods 2012, 9, 676). 
Channel 1 Channel 2
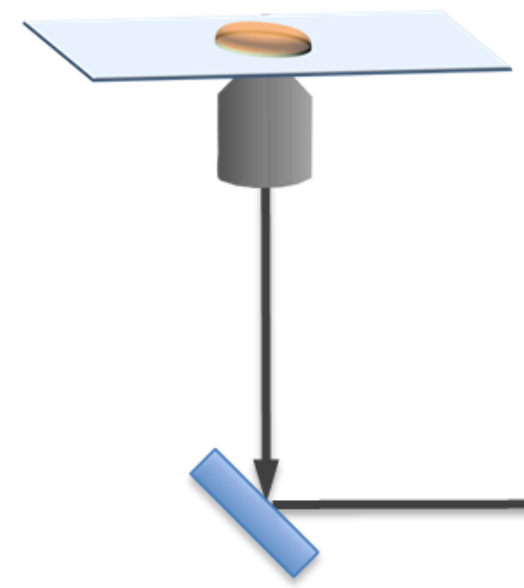

510DCXR

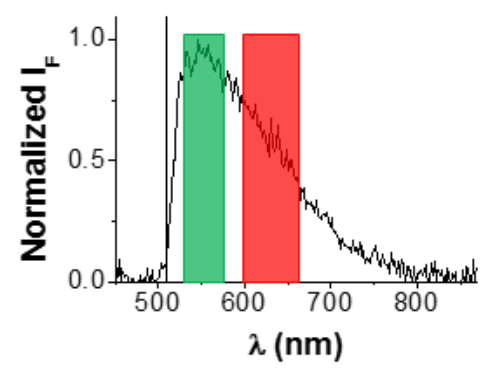

$I_{\text {Green }}$

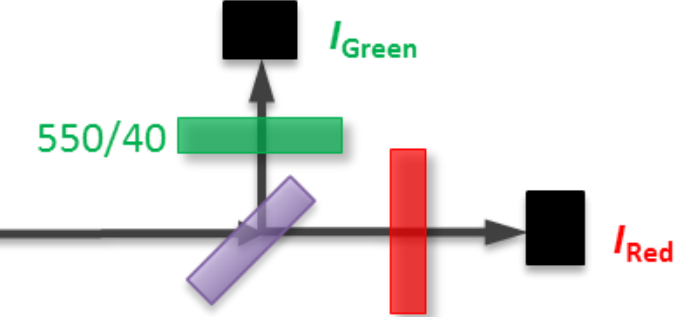

600DCXR $630 / 60$
FLIM
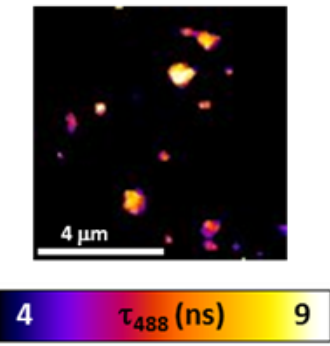

Ratio

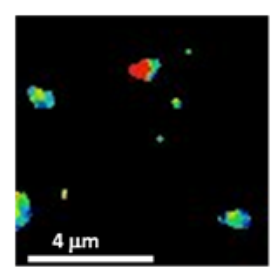

$\begin{array}{lll}0.9 & I_{630} / I_{550} & 1.7\end{array}$

Figure S15. Schematic representation of the instrumentation for fluorescence lifetime imaging (FLIM) and ratio imaging from two different detection channels (green at 550/40 and red at 630/60). 

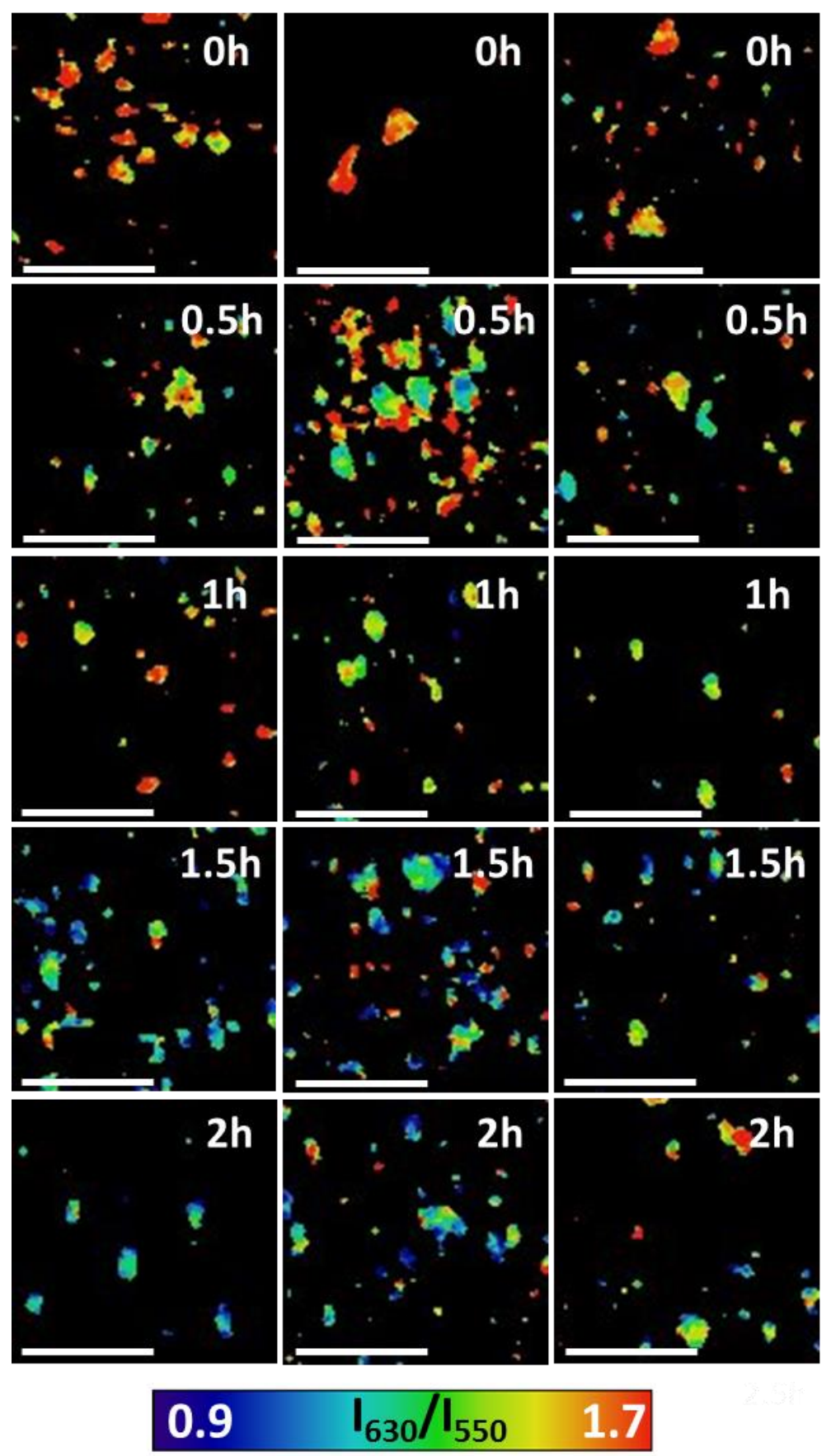

Figure S16. Examples of $\mathrm{I}_{630} / \mathrm{I}_{550}$ ratio images of $\beta$-amyloid aggregates after different incubation times. Scale bars represent $4 \mu \mathrm{m}$. 


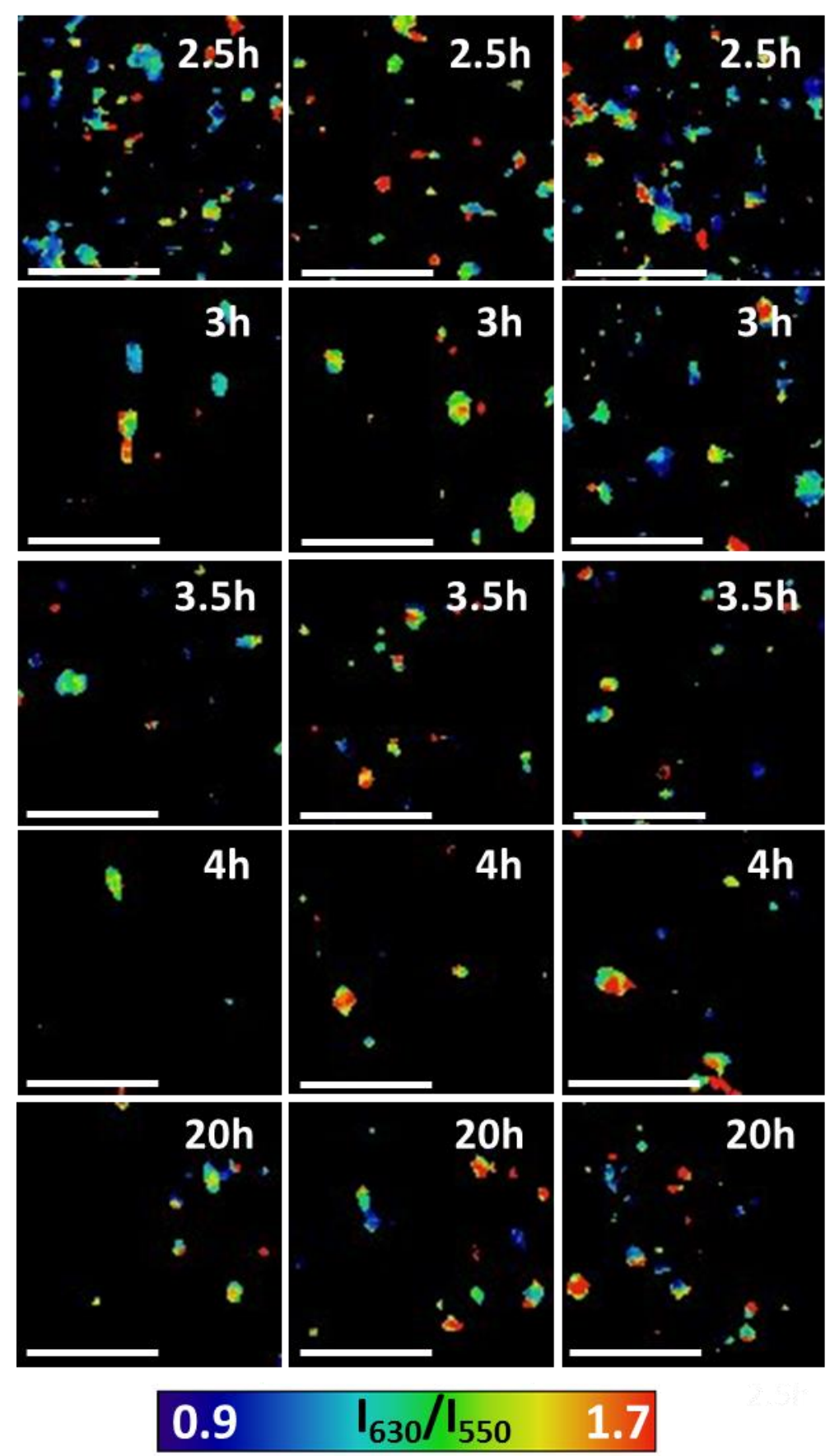

Figure S17. Examples of $\mathrm{I}_{630} / \mathrm{I}_{550}$ ratio images of $\beta$-amyloid aggregates after different incubation times. Scale bars represent $4 \mu \mathrm{m}$. 


\section{c. Transmission electron microscopy (TEM)}

Transmission electron microscopy (TEM) images, to examine the aggregation stages of $\beta$-amyloid peptide aggregates, were performed using a Libra 120 Plus transmission electron microscope (Carl Zeiss SMT, Germany) operated at $120 \mathrm{kV}$ and equipped with a LaB6 filament and an SSCCD $2 \mathrm{k} \times 2 \mathrm{k}$ direct coupling camera). TEM images of the incubated samples were collected at various incubation times by removing aliquots deposited on Formvar 300-mesh copper grids, which were washed twice with Milli-Q water and stained using $1 \%(\mathrm{w} / \mathrm{v})$ uranyl acetate.
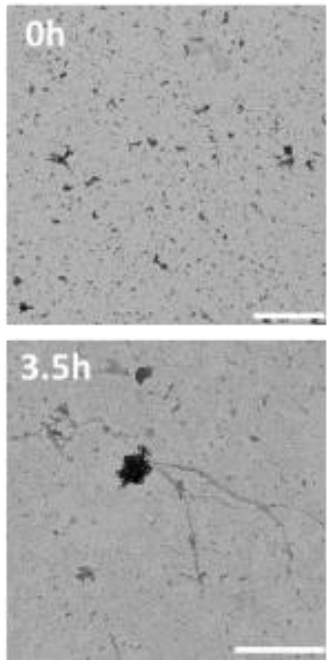
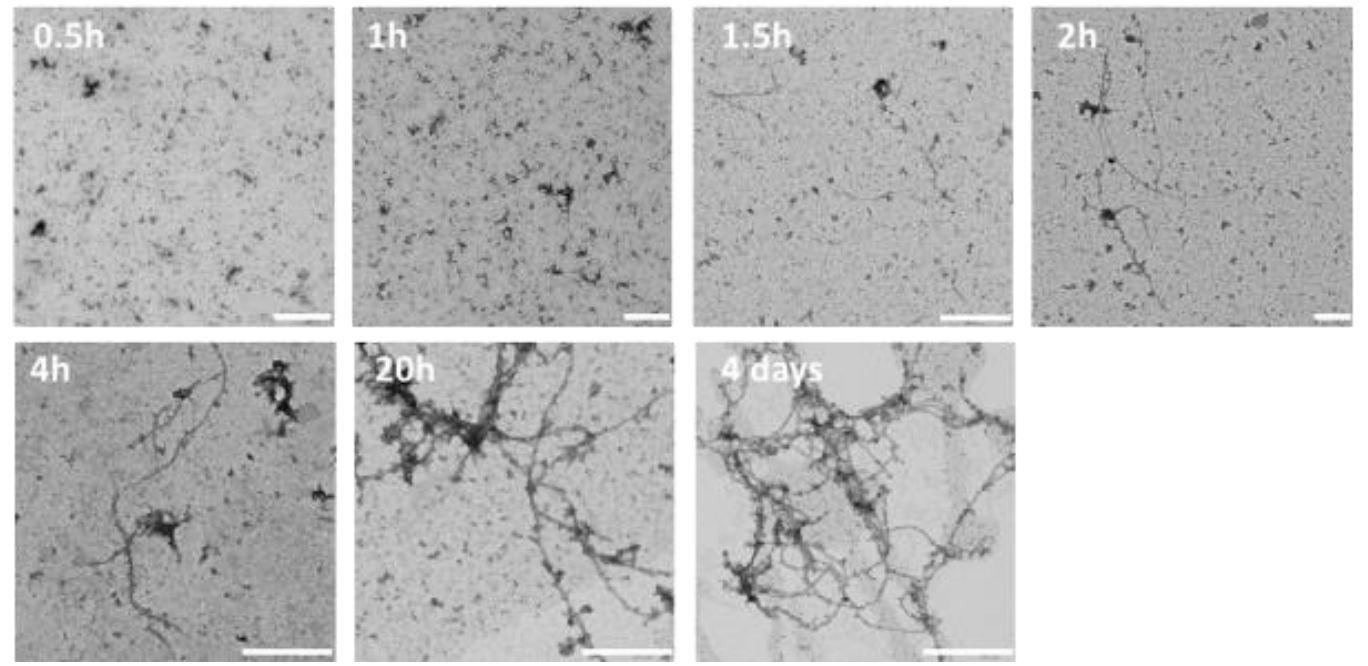

Fig. S18. TEM images of $\beta$-amyloid fibers at different incubation times. Scale bars in TEM images represent $500 \mathrm{~nm}$. 
A.
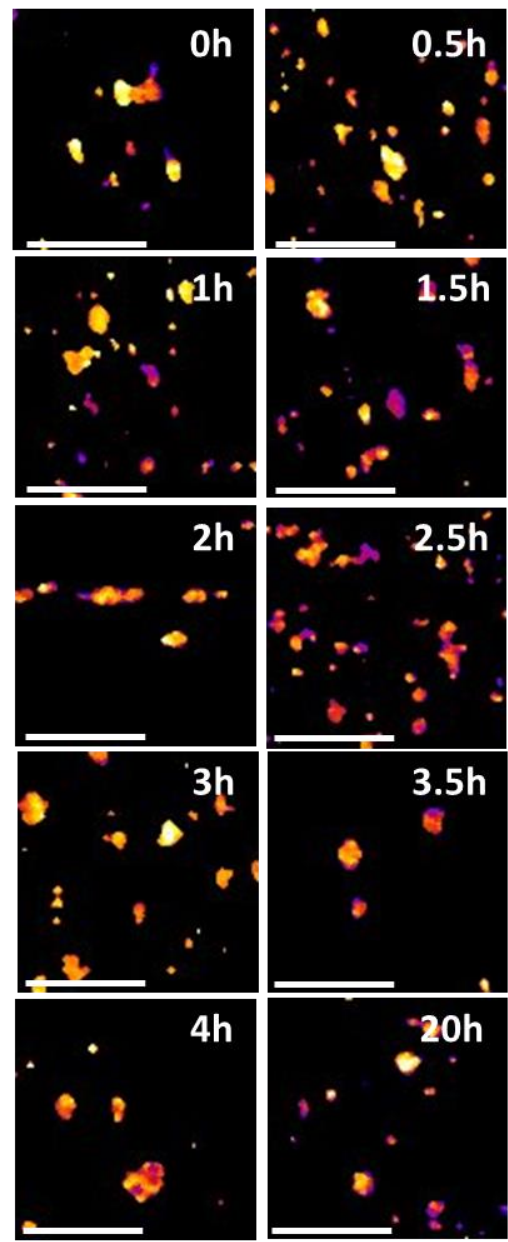

4

$\tau_{488}$ (ns)

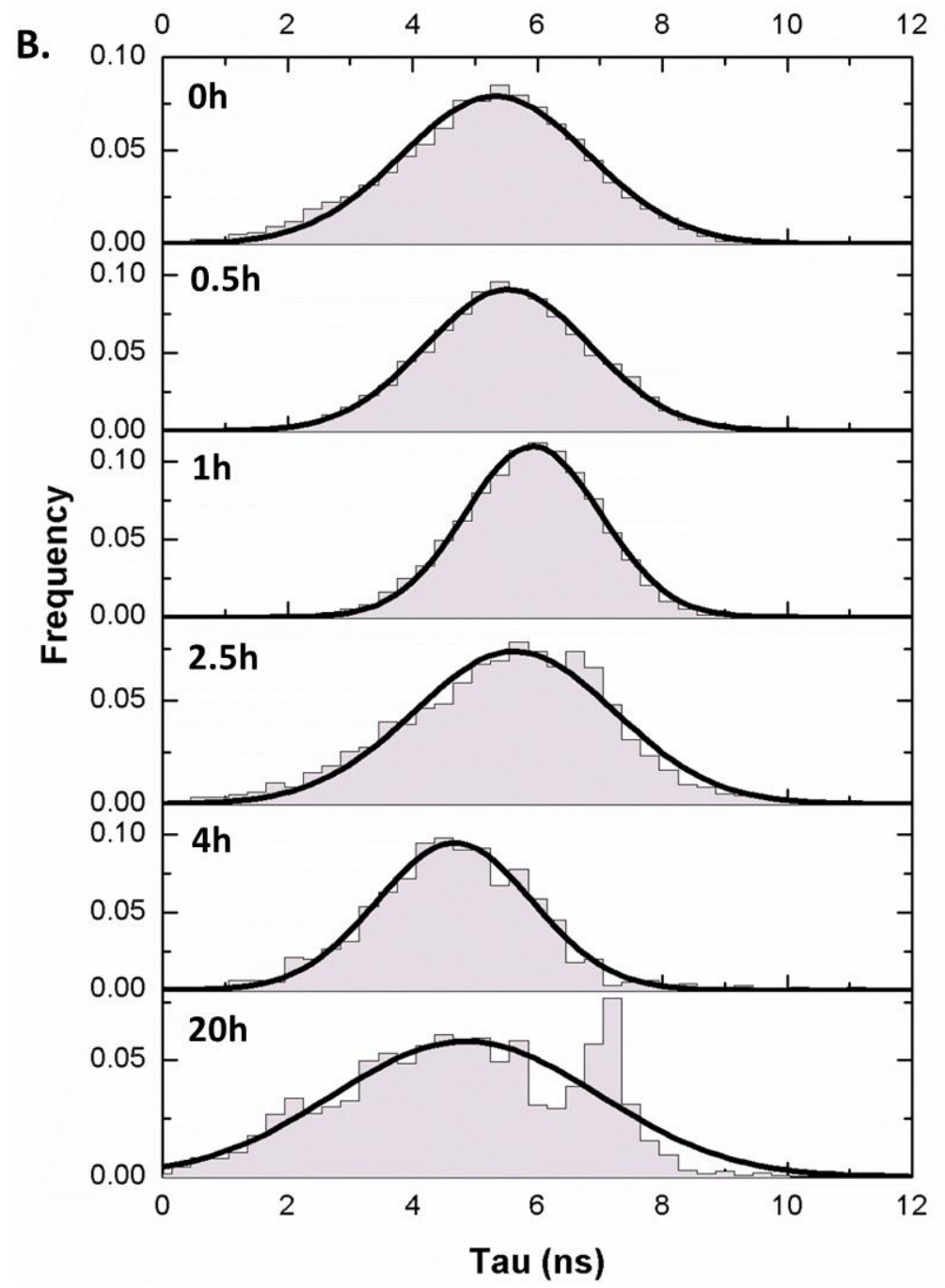

Figure S19. (A) Representative FLIM images of $\beta$-amyloid aggregates after different incubation times. (B) Frequency histograms of $\tau(\mathrm{ns})$ values in $\beta$-amyloid aggregates, averaged for at least 10 different images. Scale bars represent $4 \mu \mathrm{m}$. 


\section{d. Dual-color two-photon microscopy ratio studies}

Confocal microscopy was carried out in a Leica TCS-SP5 II (Leica, Germany) multiphoton confocal microscope with excitation at $850 \mathrm{~nm}$ (fs-pulsed Mai Tai HP Deep See) and selective detection at two different colors using a first channel with an emission band from 510 to $570 \mathrm{~nm}$ (green chanel) and a second detection channel collecting fluorescence emission from 610 to $700 \mathrm{~nm}$ (red chanel). Selection of pixels corresponding to aggregates was performed using home-coded scripts in FiJi (distribution of ImageJ. Schindelin, J.; Arganda-Carreras, I.; Frise, E.; Kaynig, V.; Longair, M.; Pietzsch, T.; Preibisch, S.; Rueden, C.; Saalfeld, S.; Schmid, B.; Tinevez, J.-Y.; White, D. J.; Hartenstein, V.; Eliceiri, K.; Tomancak, P.; Cardona, A. Fiji: an open-source platform for biological-image analysis. Nat. Methods 2012, 9, 676).

A.
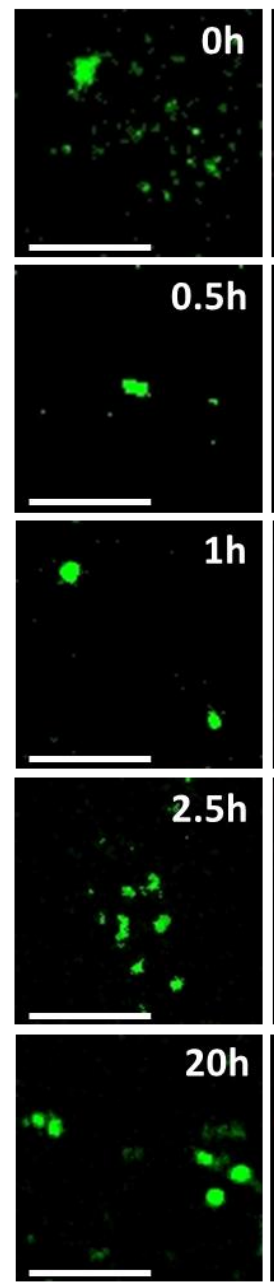

$I_{540 / 60}$
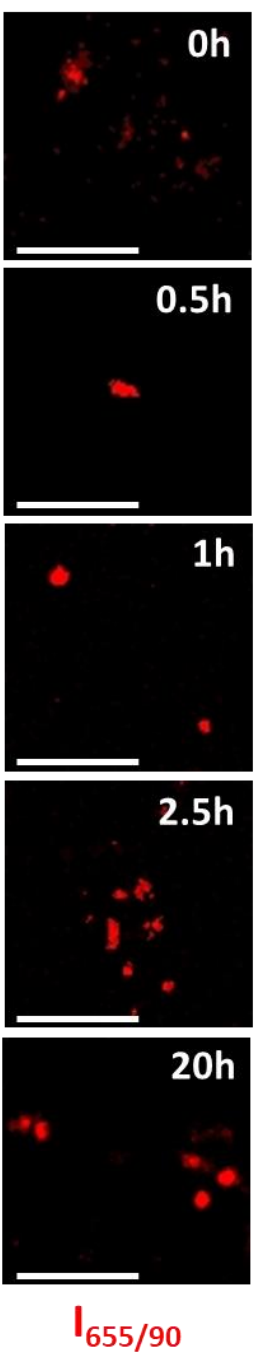

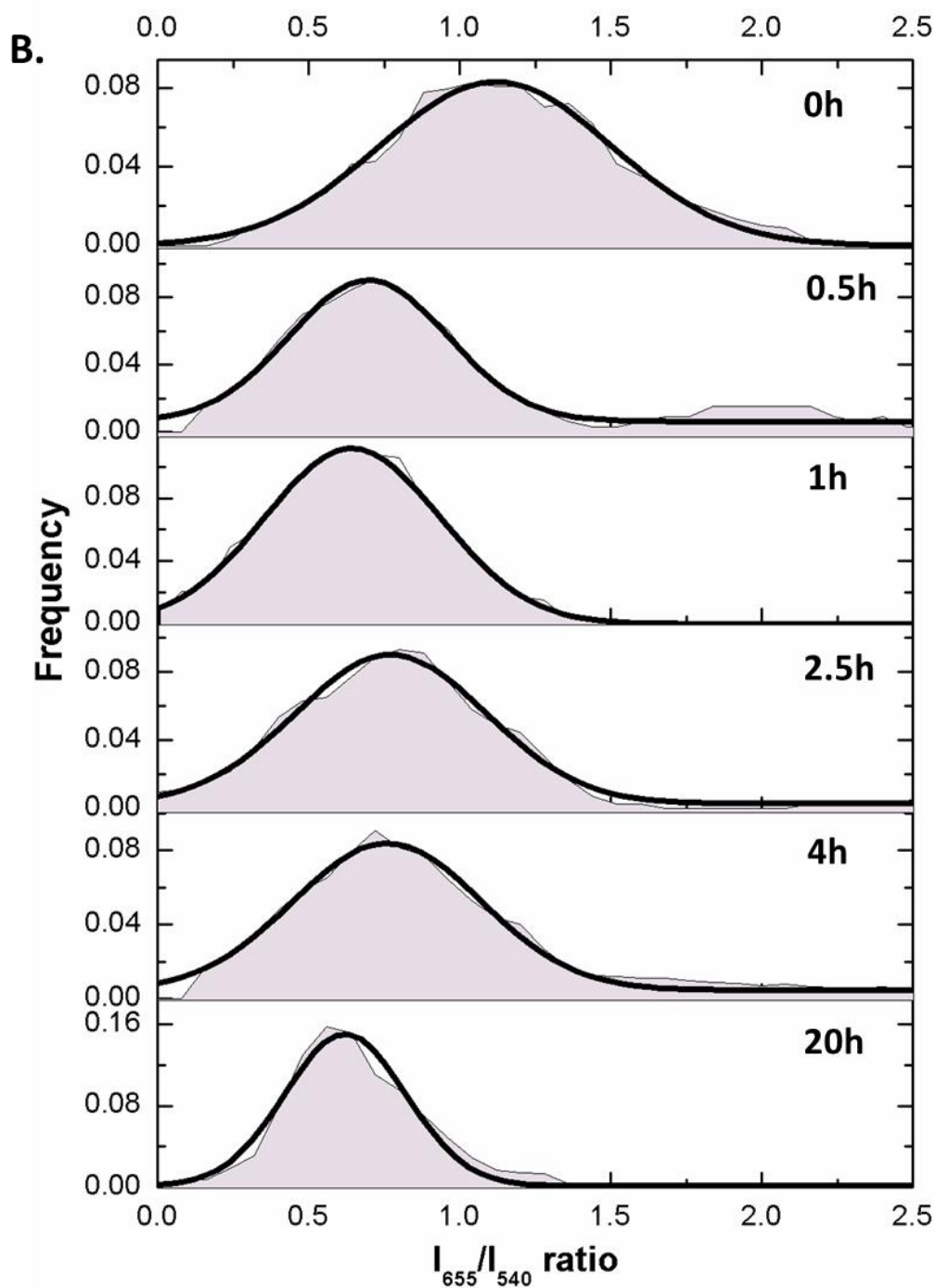

Figure S20. (A) Representative two-photon microscopy images of $\beta$-amyloid aggregates after different incubation times. (B) Frequency histograms of $I_{655} / I_{540}$ ratio values of $\mathrm{A} \beta$ aggregates upon two-photon excitation $\left(\lambda_{\mathrm{ex}}=850 \mathrm{~nm}\right)$, averaged for at least 10 different images. Scale bars represent $8 \mu \mathrm{m}$. 


\section{e. Imaging of amyloid aggregates in zebrafish}

Fish maintenance. AB-strain adult zebrafish (Danio rerio) were provided by ZFBiolabs S.L (Madrid, Spain) and were kept at the University of Granada's facility at a water temperature of $28.5 \pm 1^{\circ} \mathrm{C}$ under a photoperiod of $14: 10 \mathrm{~h}$ (lights on at 08:00 h) in a recirculation aquaculture system (Aquaneering Incorporated, Barcelona, Spain). Fish feeding, breeding, and maintenance were performed according to the published protocols. ${ }^{8}$ Adult zebrafish were used as breeding stocks and embryos obtained were cultured in E3 medium.

All experiments were performed according to a protocol approved by Ethical's Committee of the University of Granada.

PTU and MPTP treatments. Embryos were treated with Phenylthiourea $0.2 \mathrm{mM}$ (PTU, Sigma-Aldrich, Madrid, Spain) to inhibit melanization; the treatment begun just before 24 hours postfertilization (hpf) and it was maintained until the completion of the experiments, i.e., $72 \mathrm{hpf}$. The embryos were dechorionated manually at $24 \mathrm{hpf}$ and were distributed randomly, six embryos per well, in a 24-well plate in a total volume of $1 \mathrm{~mL}$ of treated and untreated E3 medium. MPTP (1-methyl-4-phenyl-1,2,3,6-tetrahydropyridine) $50 \mathrm{mM}$ (Sigma-Aldrich, Madrid, Spain) was freshly prepared in E3 medium for a final concentration of $600 \mu \mathrm{M}$ in each well. The treatment with MPTP was from $24 \mathrm{hpf}$ to $72 \mathrm{hpf}$. PTU and MPTP were renewed daily. At 72 hpf, the embryos were anesthetized with tricaine and sacrificed.

Sample preparation. The embryos were fixed with $4 \%$ paraformaldehyde (PFA) for $3 \mathrm{hr}$ at RT in a tube rotator and then washed with phosphate-buffered saline (PBS) for $10 \mathrm{~min}$. Then, the embryos were incubated $8 \mathrm{~min}$ in Proteinase K $20 \mu \mathrm{g} / \mathrm{ml}$ and washed with distilled water $3 \mathrm{~min}$. Afterwards, the embryos were fixed again 20 min with PFA 4\% and washed 3 times with PBS 10 min each time. At that moment, the embryos were incubated with different concentrations of quinolimide 6 and for different times. The control and MPTP groups were incubated with $1 \mathrm{mM}$ overnight, $200 \mu \mathrm{M}$ overnight, $1 \mathrm{mM}$ for 6 hours and $200 \mu \mathrm{M}$ for 6 hours. Also, we did other control and MPTP groups without $\mathbf{6}$. When the incubation finished, the embryos were washed 3 times with PBS 10 min each time and were mounted in agarose low melting point 1,5\% (iNtRON Biotechnology) in a cover slip. The embryos mounted were kept in a wet chamber until observation in the fluorescence microscope.

After testing the different conditions with quinolimide 6, we decided to choose $200 \mu \mathrm{M}$ for 6 hours because it has been enough to dye the embryos.

\section{One-photon microscopy}

Confocal one-photon microscopy was carried out in a Leica TCS-SP5 II (Leica, Germany) multiphoton confocal microscope with excitation at $488 \mathrm{~nm}$ from a multiline argon laser and selective detection at two different colors using a first channel with an emission band from 510 to $570 \mathrm{~nm}$ (green channel) and a second detection channel collecting fluorescence emission from 610 to $700 \mathrm{~nm}$ (red channel). 

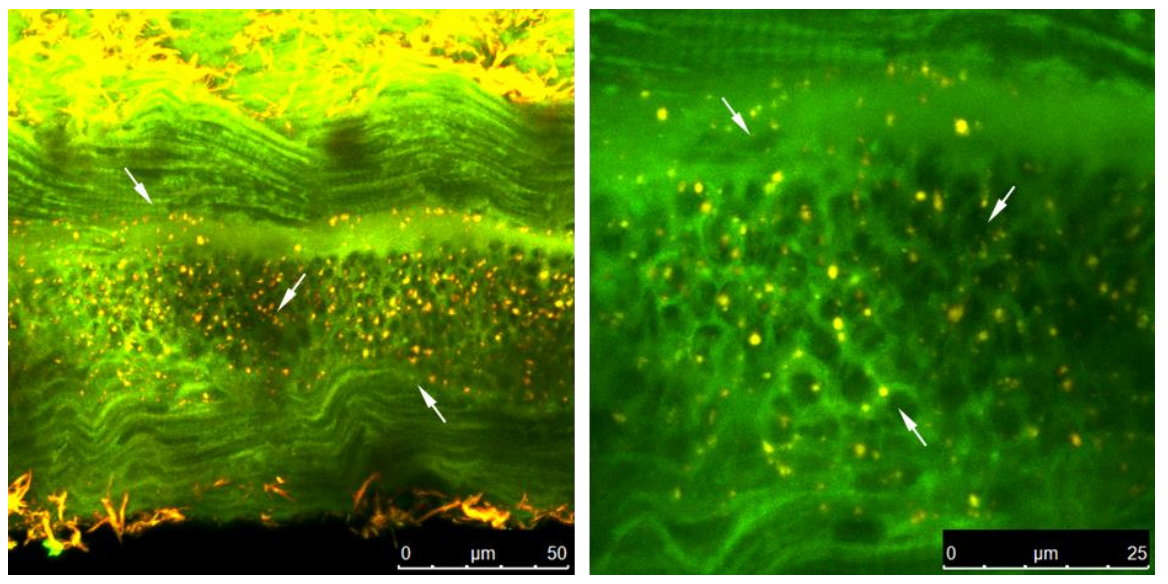

Figure S21. Representative one-photon $\left(\lambda_{\mathrm{ex}}=488 \mathrm{~nm}\right)$ fluorescence microscopy images of zebrafish embryo incubated with $6(200 \mu \mathrm{M}, 6 \mathrm{~h})$ in a model with neuronal damage induced by the neurotoxin MPTP. The observed bright orange spots correspond to amyloid aggregates.

\section{Two-photon microscopy}
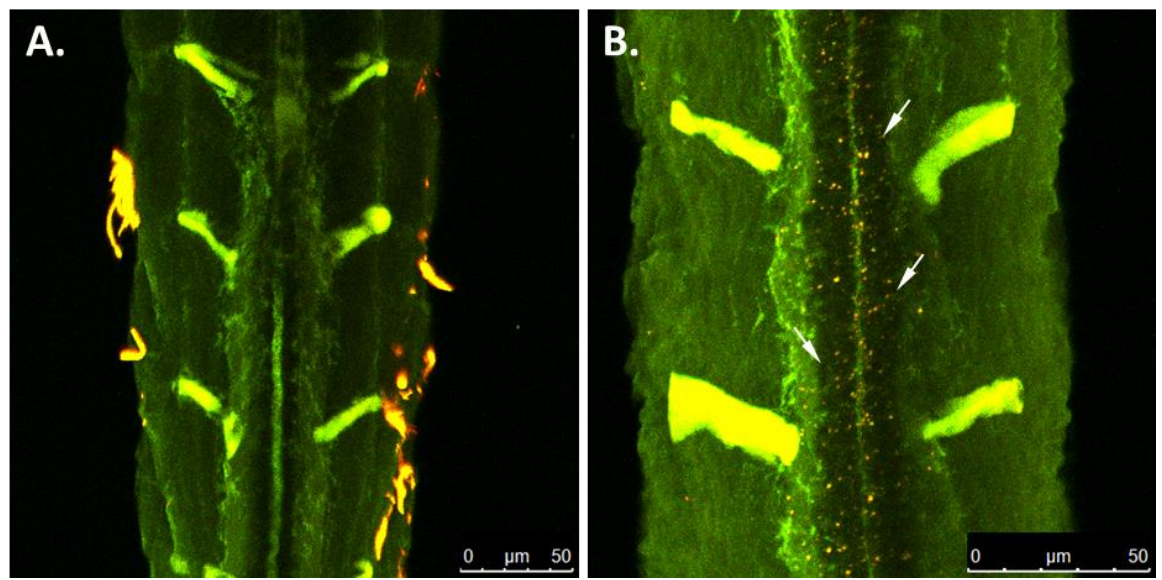

Figure S22. Representative two-photon $\left(\lambda_{\mathrm{ex}}=850 \mathrm{~nm}\right)$ fluorescence microscopy images of zebrafish embryo incubated with $6(200 \mu \mathrm{M}, 6 \mathrm{~h})$ in (A) wild type or (B) in a model with neuronal damage induced by the neurotoxin MPTP. The observed bright orange spots correspond to amyloid aggregates. 
VIII. NMR SPECTRA $\left({ }^{1} \mathrm{H}\right.$-NMR AND ${ }^{13} \mathrm{C}$-NMR) 

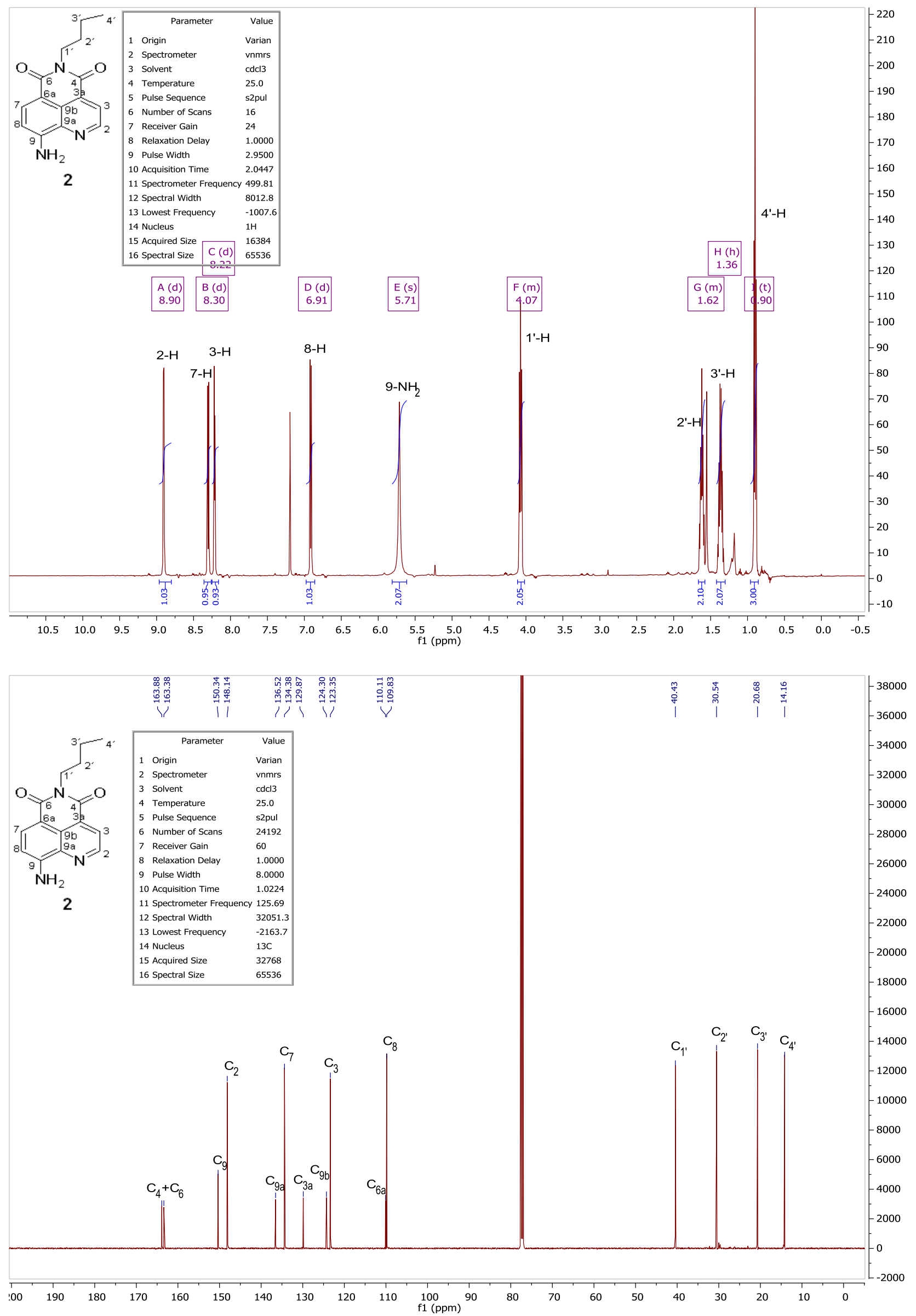

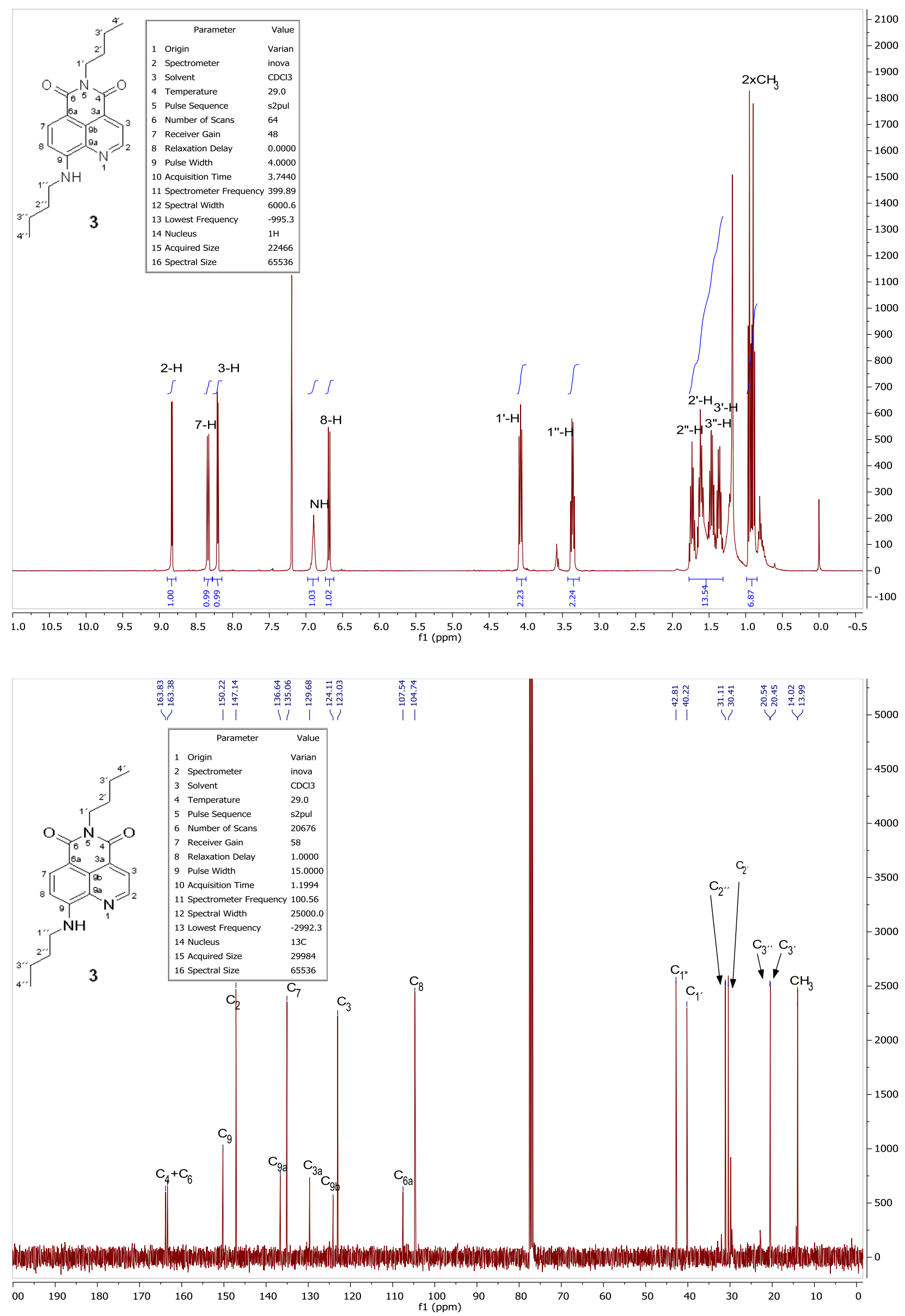


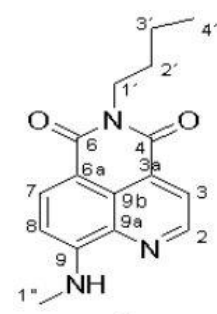

4

\begin{tabular}{lll}
\hline \multicolumn{1}{c}{ Parameter } & \multicolumn{1}{c}{ Value } \\
Varian \\
1 & Origin & vnmrs \\
2 & Spectrometer & cdcl3 \\
3 & Solvent & 25.0 \\
4 & Temperature & s2pul \\
5 & Pulse Sequence & 32 \\
6 & Number of Scans & 32 \\
7 & Receiver Gain & 30 \\
8 & Relaxation Delay & 1.0000 \\
9 & Pulse Width & 2.9500 \\
10 & Acquisition Time & 2.0447 \\
11 Spectrometer Frequency 499.81 \\
12 Spectral Width & 8012.8 \\
13 Lowest Frequency & -1040.6 \\
14 Nucleus & $1 \mathrm{H}$ \\
15 Acquired Size & 16384 \\
16 Spectral Size & 65536
\end{tabular}
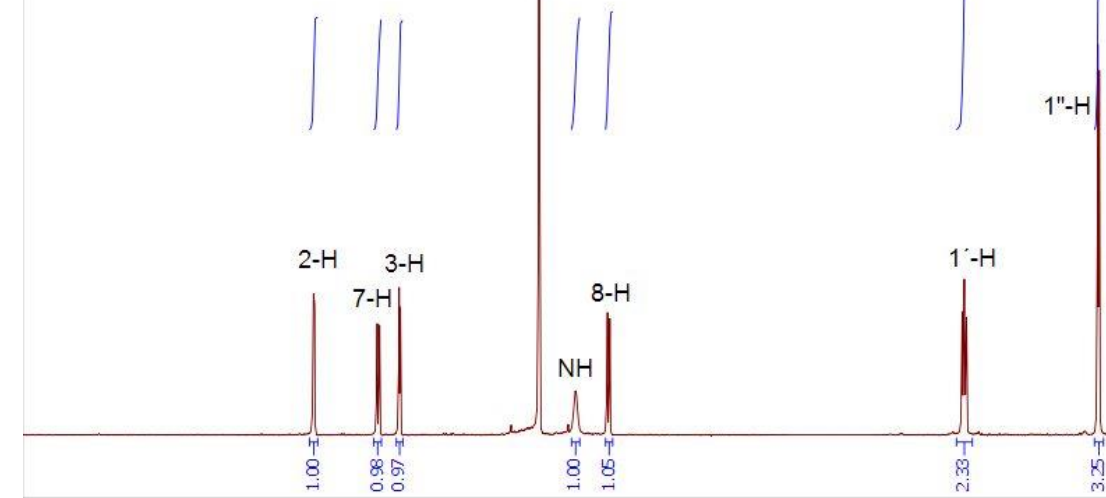

$\begin{array}{llllllllllll}10.5 & 10.0 & 9.5 & 9.0 & 8.5 & 8.0 & 7.5 & 7.0 & 6.5 & 6.0 & 5.5 & 5.0 \\ \mathrm{f} 1(\mathrm{ppm})\end{array}$
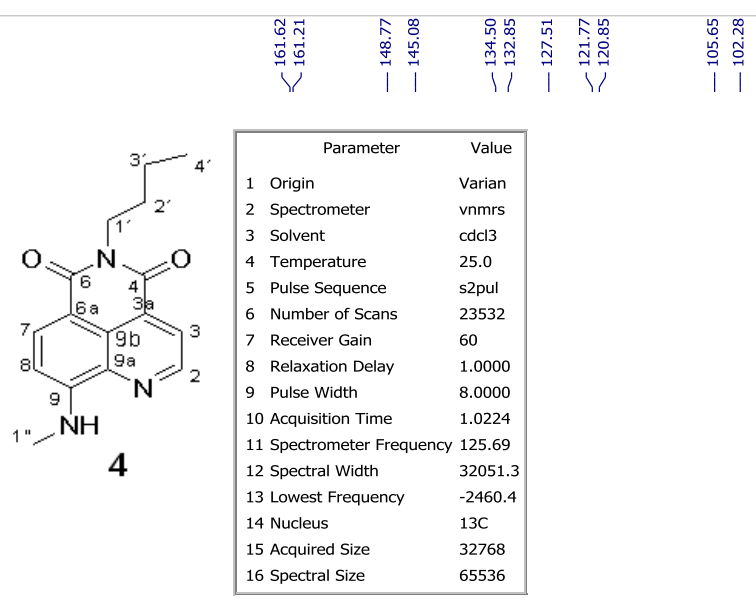

\section{|}

\begin{tabular}{|l|} 
Value \\
mrian \\
mrs \\
.0 \\
pul \\
532 \\
0000 \\
.0000 \\
0224 \\
25.69 \\
32051.3 \\
2460.4 \\
$3 C$ \\
32768 \\
65536 \\
\hline
\end{tabular}
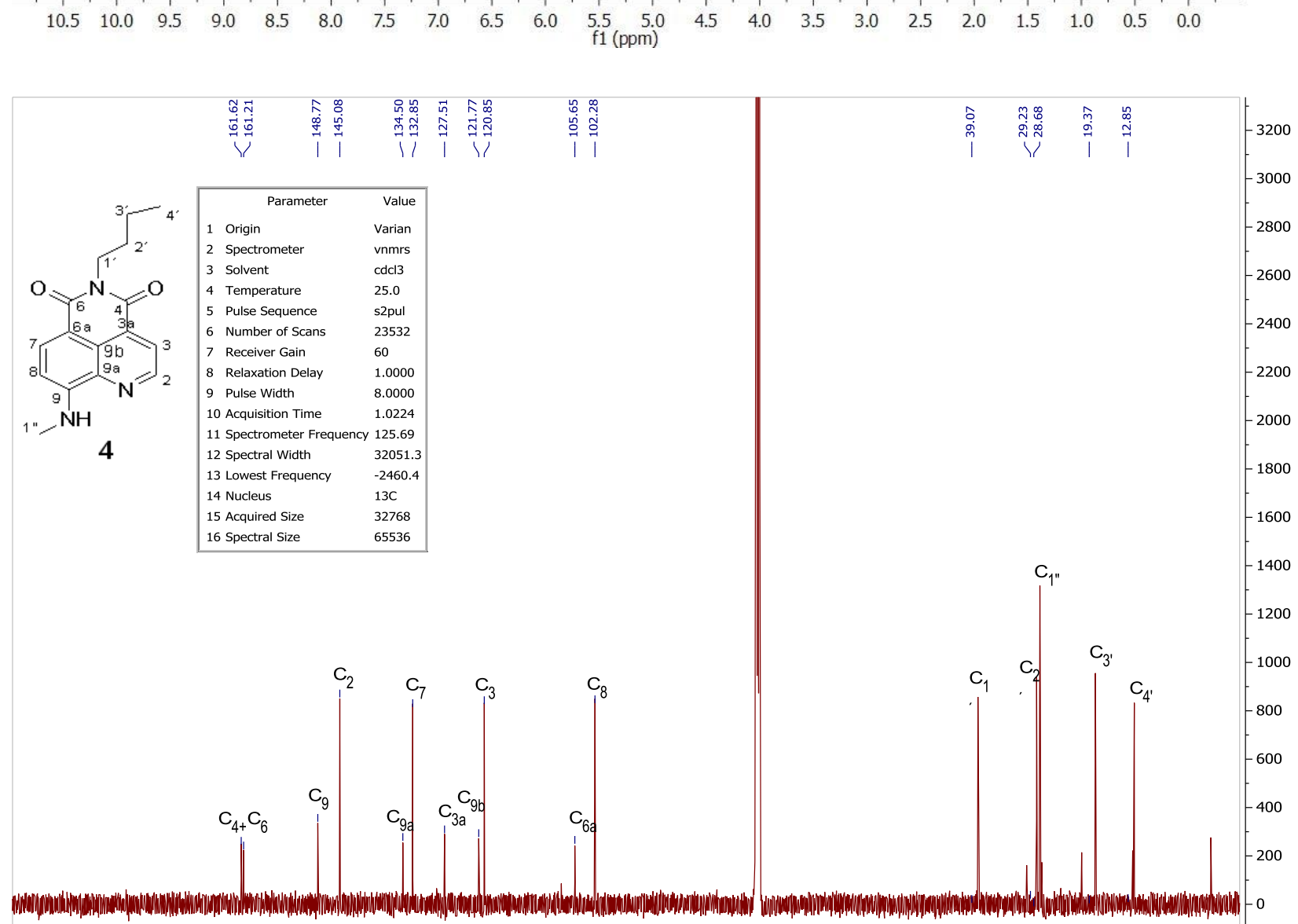

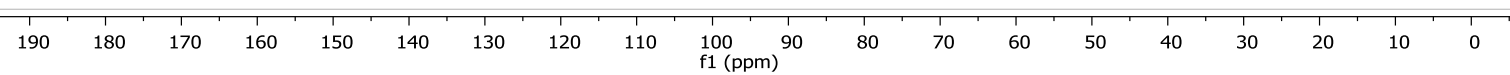



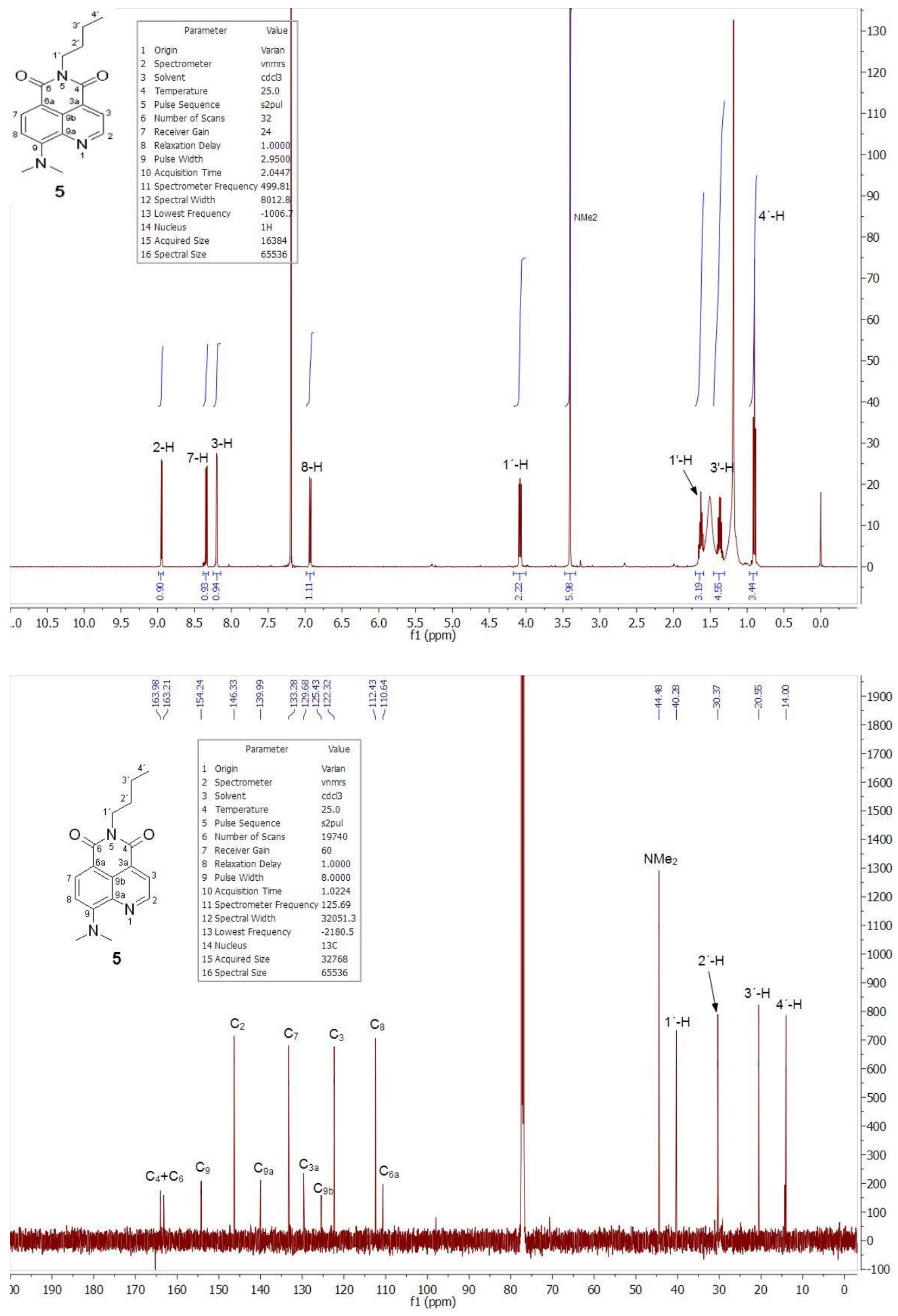

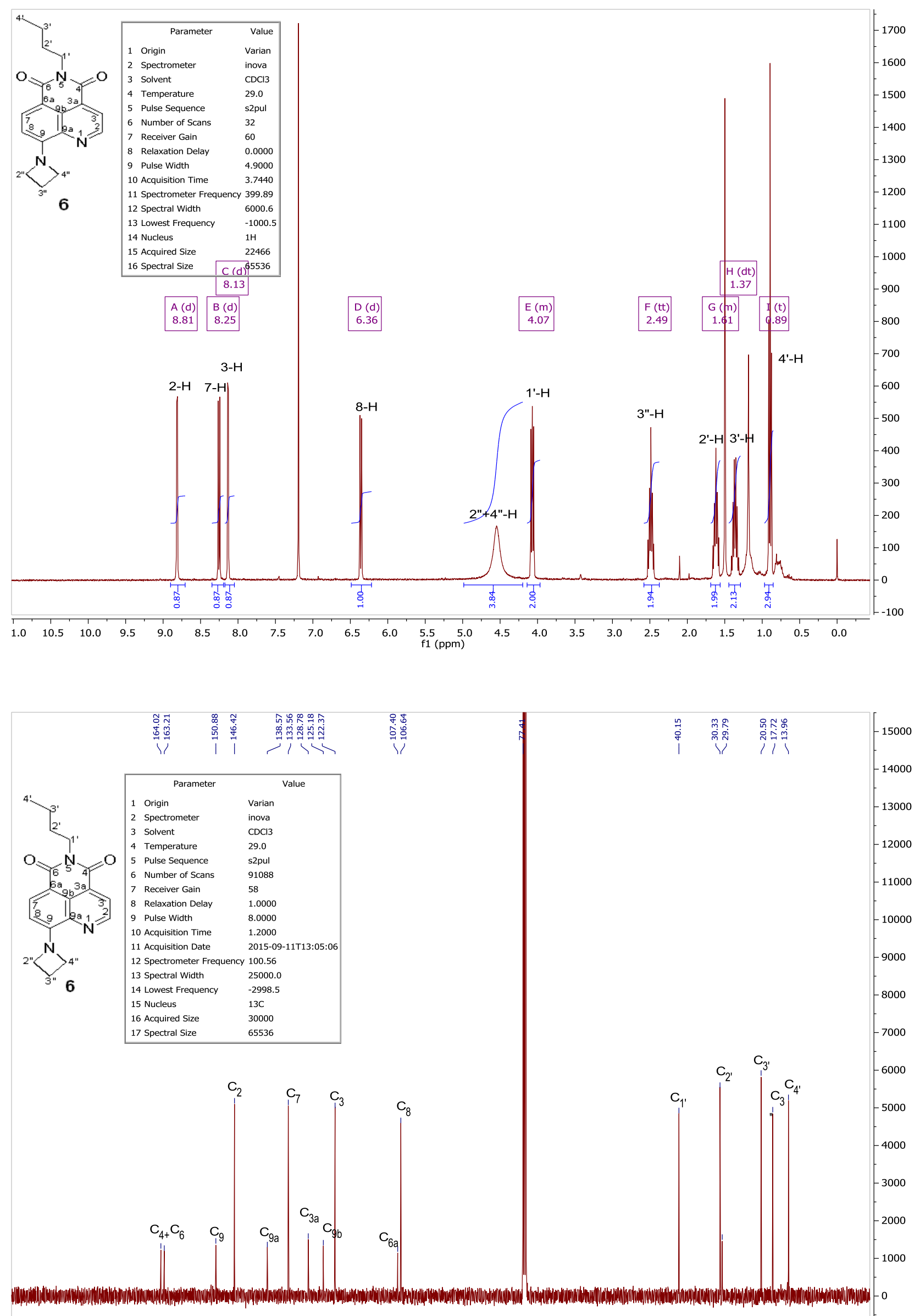


\section{References:}

${ }^{1}$ (a) Würth, C.; Grabolle, M.; Pauli, J.; Spieles, M.; Resch-Genger, U. Relative and absolute determination of fluorescence quantum yields of transparent samples. Nat. Protoc., 2013, 8, 1535-1550; (b) Brouwer, A. M. Standards for photoluminescence quantum yield measurements in solution (IUPAC Technical Report). Pure Appl. Chem., 2011, 83, 2213-2228; (c) Rurack, K.; Spieles, M. Fluorescence quantum yields of a series of red and near-infrared dyes emitting at 600-1000 nm. Anal. Chem., 2011, 83, 1232-1242.

2 (a) Van deVen, M.; Ameloot, M.; Valeur, B.; Boens, N. Pitfalls and their remedies in time-resolved fluorescence spectroscopy and microscopy. J. Fluoresc. 2005, 15, 377-413; (b) Lemmetyinen, H.; Tkachenko, N. V.; Valeur, B.; Hotta, J. -I.; Ameloot, M.; Ernsting, N. P.; Gustavsson, T.; Boens, N. Timeresolved fluorescence methods (IUPAC Technical Report). Pure Appl. Chem. 2014 86, 1969-1998; (c) Becker, W. Advanced Time-Correlated Single Photon Counting Techniques, Vol. 81, Springer, Berlin, 2005.

${ }^{3}$ González-Vera, J. A.; Fueyo-González, F.; Alkorta, I.; Peyressatre, M.; Morris, M. C.; Herranz, R. Highly solvatochromic and tunable fluorophores based on a 4,5-quinolimide scaffold: novel CDK5 probes. Chem. Commun. 2016, 52, 9652-9655.

${ }^{4}$ Saha, S.; Samanta, A. Photophysical and dynamic NMR studies on 4-amino-7-nitrobenz-2-oxa-1, 3-diazole derivatives: Elucidation of the nonradiative deactivation pathway. J. Phys. Chem. A, 1998, 102, 7903-7912.

${ }^{5}$ gNMR5.0, IvorySoft, AmorWay, Letchworth, Herts. SG61ZA, UK, 2004.

${ }^{6}$ (a) Adamo, C.; Barone, V. Toward reliable density functional methods without adjustable parameters: The PBE0 model. J. Chem. Phys., 1999, 110, 6158-6170; (b) Hariharan, P. C.; Pople, J. A. The influence of polarization functions on molecular orbital hydrogenation energies. Theor. Chim. Acta, 1973, 28, 213-222.

${ }^{7}$ Frisch, M. J.; Trucks, G. W.; Schlegel, H. B.; Scuseria, G. E.; Robb, M. A.; Cheeseman, J. R.; Scalmani, G.; Barone, V.; Mennucci, B.; Petersson, G. A.; Nakatsuji, H.; Caricato, M.; Li, X.; Hratchian, H. P.; Izmaylov, A. F.; Bloino, J.; Zheng, G.; Sonnenberg, J. L.; Hada, M.; Ehara, M.; Toyota, K.; Fukuda, R.; Hasegawa, J.; Ishida, M.; Nakajima, T.; Honda, Y.; Kitao, O.; Nakai, H.; Vreven, T.; Montgomery Jr., J. A.; Peralta, J. E.; Ogliaro, F.; Bearpark, M. J.; Heyd, J.; Brothers, E. N.; Kudin, K. N.; Staroverov, V. N.; Kobayashi, R.; Normand, J.; Raghavachari, K.; Rendell, A. P.; Burant, J. C.; Iyengar, S. S.; Tomasi, J.; Cossi, M.; Rega, N.; Millam, N. J.; Klene, M.; Knox, J. E.; Cross, J. B.; Bakken, V.; Adamo, C.; Jaramillo, J.; Gomperts, R.; Stratmann, R. E.; Yazyev, O.; Austin, A. J.; Cammi, R.; Pomelli, C.; Ochterski, J. W.; Martin, R. L.; Morokuma, K.; Zakrzewski, V. G.; Voth, G. A.; Salvador, P.; Dannenberg, J. J.; Dapprich, S.; Daniels, A. D.; Farkas, Ö.; Foresman, J. B.; Ortiz, J. V.; Cioslowski, J.; Fox, D. J. Gaussian 09, Gaussian, Inc., Wallingford, CT, USA, 2009.

${ }^{8}$ Westerfield, M. The Zebrafish Book: A Guide for the Laboratory Use of Zebrafish (Danio Rerio). University of Oregon Press: 2000. 